UNIVERSIDADE DE SÃO PAULO

INSTITUTO DE QUÍMICA DE SÃO CARLOS

\title{
PREPARAÇÃO E CARACTERIZAÇÃO FOTOQUÍMICA DE DERIVADO DE S,S-DIOXIDOTIOXANTONA: \\ APLICAÇÕES EM FOTOPOLIMERIZAÇÃO
}

\section{Leticia Felipe Abdias Pinto}

Tese apresentada ao Instituto de Química de São Carlos da Universidade de São Paulo para obtenção do título de Doutor em Ciências.

Área de Concentração: Físico-Química

Orientador: Dr. Miguel Guillermo Neumann

\section{Exemplar revisado}

O exemplar original encontra-se em

acervo reservado na Biblioteca do IQSC-USP

São Carlos 



\section{Dedicatória}

Aos meus pais, José e Luzia, por todo o amor e apoio em todas as minhas decisões. 


\section{AGRADECIMENTOS}

Ao Prof. Dr. Miguel Guillermo Neumann pela orientação, ensinamentos e confiança.

À Profa. Dra. Carla Cristina Schmitt Cavalheiro pelo apoio e amizade.

Aos amigos do grupo de Fotoquímica do Instituto de Química de São Carlos pela amizade e colaboração.

Aos docentes e funcionários do Instituto de Química de São Carlos.

À Patrícia Coelho Lombardo pela amizade e companheirismo durante todo o doutorado.

À minhas amigas Analine Crespo Ziglio e Edilaine Martins Soler por todo o carinho e por estarem sempre ao meu lado, amo vocês!

Aos meus amigos Kátia Prieto, Amanda Garcia, Camila Matheus, Juliana Coatrini, Gustavo Henrique, Natália Ferré e Junia Matsumoto.

À todas as pessoas que contribuíram para a realização deste trabalho.

Ao CNPq pelo apoio financeiro. 


\section{SUMÁRIO}

RESUMO

ABSTRACT

LISTA DE FIGURAS IX IX

LISTA DE TABELAS XIV

1. INTRODUÇÃO 16

1.1. Conceitos Básicos de Fotoquímica 17

1.1.1. Estados Eletrônicos Excitados 17

1.1.2. Supressão de Fluorescência

1.1.3. Fotoquímica de Compostos Carbonilados 24

1.1.3.1. Reações e Processos Fotoquímicos de Compostos Carbonilados 27

1.2. Polímeros 29

1.2.1. Polimerização Radicalar Fotoiniciada 30

1.2.2. Fotoiniciadores $\quad 31$

1.2.2.1. Tioxantonas e Derivados 32

2. OBJETIVOS 36

3. PARTE EXPERIMENTAL 38

3.1. Reagentes Utilizados 38

3.2. Síntese da 7,8-benzotioxanton-9-ona-10,10-dióxido, TX-Np- $\mathrm{SO}_{2}$

3.3. Purificação dos Reagentes 40

3.4. Equipamentos Utilizados 41

3.5. Técnicas Instrumentais 41

3.6. Procedimentos Experimentais 46

3.7. Estruturas e Siglas das Moléculas Presentes Neste Estudo 49

4. RESULTADOS E DISCUSSÕES

4.1. Caracterização da 7,8-benzotioxanton-9-ona-10,10-dióxido, TX-Np-SO $\mathrm{SO}_{2}$ 
4.1.1. Espectroscopia de Infravermelho com Transformada de Fourier

4.1.2. Análise Elementar 52

4.1.3. Cromatografia Líquida de Alta Eficiência 52

4.1.4. Ressonância Magnética Nuclear 53

4.1.5. Propriedades Espectroscópicas do Estado Fundamental 58

4.1.5.1. Espectros de Absorção na Região UV-Vis da TX-Np-SO

4.2. Estudos das Reações Elementares 63

4.2.1. Estudo dos Transientes da TX-Np-SO

4.2.2. Estudo da Supressão do Estado Triplete da TX-Np-SO

4.3. Aplicação da TX-Np-SO ${ }_{2}$ como Fotoiniciador de Polimerização 78

4.3.1. Polimerização do monômero metacrilato de metila (MMA) fotoiniciada por TX-Np- $\mathrm{SO}_{2}$ na presença dos co-iniciadores trietilamina (TEA) e $p$-dimetilamina 78 benzoato de etila (EDB)

4.3.2. Sistema de polimerização MMA/TX-Np-SO $/$ TEA 79

4.3.3. Sistema de polimerização MMA/TX-Np-SO $/$ EDB $\quad 85$

5. CONCLUSÕES 90

$\begin{array}{ll}\text { 6. APÊNDICES } & 92\end{array}$

7. REFERÊNCIAS 98 


\section{RESUMO}

Neste trabalho foi realizada a síntese e caracterização de um derivado de S,Sdioxidotioxantona, 7,8-benzotioxanton-9-ona-10,10-dióxido (TX-Np-SO $\mathrm{S}_{2}$. A TX-Np-SO foi caracterizada estruturalmente por espectros eletrônico e vibracional (UV-vis e fluorescência, Infravermelho) e também por ressonância magnética nuclear (RMN) de ${ }^{1} \mathrm{H}$ e ${ }^{13} \mathrm{C}$. As propriedades fotofísicas, espectros de emissão de fluorescência e fosforescência e o rendimento quântico de fluorescência da $\mathrm{TX}-\mathrm{Np}-\mathrm{SO}_{2}$ foram determinadas, assim como os tempos de vida de fluorescência $\left(\tau_{\mathrm{F}}=3,62 \mathrm{~ns}\right)$ e fosforescência $\left(\tau_{\mathrm{Ph}}=800 \mathrm{~ms}\right)$. Os espectros de absorção triplete-triplete dos transientes da TX-Np- $\mathrm{SO}_{2}$, em soluções desoxigenadas de metanol, acetonitrila e metilciclohexano, foram determinados por Fotólise por Pulso de Laser, bem como as constantes de velocidade de supressão bimoleculares do derivado pelos supressores trans-estilbeno, trietilamina, p-dimetilamina benzoato de etila e 2-propanol. A fotopolimerização do metacrilato de metila (MMA) iniciada por TX-Np-SO $\mathrm{SO}_{2}$ foi estudada por dilatometria. A reação de polimerização do iniciador $\left(\mathrm{TX}-\mathrm{Np}-\mathrm{SO}_{2}\right)$ na presença de amina e o monômero MMA foi estudada de modo a determinar a taxa de polimerização $(R p)$ a diferentes concentrações de trietilamina (TEA) e $p$-dimetilamina benzoato de etila (EDB).

Palavras-chave: derivados de tioxantona, fotofísica, fotoiniciador, fotopolimerização. 


\section{ABSTRACT}

The aim of this work was the synthesis and characterization of a S,Sdioxidethioxanthone derivative, 7,8-benzo-thioxanthen-9-one-10,10-dioxide (TX-Np- $\left.\mathrm{SO}_{2}\right)$. The TX-Np-SO $\mathrm{S}_{2}$ was structurally characterized by its electronic and vibrational spectra (UVvis and fluorescence, IR) and also by ${ }^{1} \mathrm{H}$ and ${ }^{13} \mathrm{C}$ RMN methods. The photophysical properties, fluorescence and phosphorescence emission spectra, and fluorescence quantum yield of TX-Np-SO $\mathrm{SO}_{2}$ were determined, as well as the fluorescence lifetime ( $\tau_{\mathrm{F}}=3,62 \mathrm{~ns}$ ) and the phosphorescence lifetime $\left(\tau_{\mathrm{Ph}}=800 \mathrm{~ms}\right)$. The transient absorption spectra of TX-Np-SO in degassed solutions of methanol, acetonitrile and methylcyclohexane were determined by Laser Flash Photolysis, as well as the bimolecular triplet quenching rate constants for of the derivative by various compounds. The photopolymerization of methyl methacrylate (MMA) initiated by $\mathrm{TX}-\mathrm{Np}-\mathrm{SO}_{2}$ was studied by dilatometry. The polymerization reaction of the initiator (TX-Np-SO $\mathrm{SO}_{2}$ ) in the presence of amine and MMA monomer was studied in order to determine the polymerization rate $(R p)$ at different loadings of triethylamine (TEA) and ethyl4-dimethylaminobenzoate (EDB).

Keywords: derivatives of thioxanhones, photophysics, photoinitiator, photopolymerization. 


\section{LISTA DE FIGURAS}

Figura 1 - Diagrama de Jablonski ilustrativo dos processos de absorção e emissão de energia.

Figura 2 - Mecanismos possíveis de supressão entre um fluoróforo $(F)$ e o supressor $(Q)$.

Figura 3 - Níveis de energia eletrônica molecular.

Figura 4 - Exemplo de algumas moléculas representantes de cetonas aromáticas.

Figura 5 - Diagrama de nível de energia para transições $n \rightarrow \pi^{*}$ em solvente não polar e polar. Enp - Energia em solvente não polar; Ep - Energia em solvente polar.

Figura 6 - Mecanismo proposto para a transferência de energia entre a benzofenona e 1,3-cicloexadieno.

Figura 7 - Mecanismo proposto para a o processo de abstração de hidrogênio entre a benzofenona e o 2-propanol.

Figura 8 - Reação de transferência de elétrons entre a trietilamina e a benzofenona.

Figura 9 - Exemplos de polimerização por condensação e adição.

Figura 10 - Reações de formação de espécies ativas para fotoiniciadores do Tipo I e Tipo II.

Figura 11 - Reação do estado excitado triplete da tioxantona com uma amina.

Figura 12 - Princípio da espectroscopia de fotólise por pulso de laser.

Figura 13 - Esquema simplificado de um sistema de fotólise por pulso de laser.

Figura14 - Esquema simplificado da técnica estroboscópica.

Figura 15 - Esquema do sistema de dilatometria.

Figura 16 - Espectro de infravermelho da $\mathrm{TX}-\mathrm{Np}-\mathrm{SO}_{2}$ sintetizada com os principais grupos funcionais. Pastilhas de $\mathrm{KBr}$ na proporção 1:100 de TX-Np-SO e $\mathrm{KBr}$, respectivamente.

Figura 17 - Cromatograma da TX-Np-SO $\mathrm{SO}_{2}$ e seus materiais de partida com os 
respectivos tempos de retenção. (-) Ácido tiosalicílico - 3,65 min; (-) TX-Np-SO $-4,10$ min e (-) Naftaleno - 4,43 min.

Figura 18 - Espectro de RMN de ${ }^{1} \mathrm{H}$ da TX-Np-SO,$\left(\mathrm{CDCl}_{3}, 400 \mathrm{MHz}\right)$.

Figura 19 - Ampliação do espectro de RMN de ${ }^{1} \mathrm{H}$ da TX-Np-SO $\mathrm{SO}_{2},\left(\mathrm{CDCl}_{3}\right.$, $400 \mathrm{MHz})$.

Figura 20 - Ampliação do espectro de RMN de ${ }^{13} \mathrm{C}$ da TX-Np-SO $\mathrm{SO}_{2},\left(\mathrm{CDCl}_{3}\right.$, $100 \mathrm{MHz})$.

Figura 21 - Espectro de Cosy ${ }^{1} \mathrm{H}-{ }^{1} \mathrm{H}$ de TX-Np-SO $2,\left(\mathrm{CDCl}_{3}, 400 \mathrm{MHz}\right)$.

Figura 22 - Mapa de correlações de HSQC da TX-Np-SO $\left(\mathrm{CDCl}_{3}, 400 \mathrm{MHz}\right)$.

Figura 23 - Mapa de correlações de $\mathrm{HMBC}$ da TX-Np-SO $\left(\mathrm{CDCl}_{3}, 400 \mathrm{MHz}\right)$.

Figura 24 - Estruturas químicas dos produtos possíveis para a síntese da TX-Np$\mathrm{SO}_{2}$.

Figura 25 - Estrutura química da TX-Np-SO

Figura 26 - Espectro de absorção da TX-Np-SO $\mathrm{SO}_{2}$ em diferentes concentrações em metanol.

Figura 27 - Comparação entre os espectros de absorção de S,S-dioxidotioxantona e seu derivado, $\mathrm{TX}-\mathrm{Np}-\mathrm{SO}_{2}$.

Figura 28 - Espectro de emissão da TX-Np-SO $\left(1 \times 10^{-5} \mathrm{M}\right)$ em metilciclohexano. Fluorescência a $295 \mathrm{~K}, \lambda_{\text {exc }}=285 \mathrm{~nm}$; e fosforescência a $77 \mathrm{~K}, \lambda_{\text {exc }}=285 \mathrm{~nm}$.

Figura 29 - Curva de decaimento de fosforescência da TX-Np-SO em metilciclohexano, $\lambda_{\mathrm{exc}}=285 \mathrm{~nm}$ e temperatura $\mathrm{T}=77 \mathrm{~K}$.

Figura 30 - Curva de decaimento de fluorescência da TX-Np-SO em metilciclohexano (-) e IRF (-), $\lambda_{\text {exc }}=280 \mathrm{~nm}$, e temperatura $\mathrm{T}=295 \mathrm{~K}$.

Figura 31 - Espectro de absorção triplete-triplete de TX-Np-SO em metanol $\left(\lambda_{\text {exc }}=355 \mathrm{~nm}\right.$ ), registrado (-) 2,0 $\mu \mathrm{s}$; (-) 9,2 $\mu \mathrm{s}$; (-) 26,0 $\mu \mathrm{s}$ e (-) 102,0 $\mu \mathrm{s}$ depois do pulso de laser. Inserção: Decaimento do transiente monitorado a $590 \mathrm{~nm}$.

Figura 32 - Espectro de absorção triplete-triplete de TX-Np-SO $\left(\lambda_{\mathrm{exc}}=355 \mathrm{~nm}\right)$, registrado (-) 1,6 $\mu \mathrm{s}$; (-) $8,4 \mu \mathrm{s}$; (-) $25,8 \mu \mathrm{s}$ e (-) $102,4 \mu \mathrm{s}$ depois do 
pulso de laser. Inserção: Decaimento do transiente monitorado a $590 \mathrm{~nm}$.

Figura 33 - Espectro de absorção triplete-triplete de $\mathrm{TX}-\mathrm{Np}-\mathrm{SO}_{2}$, em metilciclohexano $\left(\lambda_{\text {exc }}=355 \mathrm{~nm}\right.$ ), registrado (-) 2,0 $\mu \mathrm{s}$; (-) 9,2 $\mu \mathrm{s}$; (-) 26,0 $\mu \mathrm{s}$ e (-) $102,0 \mu$ s depois do pulso de laser. Inserção: Decaimento do transiente monitorado a $590 \mathrm{~nm}$.

Figura 34 - Formação do radical cetila da TX-Np- $\mathrm{SO}_{2}$ a partir do estado excitado triplete na presença de solvente prótico.

Figura 35 - Espectros de absorção triplete-triplete para a 7,8-benzotioxanton-9ona-10,10-dióxido (TX-Np-SO $\left.{ }_{2}\right)$ tioxanton-9-one-10,10-dióxido (TX-SO ${ }_{2}$, $\left(\lambda_{\text {exc }}=355 \mathrm{~nm}\right)$; e naftaleno $(\mathrm{Np}),\left(\lambda_{\text {exc }}=266 \mathrm{~nm}\right)$, em metanol.

Figura 36 - Decaimentos de absorção triplete-triplete de TX-Np-SO $\mathrm{SO}_{2} 590$ nm, para diferentes concentrações de trans-estilbeno (a). Gráfico de Stern-Volmer para 68 a supressão da TX-Np-SO 2 por trans-estilbeno, em metanol (b).

Figura 37 - Decaimentos de absorção triplete-triplete de TX-Np-SO $\mathrm{Sm}_{2} 50 \mathrm{~nm}$, para diferentes concentrações de trans-estilbeno (a). Gráfico de Stern-Volmer para 68 a supressão da TX-Np-SO 2 por trans-estilbeno, em acetonitrila (b).

Figura 38 - Decaimentos de absorção triplete-triplete de TX-Np-SO $\mathrm{SO}_{2} \mathrm{em} 50 \mathrm{~nm}$, para diferentes concentrações de trans-estilbeno (a). Gráfico de Stern-Volmer para a supressão da TX-Np-SO $\mathrm{SO}_{2}$ por trans-estilbeno, em metilciclohexano (b).

Figura 39 - Supressão do estado excitado triplete de $\mathrm{TX}-\mathrm{Np}-\mathrm{SO}_{2}$ por transestilbeno.

Figura 40 - Decaimento da absorção triplete-triplete de TX-Np-SO $\mathrm{SO}_{2}$ em 590 nm, com diferentes concentrações de $\operatorname{EDB}$ (a). Gráfico de Stern-Volmer para a 71 supressão da TX-Np-SO 2 por EDB, em metanol (b).

Figura 41 - Decaimento da absorção triplete-triplete de TX-Np-SO em 590 nm, com diferentes concentrações de $\operatorname{EDB}$ (a). Gráfico de Stern-Volmer para a supressão da TX-Np-SO 2 por EDB, em acetonitrila (b).

Figura 42 - Decaimento da absorção triplete-triplete de TX-Np-SO $\mathrm{SO}_{2} 590 \mathrm{~nm}$, com diferentes concentrações de $\operatorname{EDB}$ (a). Gráfico de Stern-Volmer para a supressão da TX-Np-SO 2 por EDB, em metilciclohexano (b). 
Figura 43 - Supressão do estado excitado triplete da TX-Np-SO $\mathrm{S}_{2}$ por EDB.

Figura 44 - Decaimento da absorção triplete-triplete de TX-Np-SO $\mathrm{SO}_{2} 590 \mathrm{~nm}$, com diferentes concentrações de TEA (a). Gráfico de Stern-Volmer para a supressão da TX-Np-SO $\mathrm{SO}_{2}$ por TEA, em metanol (b).

Figura 45 - Decaimento da absorção triplete-triplete de TX-Np-SO em 590 nm, com diferentes concentrações de TEA (a). Gráfico de Stern-Volmer para a supressão da TX-Np-SO 2 por TEA, em acetonitrila (b).

Figura 46 - Decaimento da absorção triplete-triplete de TX-Np-SO $\mathrm{SO}_{2} 590 \mathrm{~nm}$, com diferentes concentrações de TEA (a). Gráfico de Stern-Volmer para a supressão da TX-Np-SO $\mathrm{SO}_{2}$ por TEA, em metilciclohexano(b).

Figura 47 - Supressão do estado excitado triplete da TX-Np-SO $\mathrm{S}_{2}$ pela TEA.

Figura 48 - Decaimento da absorção triplete-triplete de TX-Np-SO $\mathrm{SO}_{2}$ em 590 nm, com diferentes concentrações de 2-propanol (a). Gráfico de Stern-Volmer para a supressão da TX-Np-SO 2 por 2-propanol, em metanol (b).

Figura 49 - Decaimento da absorção triplete-triplete de TX-Np-SO $\mathrm{SO}_{2}$ em 590 m, com diferentes concentrações de 2-propanol (a). Gráfico de Stern-Volmer para a supressão da TX-Np-SO 2 por 2-propanol, em acetonitrila (b).

Figura 50 - Decaimento da absorção triplete-triplete de TX-Np-SO $\mathrm{SO}_{2} 590$ nm, com diferentes concentrações de 2-propanol (a). Gráfico de Stern-Volmer para a 76 supressão da TX-Np-SO 2 por 2-propanol, em metilciclohexano (b).

Figura 51 - Supressão do estado excitado triplete de TX-Np-SO $\mathrm{SO}_{2}$ por 2-propanol.

Figura 52 - Espectro de emissão da lâmpada de mercúrio/xenônio utilizada nos experimentos de dilatometria, $\lambda_{\text {mon }}=360 \mathrm{~nm}$ e o espectro de absorção de TX-Np$\mathrm{SO}_{2}$ no meio reacional usado nas fotopolimerizações.

Figura 53 - Variação da altura da solução no capilar do dilatômetro em função do tempo de irradiação para a polimerização do MMA pelo sistema TX-Np$\mathrm{SO}_{2} / \mathrm{TEA}$. [TEA]= 0,02 M (a); 0,04 M (b);0,08 M (c); 0,12 M (d); 0,18 M (e) e $0,24 \mathrm{M}(\mathrm{f})$.

Figura 54 - Variação da altura da solução no capilar do dilatômetro em função do 
tempo de irradiação para solução contendo MMA e MeOH (1:1).

Figura 55 - Conversão de monômero na fotopolimerização de MMA na presença de TX-Np-SO (iniciador em diferentes concentrações de TEA).

Figura 56 - Dependência da velocidade de polimerização do MMA com a concentração de TEA.

Figura 57 - Mecanismo proposto de desativação do estado singlete da TX-Np-SO por uma amina, (A).

Figura 58 - Mecanismo proposto de desativação de exciplexos tripletes por uma amina, (A).

Figura 59 - Mecanismo proposto para a produção dos radicais livres fotoiniciadores no sistema TX-Np-SO 2 /TEA.

Figura 60 - Variação da altura da solução no capilar do dilatômetro em função do tempo de irradiação para a polimerização de MMA pelo sistema TX-Np$\mathrm{SO}_{2} / \mathrm{EDB}$. [EDB]=0,02 M (a);0,04 M (b);0,08 M (c);0,12 M (d);0,18 M (e); $0,24 \mathrm{M}(\mathrm{f})$ e $0,36 \mathrm{M}(\mathrm{g})$.

Figura 61 - Conversão de monômero na fotopolimerização de MMA na presença de TX-Np-SO 2 (iniciador com diferentes concentrações de EDB).

Figura 62 - Dependência da velocidade de polimerização de MMA com a concentração de EDB. 


\section{LISTA DE TABELAS}

Tabela 1 - Processos unimoleculares envolvendo processos radiativos e não radiativos.

Tabela 2 - Processos de desativação bimoleculares.

Tabela 3 - Principais reagentes.

Tabela 4 - Exemplos de lasers usados em fotólise por pulso de laser.

Tabela 5 - Dados da análise elementar da $\mathrm{TX}-\mathrm{Np}-\mathrm{SO}_{2}$ sintetizada $(\mathrm{MM}=$ $\left.294,25 \mathrm{~g} \mathrm{~mol}^{-1}\right)$.

Tabela 6 - Tempo de fluorescência da TX-Np-SO $\mathrm{S}_{2}$ e parâmetros estatísticos.

Tabela 7 - Tempos de vida do triplete de TX-Np-SO $\mathrm{S}_{2}$ na ausência de supressor $\left(\tau_{0}\right)$

Tabela 8 - Valores para as constantes de supressão da TX-Np-SO $\mathrm{SO}_{2}$ por 2-propanol, EDB, TEA e trans-estilbeno.

Tabela 9 - Velocidades de polimerização para diferentes concentrações de TEA utilizada no sistema.

Tabela 10 - Velocidade de polimerização, rendimento quântico de polimerização e massa molar numérica média para a polimerização do MMA fotoiniciada pelo sistema TX-Np-SO 2 TEA.

Tabela 11 - Velocidade de polimerização, rendimento quântico de polimerização e massa molar numérica média para a polimerização do MMA fotoiniciada pelo 88 sistema TX-Np-SO 2 /EDB. 


\section{INTRODUÇÃO}




\section{INTRODUÇÃO}

A Fotoquímica é uma ciência que envolve as características químicas e físicas de uma molécula eletronicamente excitada, desde ao absorver a radiação na região do visível e ultravioleta até sua desativação ${ }^{1}$.

Uma molécula ao absorver radiação pode dar origem a diferentes estados excitados. Controlando a frequência de radiação é possível excitar seletivamente elétrons associados a átomos ou grupos de átomos responsáveis pela absorção de luz em uma molécula, os chamados cromóforos, sem que os níveis energéticos dos demais elétrons sejam alterados. Essa seletividade faz da Fotoquímica uma importante ferramenta, pois permite que reações desfavorecidas termodinamicamente, possam ser realizadas sob condições brandas e em temperatura ambiente ${ }^{1,2}$.

Essa vantagem contribuiu para o desenvolvimento da Fotoquímica tanto na área acadêmica quanto na industrial. Uma das áreas que vem se destacando nas últimas décadas é a Fotoquímica de Polímeros aplicada à área de Materiais, principalmente a odontologia com o desenvolvimento e aprimoramento das resinas fotopolimerizáveis; a microeletrônica com a fabricação de circuitos impressos e a fotoestereolitografia; a óptica, em que lentes de contato são produzidas envolvendo diferentes materiais poliméricos, dentre outras aplicações ${ }^{3,4,5}$.

Considerando que o mecanismo de formação do polímero via Fotoquímica tem a radiação interagindo na etapa de iniciação da polimerização, faz dessa etapa a de interesse fotoquímico.

Como em geral, os monômeros que irão dar origem ao polímero possuem coeficiente de extinção molar baixo, torna-se necessária a adição nas formulações de uma molécula para absorver a radiação incidente, de forma a produzir espécies reativas dando início a polimerização ${ }^{3,6,7}$. Dada a importância da molécula absorvedora de radiação, o fotoiniciador, em um sistema polimérico, estudos e o desenvolvimento de novos fotoiniciadores vêm recebendo especial atenção ${ }^{8}$.

Nesse trabalho foram investigadas as propriedades fotofísicas e fotoquímicas de uma nova molécula sintetizada com carácter absorvedor de luz, assim como sua aplicação em um sistema polimérico.

A seguir são abordados alguns conceitos de fotoquímica e fotopolimerização envolvidos nesse estudo. 


\subsection{Conceitos Básicos de Fotoquímica}

\subsubsection{Estados Eletrônicos Excitados ${ }^{1,9}$}

O estado eletrônico fundamental de uma molécula pode dar origem a diferentes estados excitados quando esta absorve radiação.

As moléculas orgânicas ao absorverem radiação têm sua energia aumentada em uma quantidade igual à da radiação absorvida. Os estados eletrônicos excitados possuem tempos de vida extremamente curtos e podem ser desativados por processos fotofísicos e retornarem ao estado fundamental, ou sofrer algum tipo de reação química e formar novas espécies.

O Diagrama de Jablonski, Figura 1, ilustra os processos de absorção e emissão de energia pelos quais uma molécula no estado excitado pode perder energia e retornar ao estado fundamental.

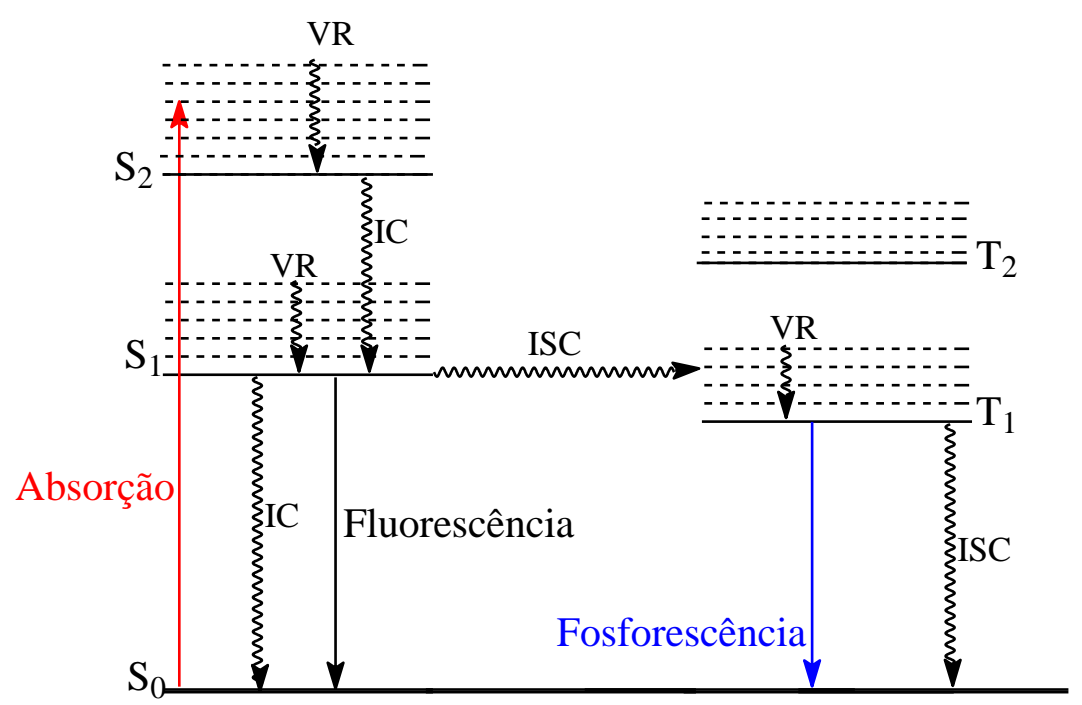

Figura 1 - Diagrama de Jablonski ilustrativo dos processos de absorção e emissão de energia. VR: relaxamento vibracional; IC: conversão interna; ISC: conversão entressistemas.

Os processos envolvidos na desativação de uma molécula excitada podem ocorrer por processos unimoleculares, que envolve a desativação por reações intramoleculares, ou por processos bimoleculares, que são as reações comumente conhecidas por processos de supressão, ocorrendo por reações intermoleculares. 


\section{- Processos Unimoleculares}

Os processos fotofísicos de desativação do estado excitado (unimolecular) podem ocorrer por processos radiativos, que envolvem a emissão de energia na forma de luz e por processos não radiativos, que são os que ocorrem com a liberação de energia na forma de calor. Os processos de desativação unimolecular podem ser classificados conforme mostrado na Tabela 1.

Tabela 1 - Processos unimoleculares envolvendo processos radiativos e não radiativos

\section{PROCESSOS UNIMOLECULARES}

Não Radiativos

\section{Conversão interna $(I C)$}

$S_{n} \longrightarrow S_{1}+$ calor

$S_{1} \longrightarrow S_{0}+$ calor

\section{Cruzamento entressistemas (ISC)}

$S_{1} \longrightarrow T_{1}+$ calor

$T_{1} \longrightarrow S_{0}+$ calor

\section{Radiativos}

Fluorescência

$$
S_{1} \longrightarrow S_{0}+h v
$$

\section{Fosforescência}

$$
T_{1} \longrightarrow S_{0}+h v
$$

Os processos não radiativos ocorrem sem a emissão de energia na forma de radiação e entre níveis de energia vibracionais degenerados de diferentes estados eletrônicos. Os processos sem emissão de radiação compreendem a conversão interna (IC) e o cruzamento entressistemas (ISC).

- Conversão interna (IC) é a transição de um estado excitado de mais alta energia para um estado excitado de mais baixa energia ou para o estado fundamental $\left(S_{0}\right)$, da mesma multiplicidade, liberando energia na forma de calor. Este processo tem um tempo estimado entre $10^{-11}$ e $10^{-9}$ segundos.

- Cruzamento entressistemas (ISC) envolve a desativação da energia absorvida na forma de calor, porém é uma transição entre estados de diferentes multiplicidades. Este processo ocorre com duração entre $10^{-10}$ e $10^{-3}$ segundos. 
Para os processos radiativos, as moléculas excitadas sofrem desativação liberando energia na forma de radiação. Esse processo pode ocorrer através da fluorescência e da fosforescência.

- Fluorescência é uma transição permitida por spin e ocorre com a emissão de luz envolvendo estados de mesma multiplicidade (singlete $\rightarrow$ singlete ou triplete $\rightarrow$ triplete). O tempo de duração de um processo de fluorescência varia entre $10^{-10}$ e $10^{-7}$ segundos. Usualmente, para moléculas poliatômicas, a transição se dá por $S_{1} \longrightarrow S_{0}$, embora possa apresentar em alguns casos a transição $S_{2} \longrightarrow S_{0}$, como exemplo para a molécula de azuleno e alguns compostos carbonílicos contendo átomos de enxofre.

- Fosforescência é um processo com tempo de vida de $10^{-6}$ a 1 segundo, é uma transição proibida por spin e a desativação ocorre com a emissão de luz entre estados de multiplicidade diferentes, $T_{1} \longrightarrow S_{0}$.

\section{- Processos Bimoleculares}

Os processos de desativação bimoleculares, ou processos de supressão, são os processos nos quais a molécula no estado excitado singlete ou triplete interage com um supressor ou outra molécula presente no meio. A supressão pode ocorrer através de um processo fotoquímico, na qual a molécula no estado excitado sofre transformações químicas, como transferência de elétrons, resultando na formação de novas espécies, ou por supressão fotofísica que é um processo que pode ser auto-supressão ou transferência de energia. Os processos de desativação bimoleculares podem ser classificados como mostra a Tabela 2. 
Tabela 2 - Processos de desativação bimoleculares

\section{PROCESSOS BIMOLECULARES}

\section{Supressão Fotofísica}

Auto-supressão

$D^{*}+D_{0} \longrightarrow D_{0}+D_{0}+$ calor

Transferência de energia

$D^{*}+B \longrightarrow D_{0}+B^{*}+$ calor

\section{Supressão Fotoquímica}

Formação de novas espécies (Produto)

Transferência de elétron

$A^{*}+D \longrightarrow[A \ldots D]^{*} \rightarrow A^{-}+D^{+}$ou $A^{+}+D^{-}$

A supressão fotoquímica engloba toda reação química que ocorre com a molécula no estado excitado.

- Reações fotoquímicas são as transformações químicas que ocorrem com a molécula no estado excitado singlete ou triplete resultando na formação de um novo produto. As transformações químicas no estado excitado incluem a formação de espécies intermediárias reativas, como a formação dos radicais livres.

Os processos de supressão fotofísica envolvem as reações de:

- Auto-supressão, que ocorre pela interação entre duas moléculas da mesma espécie, sendo uma no estado excitado $\left(D^{*}\right)$ e a outra no estado fundamental (D), fazendo com que a molécula retorne ao estado fundamental com a liberação de energia na forma de calor.

- Transferência de energia, um processo de supressão fotofísica que se dá através da transferência de energia de uma molécula no estado excitado para outra molécula presente no meio. Este processo ocorre desde que se mantenha a mesma multiplicidade e o processo seja exotérmico.

-Transferência de elétron é um processo que envolve substâncias que podem doar ou aceitar elétron de outra molécula no estado excitado. 


\subsubsection{Supressão de Fluorescência ${ }^{9}$}

A emissão de fluorescência, como descrito anteriormente, é definida como uma transição radiativa entre estados de mesma multiplicidade (singlete $\rightarrow$ singlete ou triplete $\rightarrow$ triplete). A supressão de fluorescência é um processo que compete com a emissão espontânea, isto é, a desativação através da emissão de energia na forma de radiação, de modo que o tempo de vida da molécula no estado excitado seja reduzido. Portanto, a supressão de fluorescência é um processo que diminui a intensidade de fluorescência emitida.

A supressão ocorre devido a vários processos, um deles é denominado supressão colisional ou dinâmica. Neste processo o supressor difunde até o fluoróforo, durante o tempo de vida do estado excitado, resultando em uma colisão bimolecular. Após o contato, a molécula retorna ao estado fundamental, sem emissão de fóton.

Devido à necessidade de difusão das moléculas, uma ao encontro da outra, este processo de supressão pode ser estudado por teorias de difusão. De acordo com o modelo de Smoluchowski ${ }^{10}$, quando não existe energia de ativação a velocidade de reação é controlada somente pela velocidade de difusão dos reagentes. Uma expressão aproximada da constante de difusão para processos bimoleculares em solução pode ser representada pela equação de Debye:

$$
k_{\text {difusão }} \approx \frac{8 R T}{3000 \eta} M^{-1} s^{-1}
$$

onde $\eta$ é a viscosidade do solvente e $R$ é a constante dos gases.

A supressão dinâmica, próxima ao limite difusional, é fortemente dependente do solvente e da temperatura. Em água a temperatura ambiente, $\eta \approx 10^{-3} \mathrm{~N} \mathrm{~s} \mathrm{~m}^{-2} \mathrm{e}$ $\mathrm{k}_{\text {difusão }} \approx 10^{10} \mathrm{M}^{-1} \mathrm{~s}^{-1}$.

A supressão dinâmica ou colisional compete com a desativação por processo de fluorescência, Tabela 1, e a desativação por interações com moléculas do supressor, Tabela 2.

Uma forma de representar a concentração de moléculas fluorescentes $[\mathrm{F}]^{0}$ na ausência de supressor, é dada através de:

$$
[F]^{0}=\frac{I_{a}}{k_{f}+k_{C I}+k_{I S C}}=\frac{I_{a}}{k_{f}+\sum k_{i}}
$$


na qual, $I_{a}$ é a intensidade de absorção ou a proporção da formação de moléculas excitadas, $k_{f}$ é a constante de fluorescência e $\Sigma k_{i}$ é a soma de todas as outras constantes dos processos de desativação unimolecular, tais como conversão interna $\left(k_{i c}\right)$ e cruzamento entressistemas $\left(k_{i s c}\right)$.

A concentração de moléculas fluorescentes $[\mathrm{F}]$ na presença de supressor é dada por:

$$
[F]=\frac{I_{a}}{k_{f}+\sum k_{i}+k_{q}[Q]}
$$

onde $[Q]$ é a concentração de supressor presente no meio reacional.

Em termos de rendimentos quânticos tem-se:

$$
\begin{aligned}
& \Phi_{f}^{o}=\frac{k_{f} \cdot[F]^{o}}{I_{a}}=\frac{k_{f}}{k_{f}+\sum k_{i}} \\
& \Phi_{f}=\frac{k_{f} \cdot[F]}{I_{a}}=\frac{k_{f}}{k_{f}+\sum k_{i}+k_{q} \cdot[Q]}
\end{aligned}
$$

Dividindo a Equação 4 pela Equação 5, obtém-se:

$$
\frac{\Phi_{\mathrm{f}}^{\mathrm{o}}}{\Phi_{\mathrm{f}}}=\frac{\mathrm{k}_{\mathrm{f}}+\sum \mathrm{k}_{\mathrm{i}}+\mathrm{k}_{\mathrm{q}} \cdot[\mathrm{Q}]}{\mathrm{k}_{\mathrm{f}}+\sum \mathrm{k}_{\mathrm{i}}}=1+\frac{\mathrm{k}_{\mathrm{q}} \cdot[\mathrm{Q}]}{\mathrm{k}_{\mathrm{f}}+\sum \mathrm{k}_{\mathrm{i}}}
$$

O tempo de vida da substância fluorescente na ausência de supressor $\left(\tau_{0}\right)$ é dado por:

$$
\tau_{\mathrm{o}}=\frac{1}{\mathrm{k}_{\mathrm{f}}+\sum \mathrm{k}_{\mathrm{i}}}
$$

Substituindo a Equação 7 na Equação 6, tem-se:

$$
\frac{\Phi_{f}^{o}}{\Phi_{f}}=1+k_{q} \times \tau_{o} \times[Q]=1+K_{S V} \times[Q]
$$

A Equação 8 é conhecida como a equação de Stern-Volmer, na qual $K_{\text {sv }}$ é a constante de Stern-Volmer, $\Phi_{\mathrm{f}}^{0}$ e $\Phi_{\mathrm{f}}$ são os rendimentos quânticos de fluorescência na ausência e presença de supressor, $k_{q}$ é a constante de velocidade de supressão bimolecular, $\tau_{0}$ é o tempo de vida da substância fluorescente na ausência de supressor e [Q] é a concentração do supressor.

Para simplificar, assume-se que os rendimentos quânticos de emissão são proporcionais às intensidades de fluorescência. 


$$
\frac{\Phi_{\mathrm{f}}^{\mathrm{o}}}{\Phi_{\mathrm{f}}}=\frac{\mathrm{I}_{0}}{\mathrm{I}}
$$

onde $I_{0}$ e $I$ representam as intensidades de fluorescência na ausência e presença de supressor, respectivamente.

O gráfico de Stern-Volmer para $\mathrm{I}_{0} / \mathrm{I}$ versus [Q] é linear e conhecendo o tempo de vida da espécie na ausência de supressor $\left(\tau_{0}\right)$, pode-se calcular a constante de supressão $\left(k_{q}\right)$ a partir da inclinação da reta.

Outro processo de supressão pode ocorrer devido à formação de um complexo no estado fundamental entre o supressor e a substância fluorescente. Este processo é denominado supressão estática.

$$
\mathrm{F}+Q \stackrel{K_{\text {est }}}{\rightleftharpoons}(\mathrm{F}-\mathrm{Q})
$$

A constante de equilíbrio para a formação do complexo $(F \ldots Q)$ é dada por:

$$
K_{e s t}=\frac{\mathbf{F} \cdots Q^{-}}{\mathbf{F} \times \mathbf{Q}_{-}^{\leq}}
$$

A concentração total da substância fluorescente é dada por:

$$
\mathbf{F}_{-}^{\sigma}=\mathbf{F}_{-}^{-} \mathbf{F} \ldots Q_{2}^{-}
$$

Substituindo a Equação 11 na Equação 10, obtém-se:

$$
K_{e s t}=\frac{\mathbf{F}^{\bar{\sigma}}}{\mathbf{F} \times \mathbf{D}_{-}^{-}}-\frac{1}{\mathbf{D}_{-}^{-}}
$$

Considerando-se que as concentrações de $[\mathrm{F}]^{0}$ e $[\mathrm{F}]$ são proporcionais às intensidades de fluorescência $\mathrm{I}_{0}$ e I, respectivamente, e que o complexo não emite no mesmo comprimento de onda do fluoróforo, tem-se:

$$
\frac{I_{0}}{I}=1+K_{e s t} \mathbf{D}_{-}^{-}
$$

Equação 13

A Equação 13 apresenta a mesma dependência de $\mathrm{I}_{0} / \mathrm{I}$ com o supressor $(Q)$, obtida pela equação de Stern-Volmer, porém a constante de supressão será a constante de associação entre a substância fluorescente no estado fundamental e o supressor.

Também podem ocorrer casos que apresentem supressão por ambos os mecanismos, como na Figura 2. 


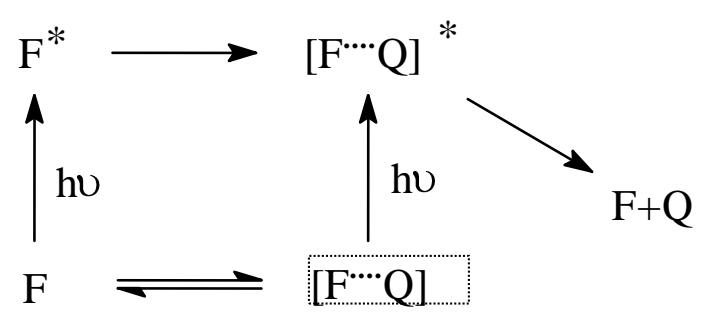

Figura 2 - Mecanismos possíveis de supressão entre um fluoróforo $(F)$ e o supressor $(Q)$.

A diferença entre a supressão estática e dinâmica pode ser verificada utilizando métodos como as medidas dos tempos de vida, estudo da variação das constantes de supressão com a temperatura e viscosidade, e também a dependência com o coeficiente de difusão do meio.

Na supressão estática o tempo de vida da substância fluorescente se mantém constante em todo o intervalo de concentração, já que o complexo é formado no estado fundamental. Um aumento de temperatura aumentará a instabilidade dos complexos no estado fundamental, diminuindo a constante de supressão estática $\left(\mathrm{K}_{\mathrm{est}}\right)$ enquanto modificações em relação à viscosidade não ocasionarão mudanças já que o processo não envolve colisões.

Na supressão dinâmica, como o processo ocorre via difusão das moléculas, o aumento de temperatura aumentará o coeficiente de difusão e a constante de supressão de fluorescência $\left(k_{q}\right)$, proporcional a $T / \eta$, aumentará. Da mesma forma, se um dado solvente é muito viscoso, a difusão das moléculas é dificultada e o processo de supressão é inibido.

\subsubsection{Fotoquímica de Compostos Carbonilados}

Como visto anteriormente, as moléculas orgânicas são capazes de absorver radiação e seus elétrons serem excitados a níveis de energia mais altos. A absorção de radiação é quantizada $(\mathrm{E}=h c / \lambda, h=$ constante de Planck, $\mathrm{c}=$ velocidade da luz e $\lambda=$ comprimento de onda) leva à excitação de um elétron de um orbital no estado fundamental (ligante ou não ligante), para um orbital excitado de maior energia (antiligantes) ${ }^{11}$. A Figura 3 mostra os quatro tipos de transições possíveis: $\sigma \rightarrow \sigma^{*}, \pi \rightarrow \pi^{*}, n \rightarrow \pi^{*}, n \rightarrow \sigma^{*}$. 


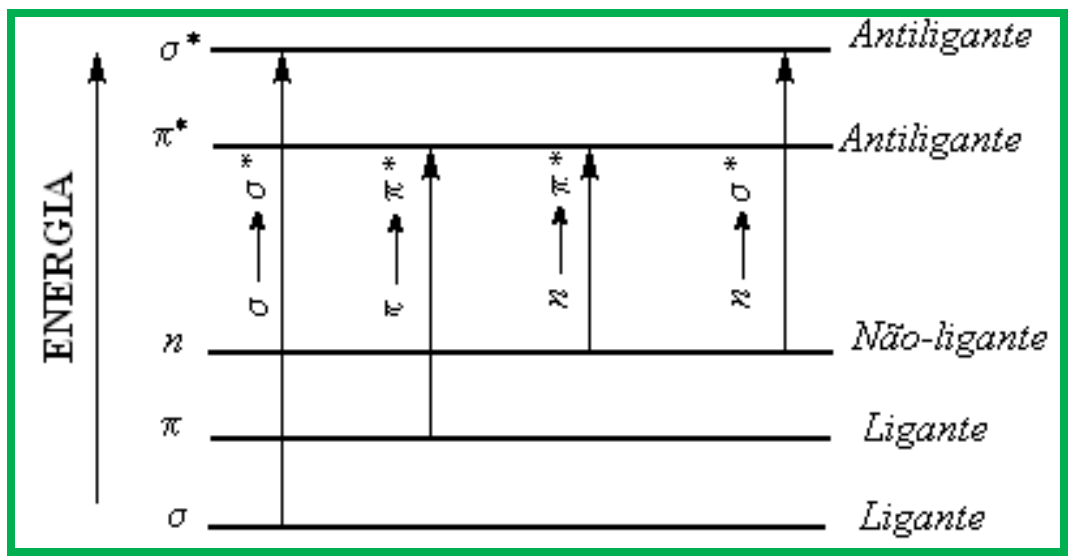

Figura 3 - Níveis de energia eletrônica molecular.

Para as moléculas que possuem em sua estrutura grupos carbonila e aromáticos há a possibilidade de transições do tipo $n \rightarrow \pi^{*}$ e $\pi \rightarrow \pi^{*}$. Essas transições apresentam algumas características relevantes que podem influenciar a reatividade das moléculas.

As transições do tipo $n \rightarrow \pi^{*}$ são características de cromóforos contendo heteroátomos, como os grupos $\mathrm{C}=\mathrm{O}, \mathrm{C}=\mathrm{N}, \mathrm{C}=\mathrm{S}, \mathrm{N}=\mathrm{N}, \mathrm{N}=\mathrm{O}$. As moléculas que apresentam esse tipo de transição exibem coeficientes de extinção molar baixos, $\varepsilon \sim 10-100 \mathrm{~cm}^{-1} \mathrm{~mol}^{-1} \mathrm{~L}$.

Os compostos insaturados apresentam transições do tipo $\pi \rightarrow \pi^{*}$. Nesse tipo de transição as moléculas apresentam coeficientes de extinção molar maiores permitidas por simetria, $\varepsilon \sim 10^{3}-10^{4} \mathrm{~cm}^{-1} \mathrm{~mol}^{-1} \mathrm{~L}^{(12)}$.

As cetonas aromáticas são compostos carbonilados que apresentam em sua estrutura grupos aromáticos, tais como benzeno ou naftaleno, podendo ter substituintes no anel ligados ao grupo carbonila. Os estados excitados de menor energia destes compostos podem ter caráter $\left(\pi, \pi^{*}\right)$ ou $\left(n, \pi^{*}\right)^{13}$.<smiles>CC(=O)c1ccccc1</smiles>

Acetofenona<smiles>O=C(c1ccccc1)c1ccccc1</smiles>

Benzofenona<smiles>O=c1c2ccccc2sc2ccccc12</smiles>

Tioxantona

Figura 4 - Exemplo de algumas moléculas representantes de cetonas aromáticas. 
A presença do anel aromático à cetona aumenta a conjugação e com isso o rendimento quântico do cruzamento entressistemas $\left(\Phi_{\text {ISC }}\right)$, podendo em alguns casos chegar à unidade. As reações químicas que ocorrem com as moléculas depois de absorver radiação podem ocorrer tanto a partir do estado excitado singlete quanto no estado triplete, porém para as cetonas aromáticas as reações ocorrem quase que exclusivamente no estado excitado triplete, devido ao alto rendimento quântico de cruzamento entressistemas ${ }^{2,14}$.

O estado eletrônico excitado de menor energia para as cetonas aromáticas pode ser $\left(n, \pi^{*}\right)$ ou $\left(\pi, \pi^{*}\right)$ e essa configuração pode ser influenciada por fatores como a polaridade do solvente no qual está dissolvido e os substituintes presentes no anel aromático.

O caráter $\left(n, \pi^{*}\right)$ ou $\left(\pi, \pi^{*}\right)$ do estado eletrônico de menor energia é de grande importância na reatividade das cetonas aromáticas, uma vez que a natureza do estado excitado pode determinar a eficiência da abstração de hidrogênio pelo grupo carbonila, por processo intermolecular ou intramolecular. No uso de cetonas aromáticas como fotoiniciadores de polimerização, as espécies ativas são formadas através da abstração de hidrogênio pelo grupo carbonila $^{11}$. Este assunto será abordado mais adiante.

- Efeito do solvente nas transições $n \rightarrow \pi^{*} e \pi \rightarrow \pi^{*}$

Dependendo da polaridade do solvente, as cetonas aromáticas apresentam uma inversão na energia dos estados excitados $\left(n, \pi^{*}\right)$ e $\left(\pi, \pi^{*}\right)$. Em solventes polares ocorre a estabilização do estado de menor energia $n$. O estado de maior energia $\pi^{*}$ não sofre alteração com a polaridade do solvente. A estabilização do orbital $n$ provoca um efeito hipsocrômico, isto é o deslocamento para menores comprimentos de onda.

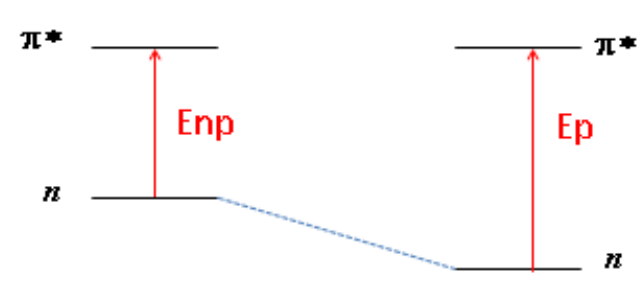

Ep $>$ Enp

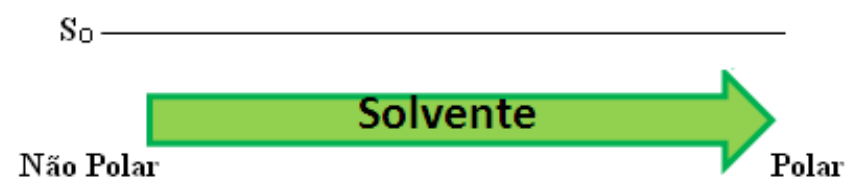

Figura 5 - Diagrama de nível de energia para transições $n \rightarrow \pi^{*}$ em solvente não polar e polar. Enp - Energia em solvente não polar; Ep - Energia em solvente polar. 
- Efeito do substituinte nas transições $n \rightarrow \pi^{*} e \pi \rightarrow \pi^{* 14}$

Outro fator que altera a estabilidade dos estados excitados de menor energia das cetonas aromáticas é a presença de substituintes com caráter doador ou aceptor de elétrons em conjugação com o anel aromático. Por exemplo, um doador de elétrons nas posições orto ou para estabilizará o estado $\left(\pi, \pi^{*}\right)$, uma vez que a densidade de elétrons é aumentada no anel.

\subsubsection{Reações e Processos Fotoquímicos de Compostos Carbonilados}

Algumas reações e processos fotoquímicos que podem ser observados para os compostos carbonilados excitados são a transferência de energia, a abstração de hidrogênio e a transferência de elétrons.

\section{Transferência de Energia}

O processo de transferência de energia em cetonas aromáticas se dá a partir do estado excitado triplete. A molécula absorve radiação na forma de luz, é levada ao estado excitado triplete e então a energia é transferida para outra molécula. Neste processo a molécula receptora deve manter a mesma multiplicidade e o processo deve ser exotérmico. Alguns exemplos de moléculas usadas em reações de transferência de energia, como aceptores, são o trans-estilbeno $\left(\mathrm{E}_{\text {triplete }}=49,3 \mathrm{kcal} \mathrm{mol}^{-1}\right), 1,3$-cicloexadieno $\left(\mathrm{E}_{\text {triplete }}=53 \mathrm{kcal} \mathrm{mol}^{-1}\right)^{(2)}, \beta$ caroteno, oxigênio, 1-metilnaftaleno, dentre outros. A Figura 6 apresenta o mecanismo proposto para o processo de transferência de energia entre a cetona aromática benzofenona e 1,3-cicloexadieno.

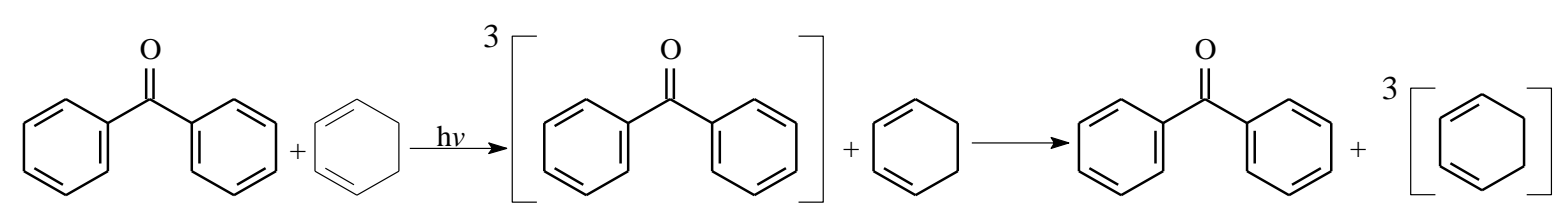

Figura 6 - Mecanismo proposto para a transferência de energia entre a benzofenona e 1,3cicloexadieno. 


\section{Reação de Abstração de Hidrogênio}

As reações de abstração de hidrogênio ocorrem através de uma reação intermolecular ou intramolecular de uma ligação $C-H$ próxima ao grupo carbonila excitado. A eficiência dessa reação depende da força da ligação do hidrogênio e também da configuração do estado excitado de menor energia da cetona aromática, $\left(n, \pi^{*}\right)$ ou $\left(\pi, \pi^{*}\right)$.

As cetonas aromáticas com estado excitado de menor energia $\left(n, \pi^{*}\right)$ abstraem com mais eficiência o hidrogênio, enquanto as que possuem estado de menor energia $\left(\pi, \pi^{*}\right)$ possuem eficiência baixa na abstração de hidrogênio ${ }^{2,14}$.

A Figura 7 mostra o mecanismo para a reação de abstração de hidrogênio de um álcool pela benzofenona.

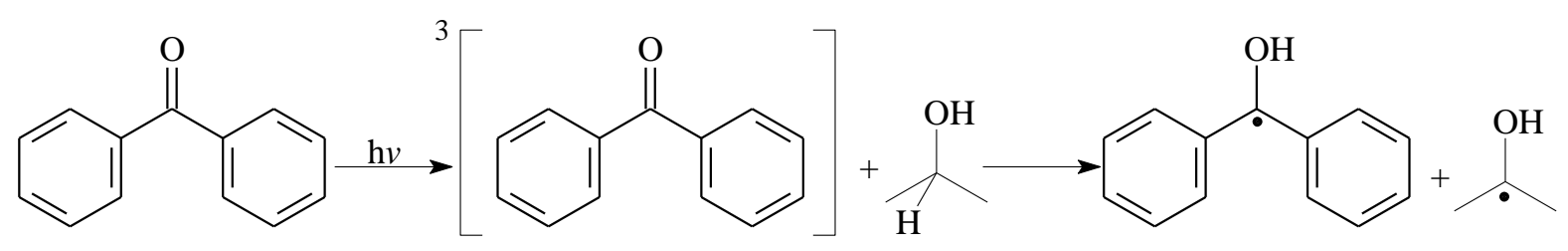

Figura 7 - Mecanismo proposto para a o processo de abstração de hidrogênio entre a benzofenona e o 2-propanol.

\section{Transferência de Elétrons}

As reações de transferência de elétron ocorrem com substâncias que apresentam pares de elétrons não ligantes, e a partir da transferência de um elétron forma-se um par de íons radicais ${ }^{2}$. As reações de transferência de elétrons acontecem com aminas, como a trietilamina.

O mecanismo de transferência de elétron entre a benzofenona e a trietilamina é mostrado na Figura 8.

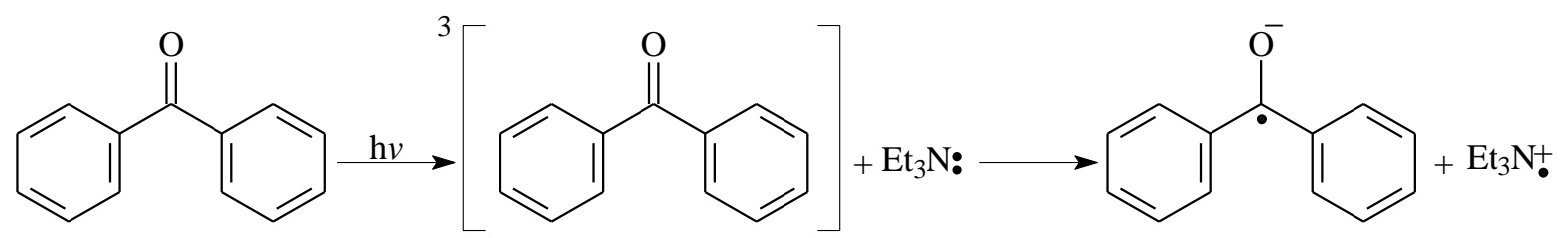

Figura 8 - Reação de transferência de elétrons entre a trietilamina e a benzofenona. 


\subsection{Polímeros ${ }^{15,16,17}$}

Polímeros são macromoléculas constituídas por unidades repetitivas de baixa massa molecular (meros) ligadas covalentemente. Podem ser classificados de várias formas, uma delas é quanto a sua origem que podem ser de dois tipos: os naturais e os polímeros sintéticos.

Os polímeros naturais podem ser formados pela repetição de unidades monoméricas diferentes, um exemplo deste tipo de polímeros são as proteínas. No entanto, os polímeros sintéticos podem ser produzidos com um número limitado de monômeros distintos, como exemplo tem-se os poliacrilatos, poliestireno, polietileno, dentre outros. Esta limitação no número de unidades repetitivas está relacionada com o grau de incorporação do monômero na cadeia polimérica durante o processo de polimerização, uma vez que a constituição do polímero está relacionada com a reatividade dos monômeros, que depende de fatores intrínsecos aos compostos utilizados e ao meio reacional, a forma estrutural e a afinidade química entre os monômeros presentes no meio.

Outra classificação para os polímeros, segundo Carothers, está relacionada com a natureza da reação química envolvida no processo de polimerização. Desta forma, os polímeros são classificados como de condensação ou adição.

Os polímeros de condensação são preparados a partir de monômeros, numa reação que é acompanhada da eliminação de moléculas menores, como água. Um exemplo de polímeros formados a partir deste tipo de reação são as poliamidas, como o Nylon-6,6.

Os polímeros de adição são formados a partir de reações em cadeia de monômeros que contêm ligações do tipo $\mathrm{C}=\mathrm{C}$. Neste tipo de polimerização (adição) não ocorre a eliminação de fragmentos menores. Como exemplo desse tipo de reação tem-se a obtenção do poliestireno.

A Figura 9 apresenta exemplos das reações de polimerização pelos processos de condensação e adição. 


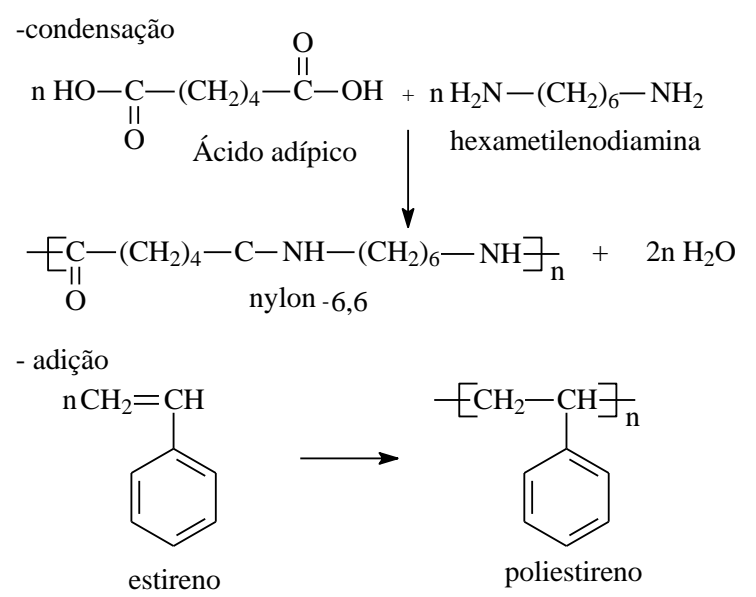

Figura 9 - Exemplos de polimerização por condensação e adição.

A polimerização em cadeia, caracterizada pelo crescimento do polímero através de sucessivas adições de monômeros, também pode ser classificada quanto à natureza da espécie iniciadora, como sendo polimerização por coordenação (que usa catalizadores de ZieglerNatta), polimerização iônica ou polimerização radicalar ${ }^{3,18}$.

\subsubsection{Polimerização Radicalar Fotoiniciada ${ }^{3,19}$}

Na polimerização radicalar fotoiniciada para que o processo de polimerização ocorra é necessário que a energia na forma de luz seja absorvida por um componente presente no sistema reacional. Em alguns casos, o próprio monômero absorve luz e dá início a polimerização. Caso contrário, é necessário acrescentar ao sistema uma espécie que absorva luz (o fotoiniciador) e produza espécies ativas capazes de iniciar a polimerização.

As reações de fotopolimerização podem ser de dois tipos, as reações de foto-cura, nas quais a irradiação provoca formação de ligações cruzadas entre polímeros pré-formados, originando materiais de alta massa molecular e a fotopolimerização em cadeia, processo este que compreende as seguintes etapas:

- iniciação, quando ocorre a produção de radicais livres $\left(R^{\bullet}\right)$ após a absorção de luz, seguida da adição a uma primeira molécula de monômero $(M)$ para produzir as espécies iniciadoras da cadeia, $\left(M^{\bullet}\right)$.

$$
\begin{aligned}
& F \stackrel{h v}{\longrightarrow} R^{\bullet} \\
& R^{\bullet}+M \stackrel{k_{i}}{\longrightarrow} M^{\bullet},\left(k_{i}\right. \text { é a constante de iniciação). }
\end{aligned}
$$


- propagação é a etapa em que ocorre o crescimento de $\left(M^{\bullet}\right)$, por adições sucessivas de moléculas do monômero (M).

$M_{n}^{\bullet}+M \stackrel{k_{p}}{\longrightarrow} M_{n+1}^{\bullet},\left(k_{p}\right.$ é a constante de propagação).

- terminação é uma reação bimolecular entre dois macrorradicais, podendo ocorrer por combinação ou desproporcionamento.

$M_{n}^{\bullet}+M_{m}^{\bullet} \stackrel{k_{t c}}{\longrightarrow} M_{n+m},\left(k_{t c}\right.$ é a constante de terminação por combinação).

$M_{n}^{\bullet}+M_{m}^{\bullet} \stackrel{k_{t d}}{\longrightarrow} M_{n}+M_{m},\left(k_{t d}\right.$ é a terminação por desproporcionamento).

Na polimerização radicalar fotoiniciada a absorção de luz pelo fotoiniciador dá início ao processo de polimerização e alguns parâmetros como velocidade de polimerização podem ser controlados através da intensidade, energia e distribuição espacial da radiação incidente.

\subsubsection{Fotoiniciadores ${ }^{4}$}

Os fotoiniciadores são definidos como moléculas que absorvem a radiação na forma de luz, gerando intermediários capazes de iniciar uma reação em cadeia. Para que o processo reacional ocorra são necessárias certas características do fotoiniciador, que deve apresentar um alto coeficiente de extinção molar $(\varepsilon)$ na região escolhida, alto rendimento quântico de formação de radicais e ser solúvel no meio reacional.

Os fotoiniciadores são classificados de acordo com o mecanismo de formação das espécies ativas, podendo ser do Tipo I ou do Tipo II.

Os fotoiniciadores do Tipo $I$ absorvem luz e sofrem uma cisão homolítica ou heterolítica de alguma ligação da molécula em um processo unimolecular. Deste modo, o fotoiniciador gera a espécie ativa, de forma direta, que dará início ao processo de polimerização.

Para os fotoiniciadores do Tipo II, após a absorção de luz a molécula no estado excitado interage com outra molécula, uma doadora ou aceptora de elétrons, para formar a espécie ativa. A molécula doadora ou aceptora de elétrons é chamada de co-iniciador.

Os co-iniciadores, por exemplo as aminas terciárias, devem possuir algumas propriedades como alto potencial de oxi-redução, alta reatividade de adição radicalar ao 
monômero, não absorver luz no mesmo comprimento de onda que o fotoiniciador e não interagir, no estado fundamental, com outras moléculas presentes no meio reacional ${ }^{20}$.

A Figura 10 mostra as reações de formação de espécies ativas por fotoiniciadores de Tipo I e Tipo II, para um composto carbonilado.

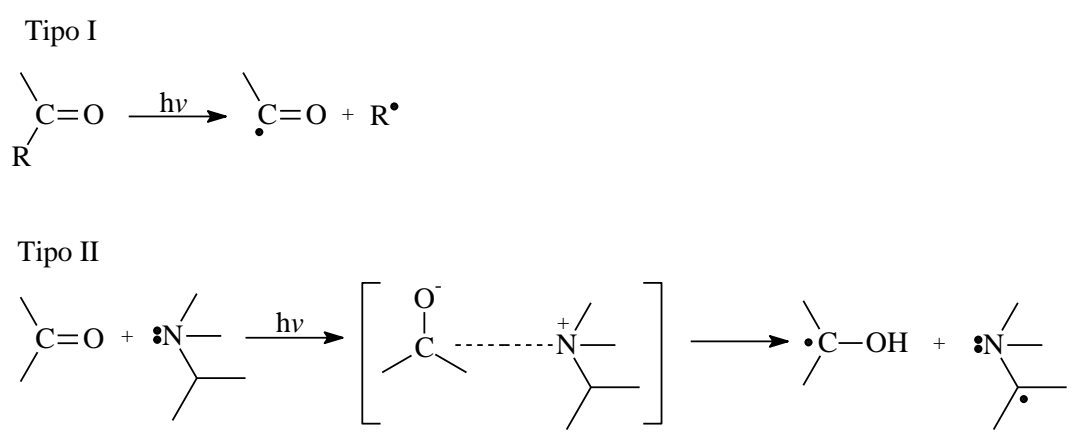

Figura 10 - Reações de formação de espécies ativas para fotoiniciadores do Tipo I e Tipo II.

\subsubsection{Tioxantonas e Derivados}

Os estados excitados de menor energia da cetona aromática tioxantona são os estados singlete e triplete $\left(n, \pi^{*}\right)$ e $\left(\pi, \pi^{*}\right)$, devido à conjugação do grupo carbonila com o anel aromático. As energias dos estados eletrônicos das tioxantonas apresentam uma dependência com a polaridade do solvente ${ }^{21,22}$.

As tioxantonas adquiriram uma grande importância industrial como fonte de radicais em fotocura de superfícies, principalmente por apresentar absorção em comprimentos de onda entre 350 e $450 \mathrm{~nm}^{23}$.

O uso da tioxantona como fotoiniciador de polimerização se deve à formação de radicais livres (radical cetila) a partir do estado excitado triplete. A tioxantona é um fotoiniciador do Tipo II.

A formação de radicais na presença de aminas terciárias ocorre através de uma reação entre a tioxantona e uma amina doadora de elétrons formando um exciplexo que se decompõe para formar radicais cetila e amino ${ }^{24}$. O radical que dará início à polimerização, em geral, é o radical amino por ser mais estável que o radical cetila.

A Figura 11 ilustra as reações do estado excitado triplete da tioxantona quando se utiliza uma amina terciária. 


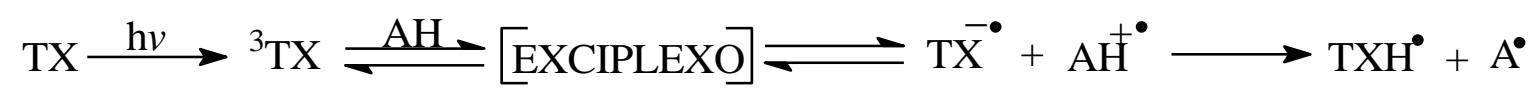

Figura 11 - Reação do estado excitado triplete da tioxantona com uma amina ${ }^{24}$.

A tioxantona pode agir também como um sensibilizador da reação de degradação. $\mathrm{O}$ estado excitado triplete da tioxantona pode abstrair um hidrogênio de uma molécula doadora, por exemplo um polímero $(\mathrm{P}-\mathrm{H})$, produzindo o radical cetila que poderá iniciar a reação de degradação ${ }^{25}$.

O termo derivados da tioxantona se refere a modificações (substituintes) na estrutura molécular da tioxantona. Os derivados de tioxantonas vêm recebendo grande importância nos estudos de sua reatividade. A proximidade entre os estados eletrônicos $T_{1}$ e $T_{2}$ dos derivados de tioxantonas permite que as propriedades fotofísicas sejam fortemente influenciadas pelo solvente e a substituição do anel aromático.

Estudos recentes vêm relatando os efeitos dos substituintes nas tioxantonas, como a introdução de grupos solúveis em meio aquoso, tornando-a solúvel em água ${ }^{26}$; substituintes que deslocam o máximo de absorção para maiores ou menores comprimentos de onda ${ }^{27}$; substituintes que fazem o papel do co-iniciador na polimerização, evitando assim o uso de outra molécula no sistema com a função do co-iniciador ${ }^{28,29}$, entre outros.

O uso de substituintes que fazem o papel do co-iniciador na polimerização foi estudado para uma tioxantona com substituinte tiol. Neste caso a nova molécula foi usada como fotoiniciador para polimerização por radicais livres. Esse fotoiniciador mostrou uma vantagem por apresentar na mesma molécula um fotossensibilizador de triplete e um doador de hidrogênio, dispensando o uso de uma molécula adicional para atuar como doadora de hidrogênio ${ }^{28}$. Outro derivado de tioxantona que também apresentou o mesmo comportamento de fotoiniciador de polimerização radicalar sem a presença de um co-iniciador, tinha dois grupos absorvedores de energia, o antraceno e a tioxantona. Nesse caso o fotoinicador se comportou de forma eficiente na polimerização via radical livre, tanto para o monômero estireno quanto para um acrilato, além de permitir o processo na presença de ar. Isso deixa claro como a introdução de substituintes pode modificar as propriedades da tioxantona ${ }^{30}$.

A S,S-dioxidotioxantona é um derivado da tioxantona. Nesta molécula há um grupo sulfona, $\left(R-\mathrm{SO}_{2}-R^{\prime}\right.$, adicionado a sua estrutura. As sulfonas possuem grande importância 
por apresentar diferentes propriedades farmacológicas, como atividade antibacteriana, antitumor, antialérgica e inibidor da protease do citomegalovírus humano. Porém, apesar de suas amplas propriedades farmacológicas, pouco se sabe a respeito da fotoestabilidade destas substâncias. Em um estudo da reatividade desta molécula foi observada a formação do estado excitado triplete reativo com caráter $\left(n, \pi^{*}\right)$. O grupo sulfona não apresentou nenhum produto decorrente da quebra de ligação $C-S^{31}$. 


\section{OBJETIVOS}




\section{OBJETIVOS}

O principal objetivo deste trabalho foi a síntese de um novo derivado da S,Sdioxidotioxantona, a 7,8-benzotioxanton-9-ona-10,10-dióxido, e o uso deste como fotoiniciador de polimerização. No entanto, para que esse objetivo fosse alcançado, uma série de objetivos secundários foi desenvolvido. Dentre esses objetivos, destacam-se:

I. A síntese e a caracterização da 7,8-benzotioxanton-9-ona-10,10-dióxido. Esta molécula combina em sua estrutura características de várias outras moléculas já descritas na literatura.

II. Estudos fotofísicos e fotoquímicos da nova molécula sintetizada. Investigação do comportamento espectral das espécies geradas no estado excitado e seus tempos de vida, e sua fotorreatividade.

III. Aplicação da 7,8-benzotioxanton-9-ona-10,10-dióxido como fotoiniciador de polimerização, investigando a cinética de fotopolimerização com o uso do monômero metacrilato de metila e como co-iniciador as aminas: trietilamina (TEA, alifática) e $p$ dimetilamina benzoato de etila (EDB, aromática). 
PARTE EXPERIMENTAL 


\section{PARTE EXPERIMENTAL}

\subsection{Reagentes Utilizados}

Na Tabela 3 estão apresentados os principais reagentes utilizados.

Tabela 3 - Principais reagentes

\begin{tabular}{lllll}
\hline Reagentes & MM $\left(\mathbf{g ~ m o l}^{-1}\right)$ & Procedência & Pureza (\%) \\
\hline $\begin{array}{l}\text { Ácido } \\
\text { tiosalicílico }\end{array}$ & & Aldrich & \\
Maftaleno \\
metila (MMA)
\end{tabular}

Outros reagentes usados: ácido sulfúrico (Qhemis, PA); ácido acético glacial (J T Baker Chemical, PA); hidróxido de sódio (LabSynth, 97\%); bicarbonato de sódio (Mallinckrodt); peróxido de hidrogênio (Merck, PA), cloreto de cálcio (LabSynth); hexano (Tedia, 95\%); metilciclohexano (Aldrich, 99\%); dioxano (Mallinckrodt, HPLC); diclorometano (Tedia, 95\%); clorofórmio (Mallinckrodt, HPLC); acetato de etila (Mallinckrodt, HPLC); acetonitrila (Tedia, HPLC); metanol (Mallinckrodt, HPLC); 2propanol (Tedia, 95\%); trans-estilbeno; sílica (Kieselgel $60 \mathrm{PF}_{254}$, Merck); solução de sílica coloidal - Ludox (Aldrich). 


\subsection{Síntese da 7,8-benzotioxanton-9-ona-10,10-dióxido, $\mathbf{T X - N p - S O _ { 2 }}{ }^{27,32}$}

A síntese do derivado da S,S-dioxidotioxantona foi realizada em duas etapas. Primeiro foi realizada a síntese da 5-tia-naftaceno-12-ona (TX-Np) e posteriormente a TX-Np foi oxidada e levada ao produto desejado, a 7,8-benzotioxanton-9-ona-10,10-dióxido.

\section{Etapa 1: Síntese da TX-Np}

Para o preparo da TX-Np adicionou-se 1,6 g de ácido tiosalicílico a $15 \mathrm{~mL}$ de ácido sulfúrico concentrado e a mistura foi agitada por 5 minutos. Em seguida, adicionou-se lentamente 5,6 g de naftaleno à mistura em agitação ao longo de um período de 30 minutos. Após a adição, a mistura reacional foi agitada a temperatura ambiente por 1 hora e depois a $60{ }^{\circ} \mathrm{C}$ por 4 horas. Após esta etapa a mistura foi deixada em repouso por uma noite (12 horas), em temperatura ambiente. A mistura obtida foi derramada cuidadosamente em $400 \mathrm{~mL}$ de água fervente, sob agitação e fervida por mais 5 minutos. Em seguida, a solução foi neutralizada com hidróxido de sódio aquoso a $10 \%(\mathrm{p} / \mathrm{V})$ e fervida por mais 5 minutos. A solução foi resfriada e filtrada. Depois de secar em dessecador, foi realizada a recristalização em dioxano-água (1:1) e filtrado.<smiles>O=C(O)c1ccccc1S</smiles>

Ácido Tiosalicílico<smiles>c1ccc2ccccc2c1</smiles>

Naftaleno<smiles>O=c1c2ccccc2sc2ccc3ccccc3c12</smiles>

TX-Np
Reação 1

\section{Etapa 2: Síntese da TX-Np-SO}

Em um balão de $500 \mathrm{~mL}$, sob refluxo a $135{ }^{\circ} \mathrm{C}$ por 2 horas, foram dissolvidos $3 \mathrm{~g}$ da TX-Np em $80 \mathrm{~mL}$ de ácido acético glacial. Após a solubilização, foram adicionados $8 \mathrm{~mL}$ de peróxido de hidrogênio, $\mathrm{H}_{2} \mathrm{O}_{2} 30 \%$, e a solução permaneceu durante 12 horas sob agitação magnética. Após 12 horas, foram adicionados mais $8 \mathrm{~mL}$ de peróxido de hidrogênio, $\mathrm{H}_{2} \mathrm{O}_{2}$ $30 \%$, e o sistema foi aquecido em banho de óleo durante 45 minutos a $135{ }^{\circ} \mathrm{C}$ (refluxo). Durante o aquecimento, a aparência da mistura era de cor amarela clara. Ao atingir a temperatura ambiente o aspecto era de um sólido branco em uma solução amarela um pouco mais escura que a do aquecimento. A solução foi neutralizada com hidróxido de sódio aquoso 
$10 \%(\mathrm{p} / \mathrm{V})$ e filtrada em seguida. A extração da $\mathrm{TX}-\mathrm{Np}-\mathrm{SO}_{2}$ foi feita com diclorometano. A fase orgânica foi seca com cloreto de cálcio, $\mathrm{CaCl}_{2}$, e o solvente foi evaporado em rotoevaporador. A TX-Np- $\mathrm{SO}_{2}$ um sólido amarelo claro, após a síntese, foi recristalizado em etanol.

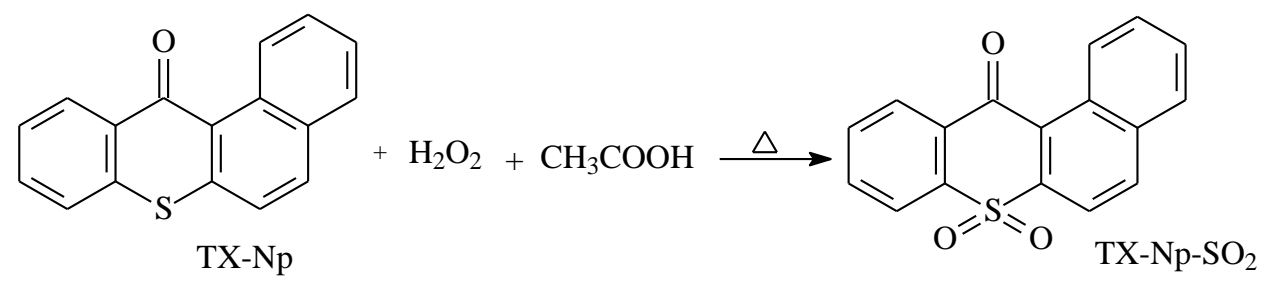

Reação 2

\section{Purificação}

A purificação do produto da síntese, $\mathrm{TX}-\mathrm{Np}-\mathrm{SO}_{2}$, foi realizada por extração com a mistura clorofórmio e bicarbonato de sódio $5 \%(1: 1)$ utilizando um funil de separação.

Após esta etapa, a separação da TX-Np- $\mathrm{SO}_{2}$ foi feita passando a amostra por uma coluna cromatográfica de $60 \mathrm{~cm}$ de altura e $4 \mathrm{~cm}$ de diâmetro, utilizado sílica como fase estacionária e uma mistura composta de $60 \%$ hexano e $40 \%$ acetato de etila como fase móvel.

A separação dos produtos na coluna cromatográfica foi acompanhada com uma lâmpada de radiação no visível, devido o produto esperado absorver nesta região. Após a purificação na coluna, o solvente foi retirado em um rotoevaporador.

\subsection{Purificação dos Reagentes}

Procedimento para retirar o inibidor hidroquinona do monômero metacrilato de metila (MMA)

Em um funil de separação foi adicionado 50\% em volume do monômero MMA e 50\% em volume de uma solução de hidróxido de sódio, $\mathrm{NaOH} 5 \%$. A mistura foi agitada e após a separação das fases retirou-se a solução de $\mathrm{NaOH} 5 \%$. Este procedimento de lavagem do monômero com $\mathrm{NaOH} 5 \%$ foi repetido por mais 3 vezes e, posteriormente, lavado por mais 3 vezes com água destilada para retirada do excesso da base. $\mathrm{O}$ monômero foi seco com cloreto de cálcio por um período de 12 horas, filtrado e armazenado ao abrigo da luz e sob refrigeração. 


\subsection{Equipamentos Utilizados}

- Espectrofotômetro UV-Vis Shimadzu UV-2550;

- Espectrofluorímetro Hitachi F-4500;

- Sistema de Flash Photolysis LuzChem. Laser de Nd-YAG (Brilliant B, Quantel, 5,2 ns e 165 $\mathrm{mJ} / \mathrm{pulso})$;

- Dilatômetro acoplado a um catetômetro;

- Cromatógrafo Líquido de Alta Eficiência Shimadzu LC-10AD;

- Espectroradiômetro LuzChem SPR-01;

- Sistema de Fluorescência Resolvida no Tempo, EasyLife V ${ }^{\mathrm{TM}}$ OBB Corporation.

\subsection{Técnicas Instrumentais}

\section{Fotólise por Pulso de Laser $^{33,34}$}

O sistema de fotólise por pulso de laser é muito usado na investigação fotofísica e fotoquímica de moléculas orgânicas. Esta técnica foi introduzida em 1949 por Norrish e Porter para o estudo direto de espécies transientes, como estados tripletes e radicais ${ }^{35}$.

No entanto, sua aplicação foi aprimorada com o surgimento do laser em 1960, o que permitiu que esta técnica atingisse completamente seu potencial. $\mathrm{O}$ uso de fontes de alta intensidade (pulso de luz curto e intenso) tornou possível a geração de altas concentrações de transientes de tempos de vida curtos $\left(\tau<10^{-3} \mathrm{~s}\right)$. Com este método de detecção pode-se chegar a resolução de picossegundos.

A análise do estado excitado triplete consiste em incidir na amostra um pulso de luz (laser) com a finalidade de gerar uma alta quantidade de espécies excitadas, as quais por cruzamento entresistemas (ISC) vão, em geral, a um estado excitado $\mathrm{T}_{1}$. Antes que as mesmas retornem ao estado fundamental uma segunda fonte de luz (luz de análise) é incidida para excitar estas espécies a um estado excitado triplete de maior energia $T_{2}$ ou $T_{n}$ por absorção de um fóton, como ilustrado na Figura 12. Após esta etapa, as espécies excitadas podem ser detectadas por absorção óptica. 


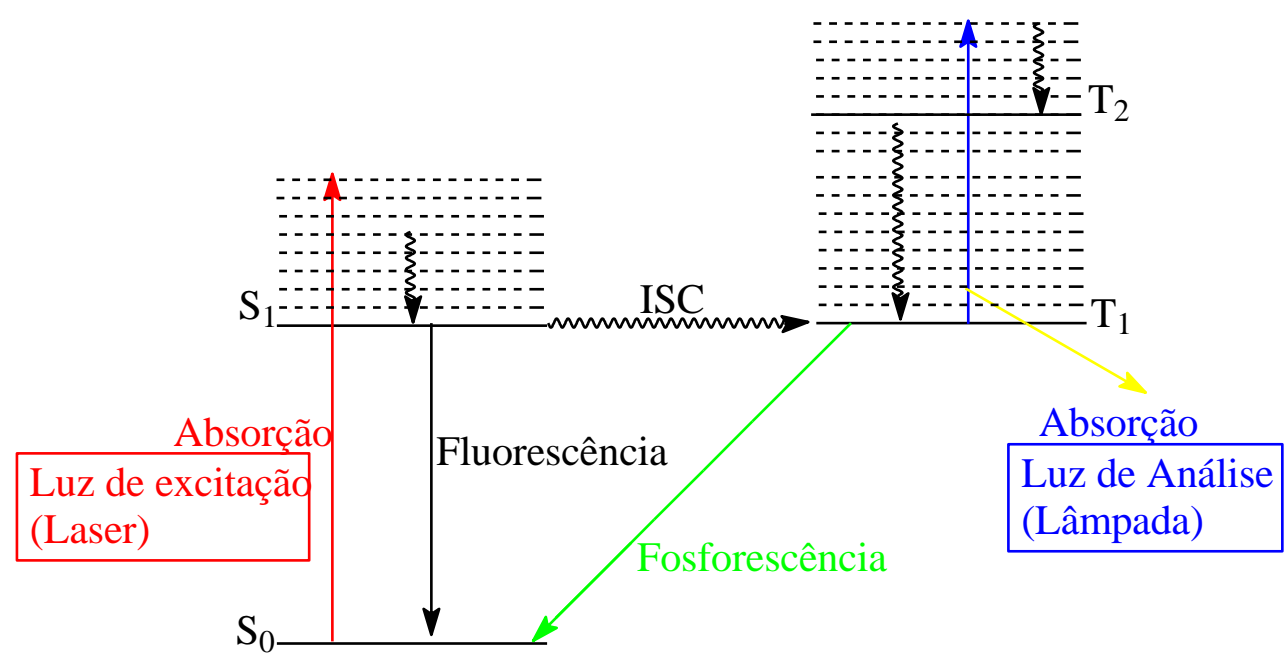

Figura 12 - Princípio da espectroscopia de fotólise por pulso de $\operatorname{laser}^{36}$.

Algumas das fontes de laser mais utilizadas em sistema de fotólise por pulso de laser estão listadas na Tabela 4.

Tabela 4 - Exemplos de lasers usados em fotólise por pulso de laser ${ }^{37}$

\begin{tabular}{lcc}
\hline \multicolumn{1}{c}{ Laser } & Fundamental $(\mathbf{n m})$ & Harmônicos $(\mathbf{n m})$ \\
\hline Nitrogênio & 337 & \\
Excímero & $157 ; 193 ; 248 ; 308 ; 351$ & \\
Rubi & 694 & 347 \\
Nd-YAG & 1064 & $532,355,266$ \\
\hline
\end{tabular}

A aquisição dos dados é obtida por meio de um sistema de detecção que é formado, por uma fotomultiplicadora e um osciloscópio de resposta rápida. O esquema de um equipamento de fotólise por pulso de laser é mostrado na Figura 13. 


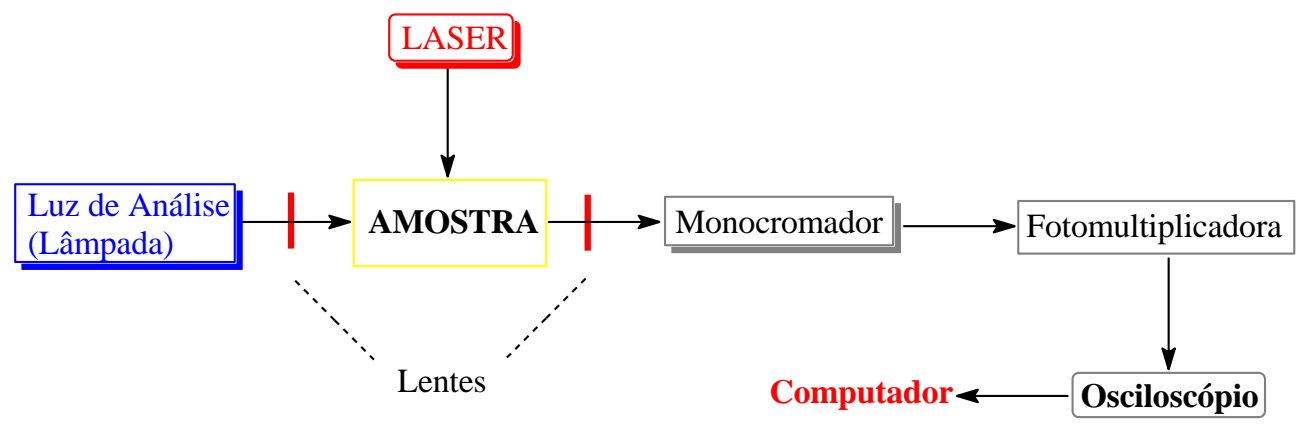

Figura 13 - Esquema simplificado de um sistema de fotólise por pulso de laser ${ }^{36}$.

O sistema de fotólise por pulso de laser permite a obtenção dos tempos de decaimento dos transientes $\left(\tau_{0}\right)$, espectros de absorção triplete-triplete numa determinada faixa de comprimento de onda de excitação e as constantes de velocidade $\left(k_{o b s}\right)$ para o decaimento do triplete Esta última relacionada com os tempos de vida dos transientes na ausência do supressor $\left(\tau_{0}\right)$, dada pela equação de Stern-Volmer, Equação 8:

$$
k_{\text {obs }}=\frac{1}{\tau}=\frac{1}{\tau_{0}}+k_{q} \mathbf{D}_{-}^{-}=\frac{\tau_{0}}{\tau}=1+k_{q} \tau_{0} \mathbf{D}_{-}^{-}
$$

Através desta técnica foi possível estudar os espectros de absorção triplete-triplete e os decaimentos dos transientes da TX-Np-SO $\mathrm{SO}_{2}$. Os experimentos foram realizados a temperatura de $295 \mathrm{~K}$, e as soluções da TX-Np-SO ${ }_{2}$ foram preparadas nos solventes metanol, acetonitrila e metilciclohexano. A concentração das soluções foi escolhida de forma que a absorbância no comprimento de onda de excitação $(355 \mathrm{~nm})$ fosse de 0,3 a fim de se evitar o efeito de ondas de choque. As soluções foram desoxigenadas borbulhando nitrogênio por 30 minutos e excitadas em $355 \mathrm{~nm}$, utilizando o $3^{\circ}$ harmônico do laser Nd-YAG com pulsos entre 12 - 15 $\mathrm{mJ}$ e um intervalo de disparo de 5,2 ns entre os pulsos. As constantes de velocidade $\left(k_{q}\right)$ de supressão foram determinadas usando trans-estilbeno, EDB, TEA e 2-propanol. 


\section{$>\quad$ Fluorescência Resolvida no Tempo ${ }^{38}$}

A espectroscopia de fluorescência é largamente utilizada no estudo de tempos de vida de espécies no estado excitado. As informações contidas nos decaimentos podem revelar características sobre a estrutura molecular, interações às quais esta espécie está submetida e o ambiente na qual está inserida.

Atualmente são utilizados três métodos para medir os tempos de vida de fluorescência de uma molécula. Estes métodos são: modulação de frequência ou harmônico, técnica de contagem de fótons correlacionada com tempo (TCSPC), do inglês Time Correlated Single Photon Counting, e mais recentemente, a técnica estroboscópica. A primeira é uma técnica no domínio de frequência e as outras são técnicas no domínio de tempo.

Nas técnicas de domínio de tempo são medidas curvas de decaimento de fluorescência, isto é, intensidade de fluorescência em função do tempo, de forma direta. As técnicas estroboscópica e TCSPC se assemelham no tipo de medida e no modo que os dados são analisados, no entanto a principal diferença entre elas está no arranjo físico do equipamento. Estas duas técnicas usam eletrônicas para a detecção e fontes de luz diferentes, embora algumas fontes de luz possam ser comuns às duas técnicas.

Num experimento típico usando a técnica de domínio de tempo, são medidas duas curvas de decaimento: o decaimento da amostra em estudo e a IRF (do inglês Instrument Response Function, que é a função de resposta do equipamento) utilizando uma solução de espalhamento. A análise é realizada através da convolução do IRF com uma função modelo, que pode ser um decaimento exponencial simples ou outra função qualquer, e comparada ao decaimento experimental. Esse procedimento é feito através de um método numérico iterativo até o melhor ajuste com o decaimento experimental.

\section{- Arranjo Experimental da Técnica Estroboscópica}

A aquisição dos dados na técnica estroboscópica é obtida através de um sistema de detecção constituído por uma fotomultiplicadora (PMT) e um controlador eletrônico. A Figura 14 mostra o diagrama simplificado de um equipamento que utiliza a técnica estroboscópica. Toda a eletrônica é controlada por um programa que fornece uma sincronização precisa entre o LED de excitação e o pulso que controla o ganho da PMT na janela de domínio do tempo. 


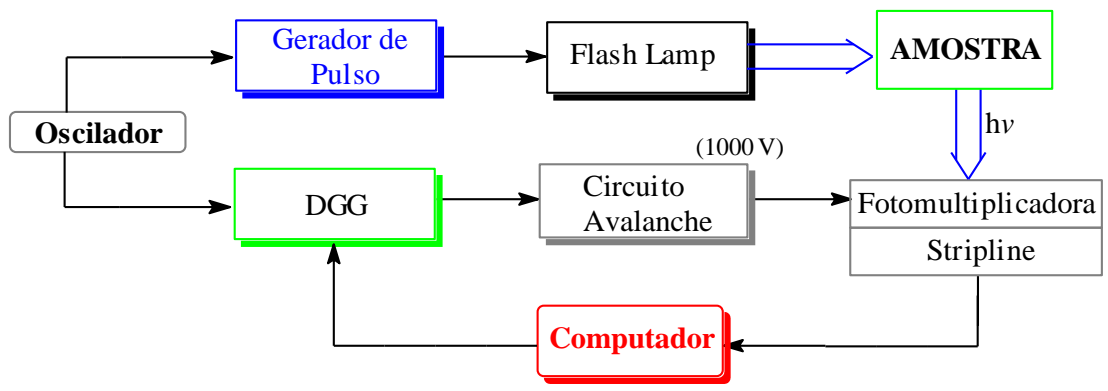

Figura 14 - Esquema simplificado da técnica estroboscópica.

O funcionamento básico do equipamento consiste em um oscilador que gera pulsos elétricos a uma determinada frequência e então são enviados simultaneamente a um gerador de pulso e a um gerador de atraso (DGG), do inglês Delay Gate Generator, criando assim uma defasagem no sinal recebido. O sinal defasado atravessa um circuito avalanche que fornece um pulso de alta tensão para o circuito de detecção, composto por uma fotomultiplicadora. Esse sinal é recebido no mesmo instante que o fóton emitido pela amostra. O sinal então gerado é enviado ao computador e processado.

Utilizando a técnica estroboscópica foi possível determinar o tempo de vida da fluorescência da TX-Np-SO $\mathrm{SO}_{2}$. As medidas foram realizados a temperatura de $295 \mathrm{~K}$, e as soluções da TX-Np- $\mathrm{SO}_{2}$, na concentração de $1 \times 10^{-5} \mathrm{M}$, foram preparadas em metilciclohexano. A solução espalhadora (IRF) utilizada foi a sílica coloidal (LUDOX). O LED de excitação usado no experimento foi de $280 \mathrm{~nm}$ e o filtro de corte de $305 \mathrm{~nm}$. 


\subsection{Procedimentos Experimentais}

\section{$>\quad$ Dilatometria $^{3}$}

A dilatometria é um método que utiliza as variações de volume que ocorrem durante a polimerização para se avaliar a velocidade de polimerização, já que a densidade dos polímeros é, geralmente, maior que a dos monômeros.

A velocidade de polimerização fotoiniciada foi acompanhada através de um sistema que consiste de uma bancada de iluminação que permite a irradiação da solução em um dilatômetro. A contração do volume no capilar do dilatômetro é acompanhada por de um catetômetro, simultaneamente à irradiação do sistema. A Figura 15 ilustra o sistema utilizado para acompanhar a cinética de polimerização.

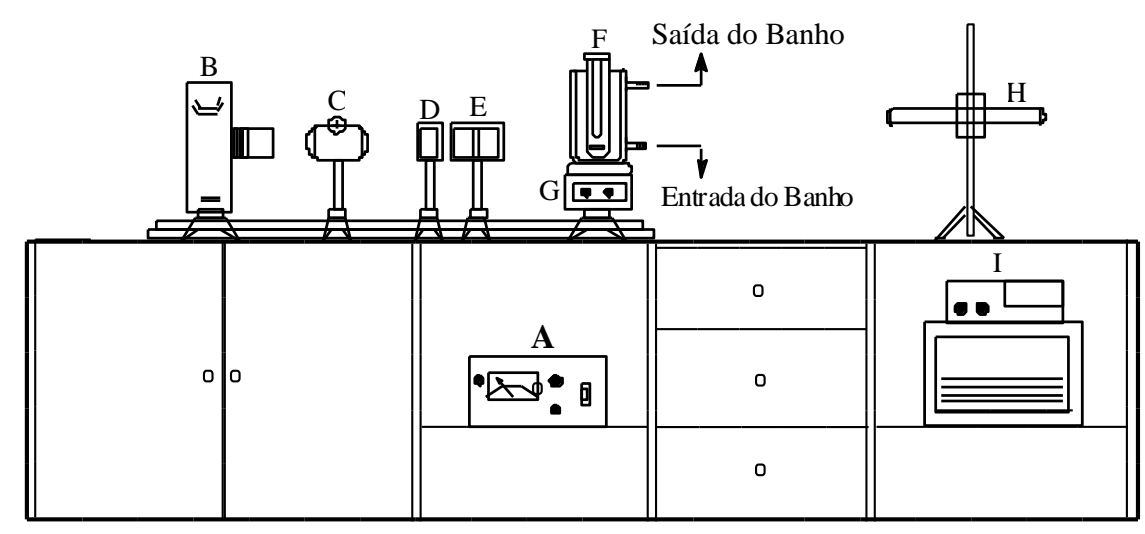

Figura 15 - Esquema do sistema de dilatometria: (A) fonte de tensão da lâmpada; (B) lâmpada de mercúrio/xenônio - Oriel Hg/Xe 200 W; (C) filtro de infravermelho; (D) lente focalizadora; (E) monocromador; (F) dilatômetro em banho termostatizado; $(\mathrm{G})$ agitador magnético; (H) catetômetro $40 \mathrm{~cm}$ - Eberbach Corporation; (I) banho termostatizado Polyscience.

O dilatômetro utilizado neste experimento foi previamente calibrado com tetracloreto de carbono para obter-se exatamente seu volume e a área do capilar. As dimensões do dilatômetro determinadas foram de $2,39 \mathrm{~cm}$ de diâmetro do cilindro e $0,28 \mathrm{~cm}$ do capilar e um volume do cilindro de $11 \mathrm{~mL}$.

Para acompanhar a cinética de polimerização o dilatômetro foi ajustado no banho termostatizado a $22,0 \pm 0,1{ }^{\circ} \mathrm{C}$ de forma que o feixe de luz incidisse no centro do cilindro. Este foi mantido no escuro por 40 minutos para que a expansão térmica não comprometesse 
as medidas e só depois foi iniciada a irradiação. As variações de altura da solução no capilar durante a irradiação foram medidas com o catetômetro.

Para as polimerizações, as velocidades de polimerização $(R p)$ foram determinadas utilizando a expressão:

$$
R p=\frac{\Delta V}{F \times f \times t}[M]
$$

na qual $\Delta V$ é a contração de volume do capilar determinada através da relação:

$$
\Delta V=2 \times \Delta h \times \pi \times r^{2}
$$

sendo $\Delta h$ a variação na altura do capilar em um determinado tempo e $r$ o raio do capilar; F é o fator de contração de volume, relacionado com as densidades do monômero e polímero, segundo:

$$
F=\frac{d_{p}-d_{m}}{d_{p}}
$$

onde $d_{m}$ e $d_{p}$ são, respectivamente, as densidades do monômero e do polímero; $f$ é o volume do monômero presente em solução:

$$
f=\frac{m_{m}}{d_{m}}
$$

Equação 17

sendo $m_{m}$ e $d_{m}$ a massa e a densidade do monômero, respectivamente; [M] é a concentração de monômero.

\section{$>\quad$ Cromatografia por Exclusão de Tamanho ${ }^{39}$}

Cromatografia por exclusão de tamanho é uma técnica de fracionamento das cadeias poliméricas, que permite separar e analisar as frações com diferentes massas molares presentes em uma amostra de polímero.

As massas molares dos polímeros obtidos a partir da fotopolimerização foram determinadas através da injeção da solução de polímero em uma coluna de cromatografia específica. Esta coluna é composta por partículas porosas de estrutura rígida ou semi-rígida. As macromoléculas maiores não entram nos poros e atravessam a coluna mais rapidamente, já as macromoléculas menores penetram nos poros e ficam retidas na coluna por um tempo 
maior. Através dessa técnica pode-se determinar a massa molar numérica média, $\overline{M_{n}}$, a massa molar ponderal média, $\overline{M_{w}}$, e a polidispersidade $\left(\frac{\overline{M_{w}}}{\overline{M_{n}}}\right)$ de uma amostra de polímero.

A massa molar numérica média, $\overline{M_{n}}$, definida como a massa molar total de todas as moléculas de polímero presentes em uma amostra dividida pelo número total de moléculas de polímero é definida como:

$$
\overline{M_{n}}=\frac{\sum_{i-1}^{\infty} N_{i} \cdot M_{i}}{\sum_{i=1}^{\infty} N_{i}}
$$

em que:

$\overline{M_{n}}$ é a massa molar numérica média;

$M_{i}$ é a massa molar de moléculas de classe $i$;

$N_{i}$ é o número de moléculas de classe $i$.

A massa molar ponderal média, $\overline{M_{w}}$, depende do número e da massa de cada molécula de polímero presente na solução é definida como:

$$
\overline{M_{w}}=\frac{\sum_{i=1}^{\infty} N_{i} \cdot M_{i}^{2}}{\sum_{i=1}^{\infty} N_{i} \cdot M_{i}}
$$

onde:

$\overline{M_{w}}$ é a massa molar ponderal média;

$M_{i}$ é a massa molar de moléculas de classe $i$;

$N_{i}$ é o número de moléculas de classe $i$.

A relação entre $\overline{M_{w}}$ e $\overline{M_{n}},\left(\frac{\overline{M_{w}}}{\overline{M_{n}}}\right)$, define a polidispersidade da amostra polimérica e é tanto maior quanto mais heterogêneas forem as massas molares dos polímeros. 
Os cromatogramas foram obtidos utilizando um cromatógrafo, Shimadzu, modelo LC$10 \mathrm{AD}$ com detector de índice de refração. As amostras foram dissolvidas no eluente tetrahidrofurano. Para as medidas foi usada uma combinação de quatro colunas, sendo duas Styragel HR 4 e duas Styragel HR 5, cujo enchimento é constituído por partículas rígidas do copolímero poli(estireno-co-divinilbenzeno). Como padrões para a curva de calibração foram utilizados os poli(metacrilatos de metila), American Polymer Standards Corporation, com massas molares entre $7200-2.200 .000 \mathrm{~g} \mathrm{~mol}^{-1}$. Para a preparação das soluções padrões e das amostras utilizou-se uma massa de $2 \mathrm{mg}$ dissolvida em $2 \mathrm{~mL}$ de tetrahidrofurano. As medidas foram realizadas à temperatura de $40{ }^{\circ} \mathrm{C}$ e com fluxo de $1 \mathrm{~mL} \mathrm{~min}{ }^{-1}$.

\subsection{Estruturas e Siglas das Moléculas Presentes Neste Estudo}

No quadro abaixo são mostradas a estrutura da molécula sintetizada neste estudo (TX$\mathrm{Np}-\mathrm{SO}_{2}$ ) e as principais estruturas citadas nesse trabalho.<smiles>O=C1c2ccccc2S(=O)(=O)c2ccc3ccccc3c21</smiles>

7,8-benzotioxanton-9-ona-10,10dióxido

TX-Np-SO<smiles>O=c1c2ccccc2sc2ccccc12</smiles>

Tioxantona

(9H-tioxanton-9-ona)<smiles>O=C1c2ccccc2S(=O)(=O)c2ccccc21</smiles>

S,S-dioxidotioxantona

(Tioxanton-9-ona-10,10-dióxido)

TX-SO<smiles>O=c1c2ccccc2sc2cc3ccccc3cc12</smiles>

5-tia-naftaceno-12-ona

TX-Np

TX<smiles>c1ccc2ccccc2c1</smiles>

Naftaleno

Np 


\section{RESULTADOS E DISCUSSÕES}




\section{RESULTADOS E DISCUSSÕES}

\subsection{Caracterização da 7,8-benzotioxanton-9-ona-10,10-dióxido, TX-Np-SO}

Neste tópico serão apresentados os resultados da caracterização da TX-Np- $\mathrm{SO}_{2}$. Quatro técnicas foram utilizadas para identificar a estrutura e pureza do produto isolado. As técnicas usadas como ferramentas para auxiliar a identificação da estrutura foram espectroscopia de infravermelho (FTIR), análise elementar (AE), cromatografia líquida de alta eficiência (CLAE) e ressonância magnética nuclear (RMN) de 1D e 2D.

\subsubsection{Espectroscopia de Infravermelho com Transformada de Fourier}

A Figura 16 ilustra o espectro de infravermelho da $\mathrm{TX}-\mathrm{Np}-\mathrm{SO}_{2}$ sintetizada inicialmente neste trabalho, como descrito no procedimento experimental.

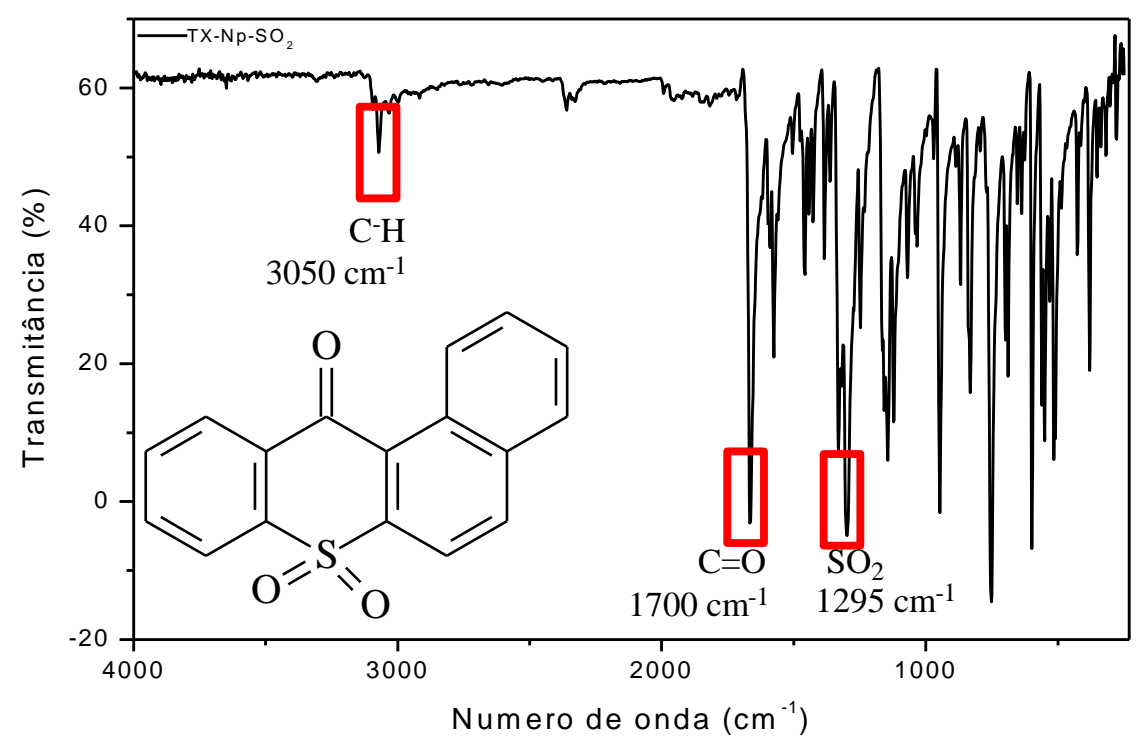

Figura 16 - Espectro de infravermelho da $\mathrm{TX}-\mathrm{Np}-\mathrm{SO}_{2}$ sintetizada com os principais grupos funcionais. Pastilhas de $\mathrm{KBr}$ na proporção 1:100 de TX-Np-SO $\mathrm{S}_{2}$ e $\mathrm{KBr}$, respectivamente.

Através desta técnica pode-se verificar a presença de grupos funcionais e algumas ligações específicas existentes na molécula.

A presença do grupo $\mathrm{SO}_{2}$ na molécula foi confirmada por picos intensos em 1295 e $1438 \mathrm{~cm}^{-1}$ atribuídos ao modos de estiramento simétrico e antissimétrico, respectivamente. Em torno de $1700 \mathrm{~cm}^{-1}$ observa-se um pico de alta intensidade característico do estiramento da ligação $C=O$. O sinal atribuído ao estiramento da ligação $C-H$ em compostos aromáticos é 
observado em $3050 \mathrm{~cm}^{-1}$ e este sinal se torna mais intenso conforme o número de anéis aromáticos é aumentado em uma molécula ${ }^{12,40}$.

\subsubsection{Análise Elementar}

A composição atômica do composto $\mathrm{TX}-\mathrm{Np}-\mathrm{SO}_{2}$ foi verificada utilizando a técnica de análise elementar que permite verificar a composição da molécula e detecta a presença de átomos de enxofre $(\mathrm{S})$, hidrogênio $(\mathrm{H})$ e carbono $(\mathrm{C})$. A Tabela 5 resume os valores teóricos e experimentais dos átomos que constituem a molécula.

Tabela 5 - Dados da análise elementar da TX-Np-SO 2 sintetizada $\left(\mathrm{MM}=294,25 \mathrm{~g} \mathrm{~mol}^{-1}\right)$

\begin{tabular}{llcl}
\hline Elementos & $\begin{array}{c}\text { Composição } \\
\text { Teórica (\%) }\end{array}$ & $\begin{array}{c}\text { Composição } \\
\text { Experimental (\%) }\end{array}$ & Diferença (\%) \\
\hline Hidrogênio & 3,40 & 3,63 & 6,80 \\
Carbono & 69,39 & 67,88 & 2,20 \\
Enxofre & 10,90 & 12,30 & 12,80 \\
Nitrogênio & 0 & 0 & 0 \\
\hline
\end{tabular}

Os valores da Tabela 5, mostram que as porcentagens calculadas e os valores encontrados por análise elementar estão muito próximos, indicando que a síntese foi satisfatória.

\subsubsection{Cromatografia Líquida de Alta Eficiência}

Dado que cada composto apresenta um tempo de retenção específico, foi possível através da técnica de cromatografia líquida de alta eficiência, CLAE, distinguir o produto obtido na síntese de seu material de partida e verificar a pureza do material. O tempo de retenção determinado para a $\mathrm{TX}-\mathrm{Np}-\mathrm{SO}_{2}$ foi de 4,10 min e para os materiais de partida os tempos de retenção foram de 3,65 min para o ácido tiosalicílico e de 4,43 min para o naftaleno. Observou-se também que os picos foram distintos e apresentaram apenas um sinal (pico) bem definido nas medidas realizadas, indicando um alto grau de pureza dos materiais. 
A Figura 17 mostra o cromatograma do produto da síntese, TX-Np-SO ${ }_{2}$, e dos materiais de partida ácido tiosalicílico e naftaleno.

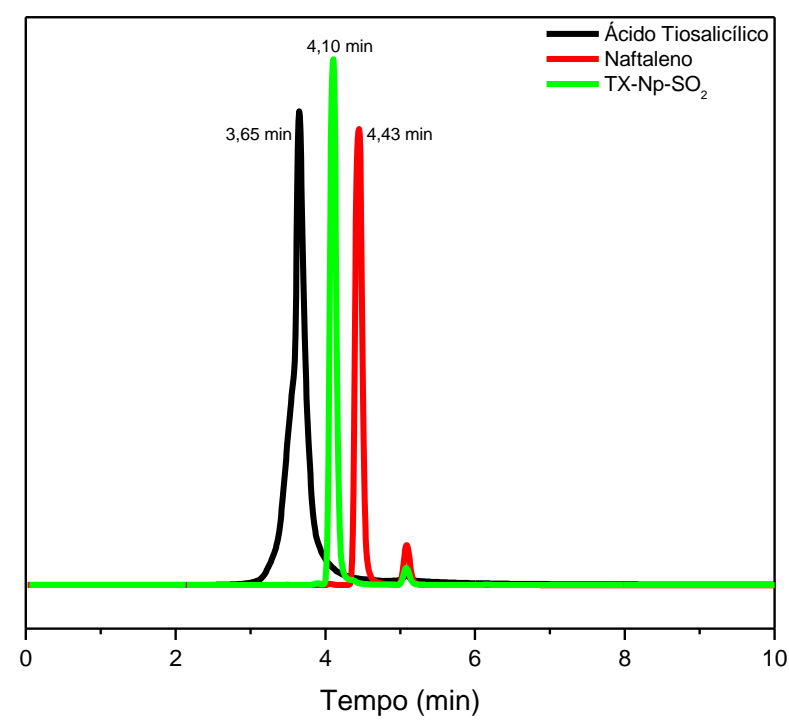

Figura 17 - Cromatograma da $\mathrm{TX}-\mathrm{Np}-\mathrm{SO}_{2}$ e seus materiais de partida com os respectivos tempos de retenção. (-) Ácido tiosalicílico - 3,65 min; (-) TX-Np-SO $\mathrm{S}_{2}-4,10$ min e (-) Naftaleno $-4,43 \mathrm{~min}$.

\subsubsection{Ressonância Magnética Nuclear}

A técnica de ressonância magnética nuclear (RMN) está entre as técnicas mais importantes de determinação de estruturas moleculares. Com o auxílio desta técnica foi possível determinar a estrutura da $\mathrm{TX}-\mathrm{Np}-\mathrm{SO}_{2}$. Sua estrutura foi identificada através dos experimentos de RMN de ${ }^{1} \mathrm{H}$ e ${ }^{13} \mathrm{C}$, espectro Cosy e os mapas de correlações HSQC e HMBC, mostrados na Figura 18 à Figura 23.

Da análise dos espectros de $\mathrm{RMN}{ }^{1} \mathrm{H}$, Figura 18 e Figura 19, pode-se verificar a presença de quatro dubletos e dois multipletos na região dos aromáticos, com um deslocamento químico variando de 9,11 a 7,79 ppm, com constantes de acoplamento $J$ de 7,92 a $8,8 \mathrm{~Hz}$, o que confirma a presença de anéis aromáticos na estrutura. 


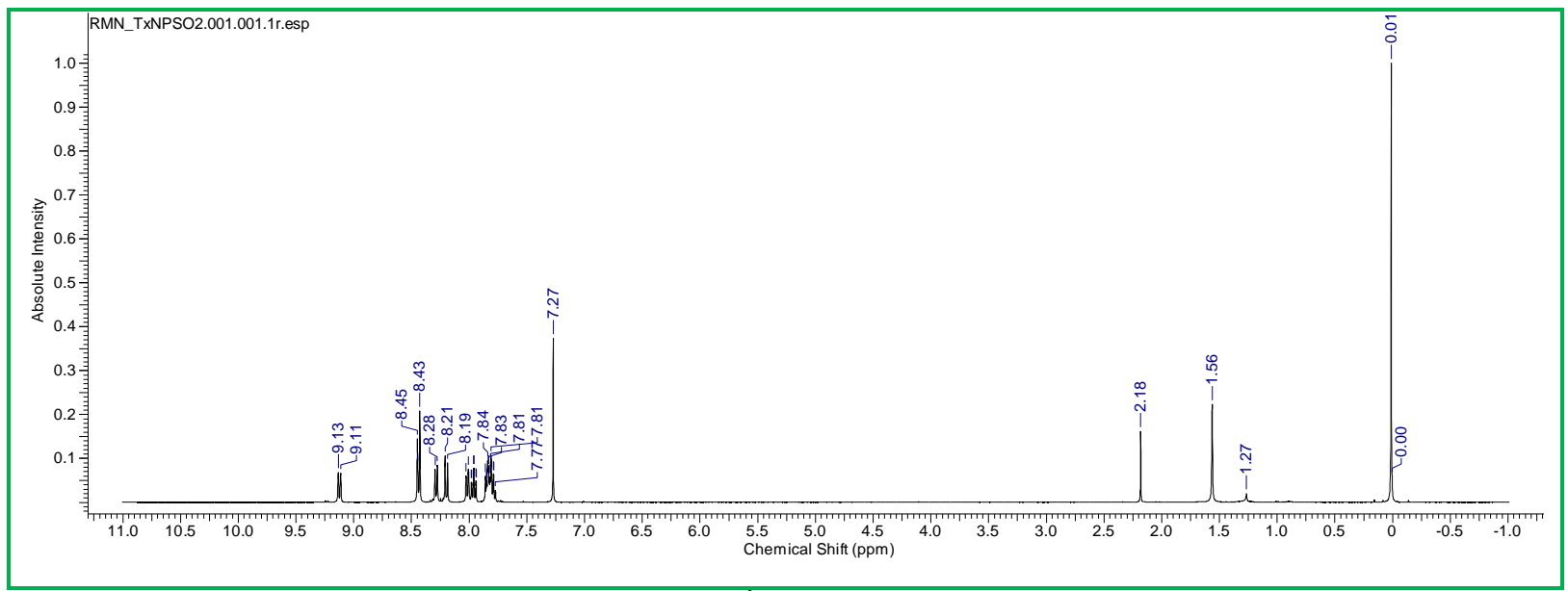

Figura 18 - Espectro de $\mathrm{RMN}$ de ${ }^{1} \mathrm{H}$ da TX-Np-SO,$\left(\mathrm{CDCl}_{3}, 400 \mathrm{MHz}\right)$.

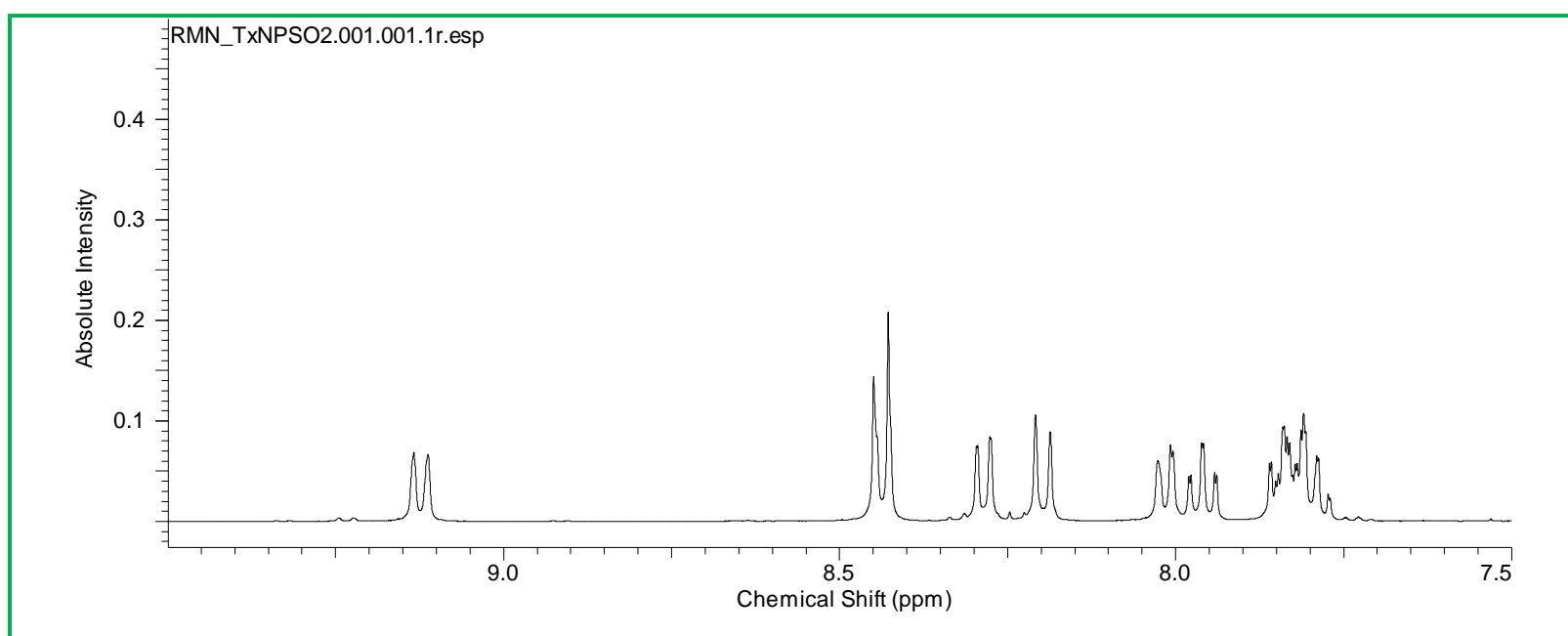

Figura 19 - Ampliação do espectro de RMN de ${ }^{1} \mathrm{H}$ da TX-Np-SO ${ }_{2},\left(\mathrm{CDCl}_{3}, 400 \mathrm{MHz}\right)$.

No espectro de RMN de ${ }^{13} \mathrm{C}$, Figura 20, observou-se sinais na região de 142,6 a 123,2 ppm e um sinal de baixa intensidade em 178,8 ppm, indicando a presença de uma carbonila ligada a um anel aromático. 


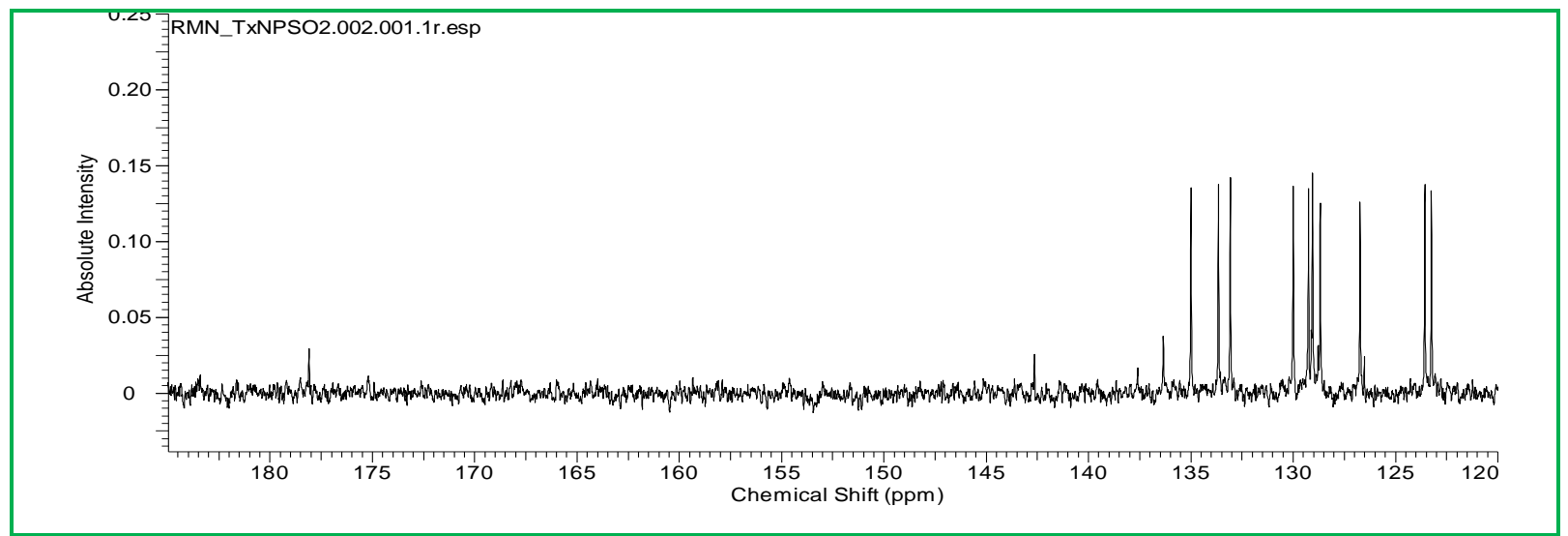

Figura 20 - Ampliação do espectro de RMN de ${ }^{13} \mathrm{C}$ da TX-Np-SO,$\left(\mathrm{CDCl}_{3}, 100 \mathrm{MHz}\right)$.

Analisando o espectro de COSY homonuclear ${ }^{1} \mathrm{H}-{ }^{1} \mathrm{H}$, Figura 21, pode-se identificar os hidrogênios acoplados. Com o mapa de correlação heteronuclear ${ }^{1} \mathrm{H}_{-}{ }^{13} \mathrm{C}$ (HSQC), Figura 22, pode-se identificar os hidrogênios e carbonos ligados diretamente e através do mapa de correlação heteronuclear ${ }^{1} \mathrm{H}_{-}{ }^{13} \mathrm{C}$ (HMQC), Figura 23, identificaram-se os hidrogênios e carbonos acoplados a longa distância.

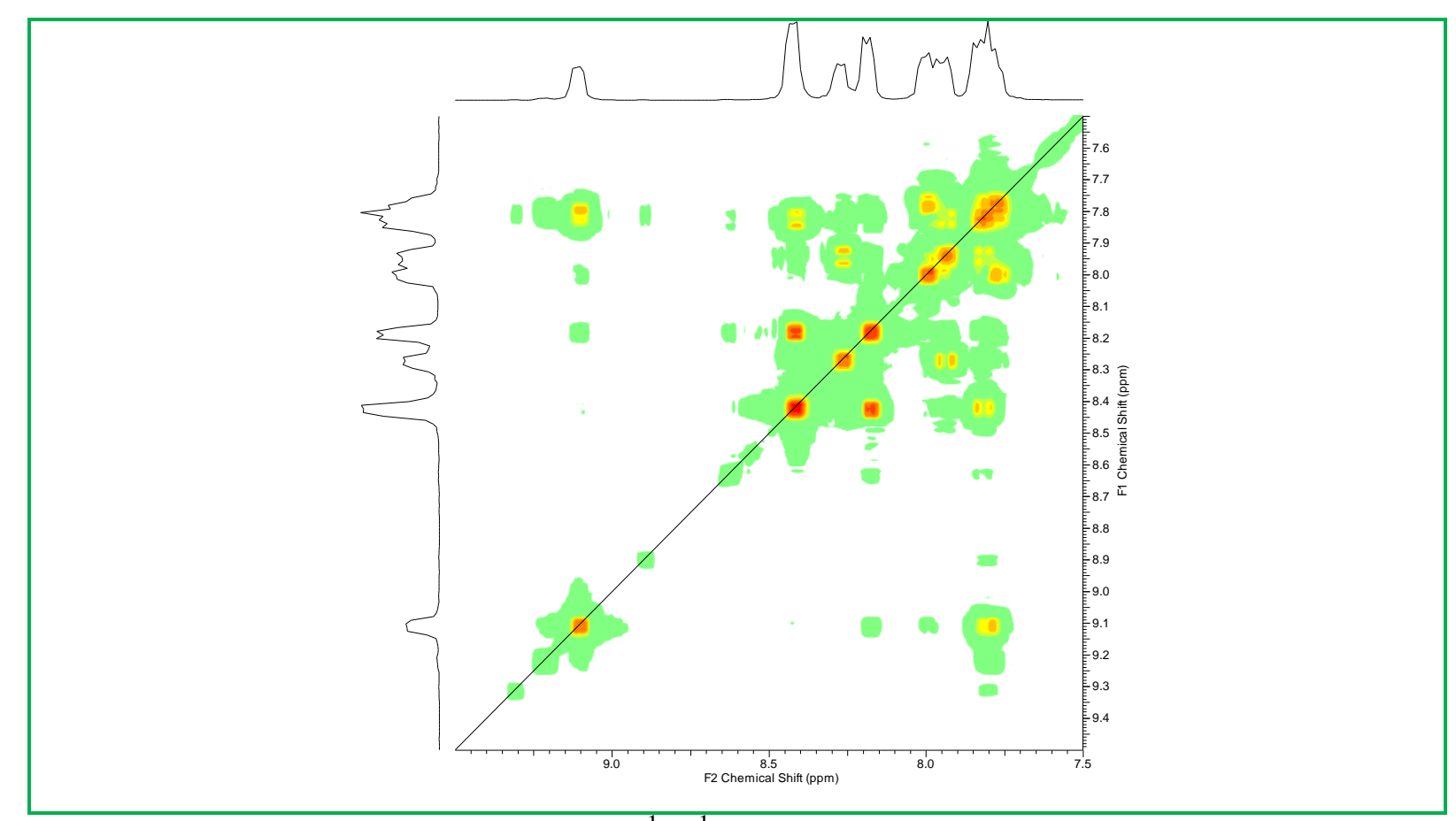

Figura 21 - Espectro de Cosy ${ }^{1} \mathrm{H}-{ }^{1} \mathrm{H}$ de TX-Np-SO,$\left(\mathrm{CDCl}_{3}, 400 \mathrm{MHz}\right)$. 


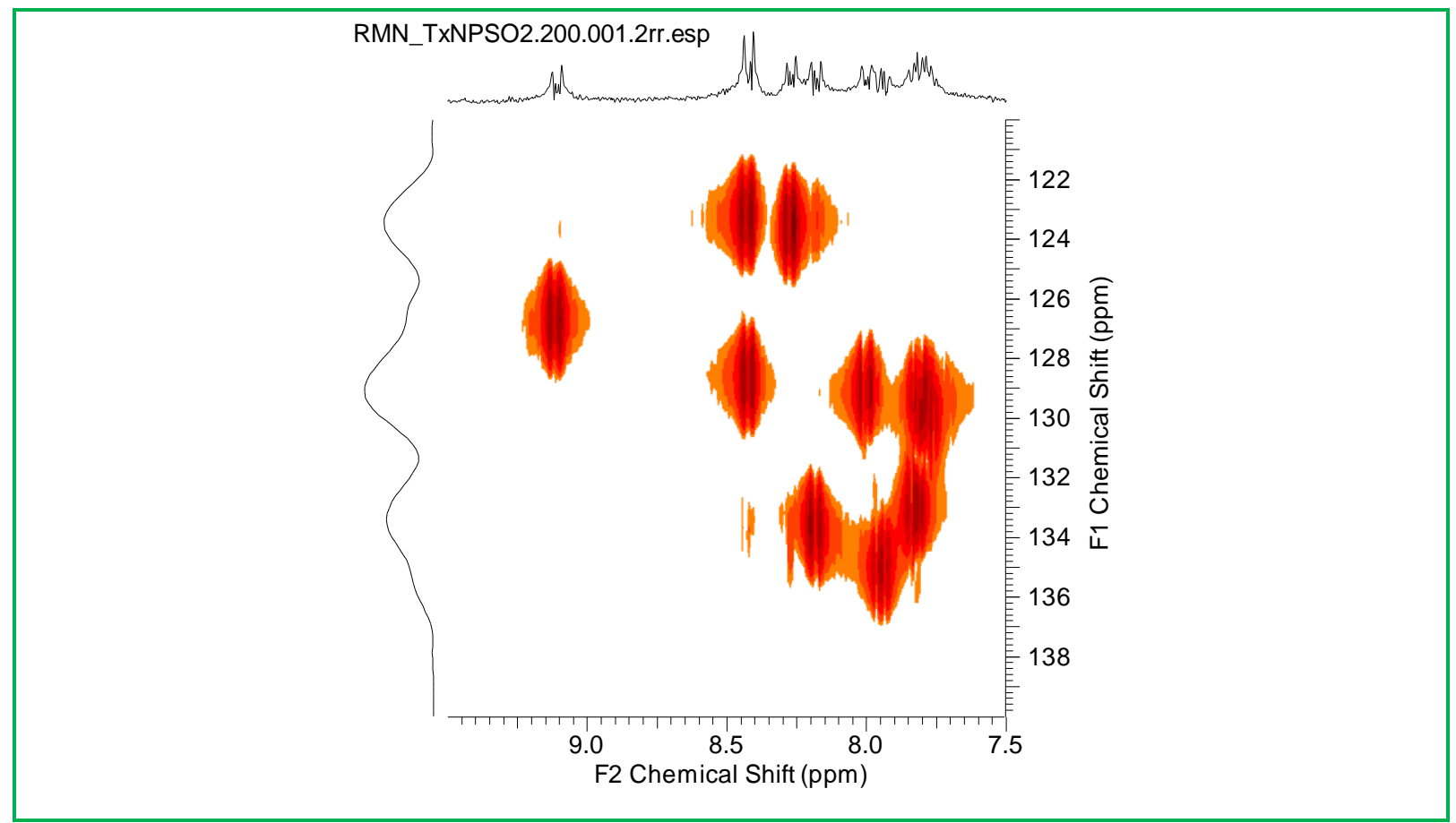

Figura 22 - Mapa de correlações de HSQC da TX-Np-SO $\left(\mathrm{CDCl}_{3}, 400 \mathrm{MHz}\right)$.

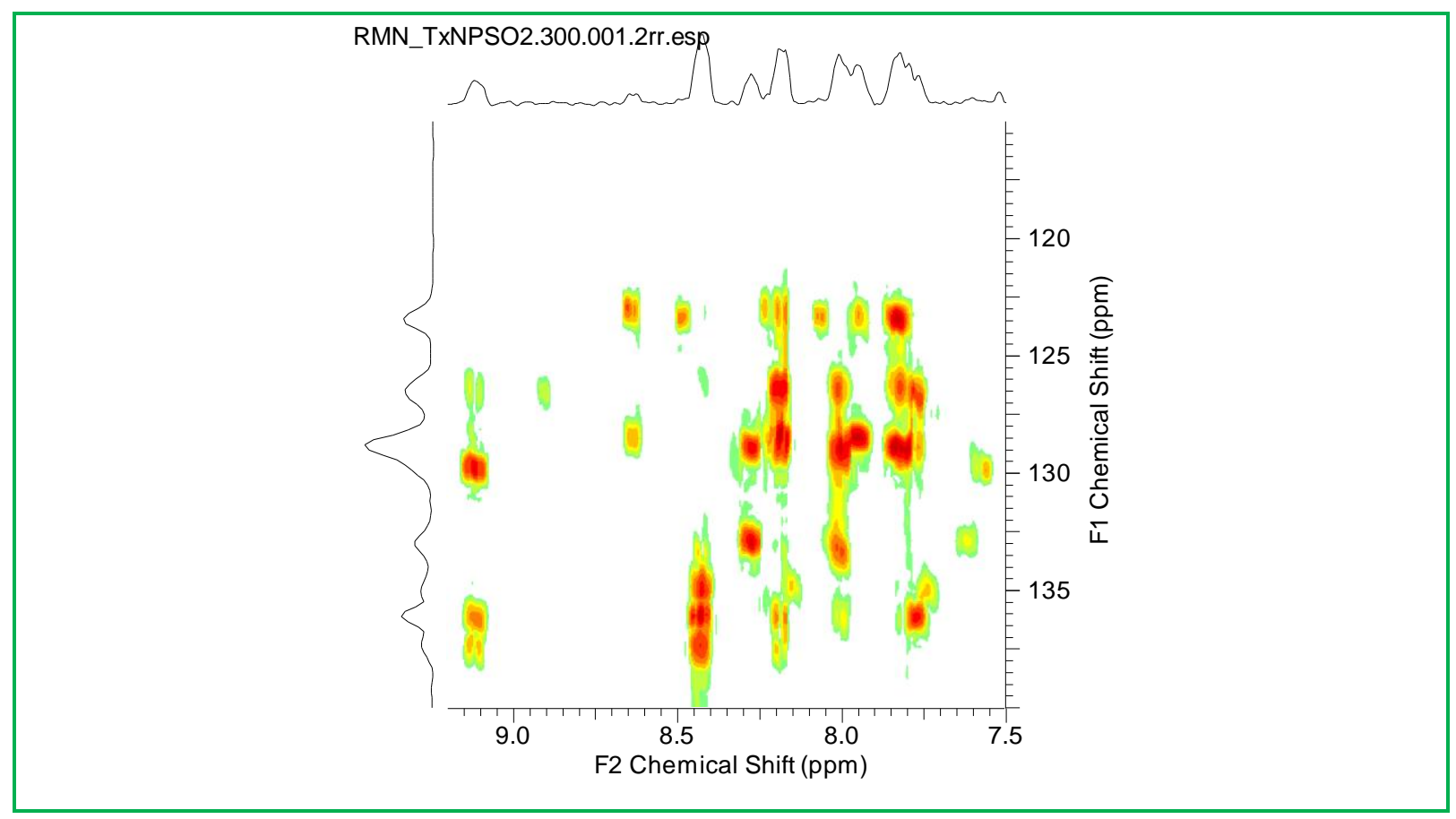

Figura 23 - Mapa de correlações de $\mathrm{HMBC}$ da TX-Np-SO $\left(\mathrm{CDCl}_{3}, 400 \mathrm{MHz}\right)$.

Em determinadas sínteses de compostos contendo anéis aromáticos pode ocorrer a formação de produtos com diferentes estruturas, devido à possibilidade de adição em diferentes pontos do anel. A Figura 24 exibe as possíveis estruturas para o produto desejado neste estudo, com a adição do anel aromático em diferentes posições ${ }^{41}$. 
<smiles>O=C1c2ccccc2S(=O)(=O)c2c1ccc1ccccc21</smiles>

(a)<smiles>O=C1c2ccccc2S(=O)(=O)c2cc3ccccc3cc21</smiles>

(b)<smiles>O=C1c2ccccc2S(=O)(=O)c2ccc3ccccc3c21</smiles>

(c)

Figura 24 - Estruturas químicas dos produtos possíveis para a síntese da TX-Np- $\mathrm{SO}_{2}$.

A determinação da estrutura obtida para a síntese da $\mathrm{TX}-\mathrm{Np}-\mathrm{SO}_{2}$ levou em consideração os espectros de hidrogênio e carbono e os mapas de correlação. No espectro de hidrogênio observou dubletos e multipletos na região dos aromáticos e um singleto com alto deslocamento químico $(9,11 \mathrm{ppm})$ que se refere a hidrogênio próximo a grupos eletronegativos.

Analisando as três possibilidades de estruturas na Figura 24 acima, verifica-se que para a estrutura (a) é esperada a presença de três hidrogênios altamente desblindados (posições 1, 10 e 5) e para as estruturas (b) e (c) são esperados dois hidrogênios desblindados (posições 1 e 10). De acordo com espectros de $\mathrm{H}$ e Cosy pode-se verificar que as estruturas (a) e (b) não estão presentes. O sinal de um singlete em 9,11 ppm é característico da estrutura (c), correspondendo ao acoplamento do hidrogênio na posição 10 com o da posição $9^{(41)}$.

Com base nas informações espectrais, nos mapas de correlações e com dados da literatura $^{41}$ foi determinado que a estrutura da TX-Np-SO $\mathrm{Se}_{2}$ a mostrada na Figura 25.<smiles>O=C1c2ccccc2S(=O)(=O)c2ccc3ccccc3c21</smiles>

Figura 25 - Estrutura química da TX-Np-SO 2 . 


\subsubsection{Propriedades Espectroscópicas do Estado Fundamental}

O conhecimento das propriedades espectroscópicas de um novo composto, que será usado como fotoiniciador de polimerização, é de grande importância. Estas informações irão auxiliar na compreensão dos mecanismos das etapas da fotopolimerização. Os aspectos gerais da espectroscopia de absorção eletrônica UV-Vis e das propriedades luminescentes da TX$\mathrm{Np}-\mathrm{SO}_{2}$ serão apresentados a seguir.

\subsubsection{Espectros de Absorção na Região UV-Vis da TX-Np-SO}

A Figura 26 mostra o espectro da absorção da TX-Np-SO em metanol. Observa-se a presença de quatro bandas com máximos em 215, 270, 312 e 360 nm.

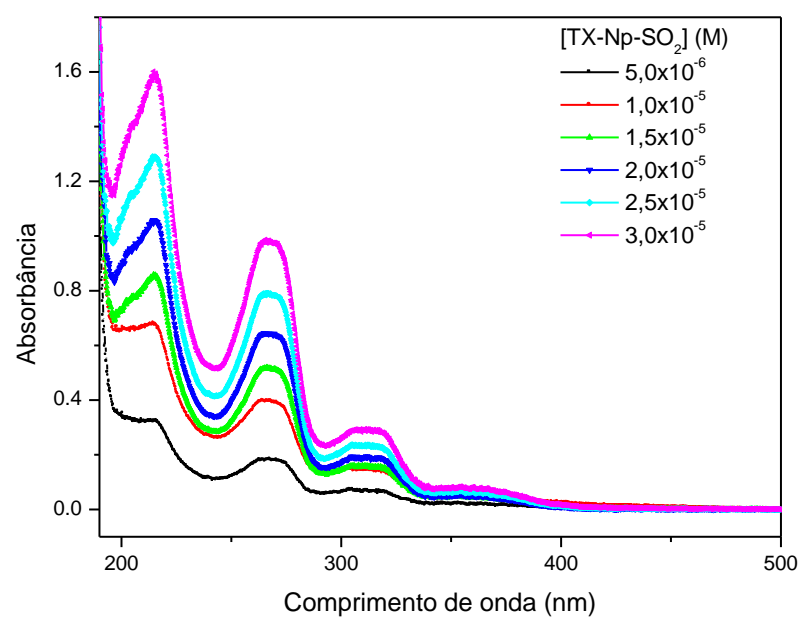

Figura 26 - Espectro de absorção da TX-Np-SO $\mathrm{SO}_{2}$ em diferentes concentrações em metanol.

O espectro de absorção da S,S-dioxidotioxantona é comparada com seu derivado, a TX-Np-SO 2 , na Figura 27. 


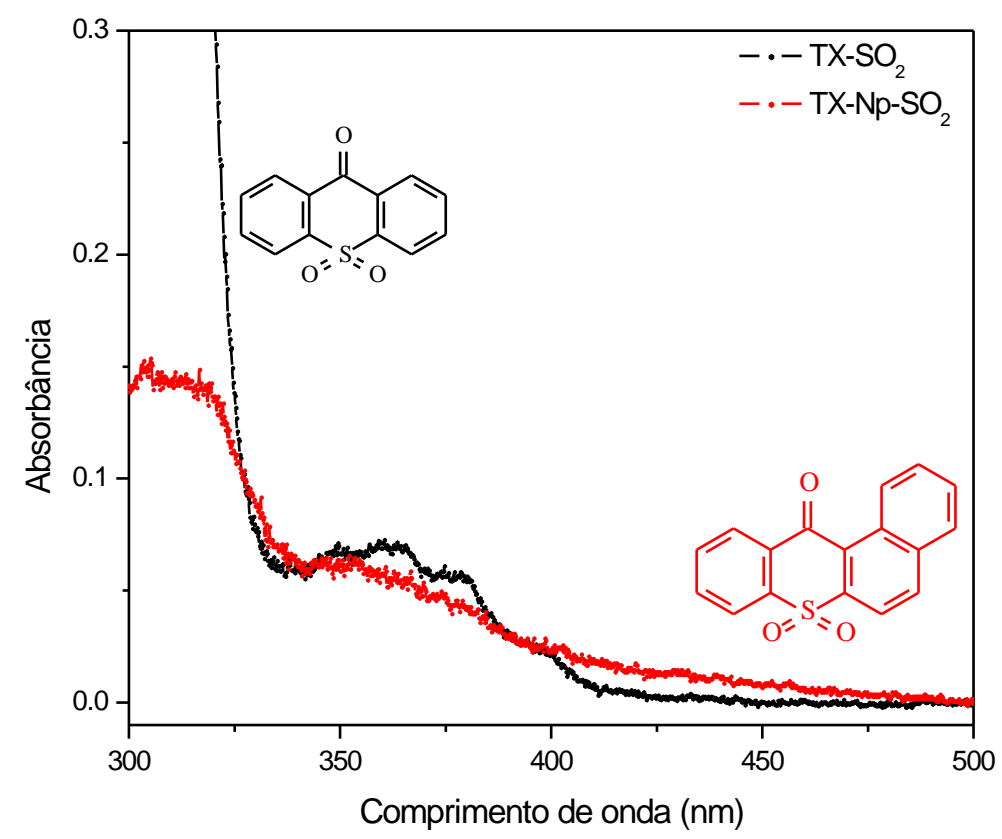

Figura 27 - Comparação entre os espectros de absorção de S,S-dioxidotioxantona e seu derivado, $\mathrm{TX}-\mathrm{Np}-\mathrm{SO}_{2}$.

Na Figura 27 observam-se os espectros de absorção das cetonas aromáticas tioxanton9-ona-10,10-dióxido e 7,8-benzotioxanton-9-ona-10,10-dióxido.

\section{- Espectros de Fluorescência e Fosforescência da TX-Np-SO}

Os espectros de fluorescência e fosforescência em metilciclohexano, a temperatura de $295 \mathrm{~K}$ (fluorescência) e $77 \mathrm{~K}$ (fosforescência) são mostrados na Figura 28. O solvente metilciclohexano foi utilizado por ser um solvente aprótico, de baixa constante dielétrica e não apresentar precipitados de TX-Np-SO $\mathrm{SO}_{2}$ baixas temperaturas. 


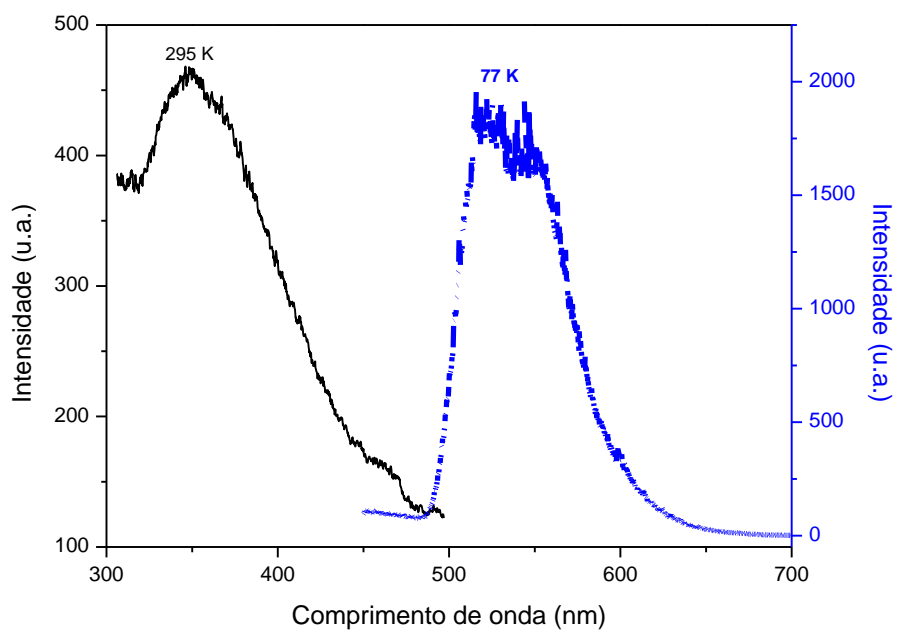

Figura 28 - Espectro de emissão da TX-Np-SO $\left(1 \times 10^{-5} \mathrm{M}\right)$ em metilciclohexano. Fluorescência a $295 \mathrm{~K}, \lambda_{\mathrm{exc}}=285 \mathrm{~nm}$; e fosforescência a $77 \mathrm{~K}, \lambda_{\mathrm{exc}}=285 \mathrm{~nm}$.

A Figura 29 apresenta a curva de decaimento de fosforescência da TX-Np-SO em metilciclohexano. O tempo de decaimento da TX-Np-SO foi de $800 \mathrm{~ms}$. O tempo de fosforescência, muito maior que $100 \mathrm{~ms}$, sugere uma transição $\left(\pi, \pi^{*}\right)$ para o estado excitado triplete de menor energia, além de apresentar espectro com pouca definição, como mostrado na Figura 28 , característicos de transição $\left(\pi, \pi^{*}\right)$. Este fato pode ser baseado no tempo de fosforescência para transições $\left(n, \pi^{*}\right)$ que são curtos, na ordem de poucos milissegundos, quando comparados aos tempos de fosforescência para transições $\left(\pi, \pi^{*}\right)$ que são, em geral, maiores que $100 \mathrm{~ms}^{23}$. Comparando o tempo de vida da TX-Np-SO $\mathrm{SO}_{2}$ com o da tioxantona $\left(\tau_{\mathrm{ph}}=180 \mathrm{~ms}\right)^{42}$ e do naftaleno $\left(\tau_{\mathrm{ph}}=700 \mathrm{~ms}\right)^{43}$, a TX-Np-SO apresenta uma similaridade ao tempo de decaimento do naftaleno, que possui estrutura semelhante a TX-Np-SO

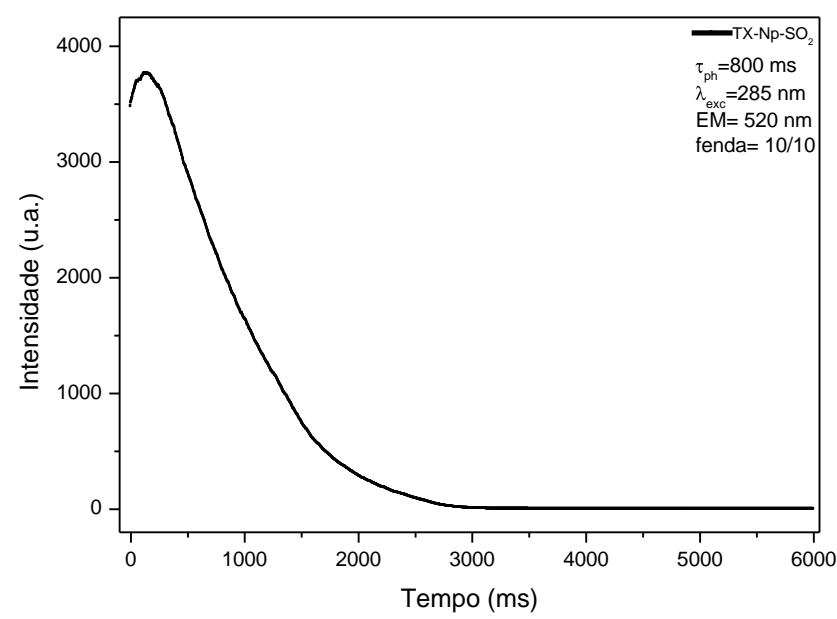

Figura 29 - Curva de decaimento de fosforescência da TX-Np-SO $\mathrm{SO}_{2}$ metilciclohexano,

$$
\lambda_{\text {exc }}=285 \mathrm{~nm} \text { e temperatura } \mathrm{T}=77 \mathrm{~K} \text {. }
$$




\section{-Fluorescência Resolvida no Tempo}

Com o objetivo de caracterizar as espécies formadas no estado excitado singlete foi medido o decaimento de fluorescência da $\mathrm{TX}-\mathrm{Np}-\mathrm{SO}_{2}$, em metilciclohexano utilizando a técnica de fluorescência resolvida no tempo. A Figura 30 mostra a curva de decaimento da $\mathrm{TX}-\mathrm{Np}-\mathrm{SO}_{2}$.

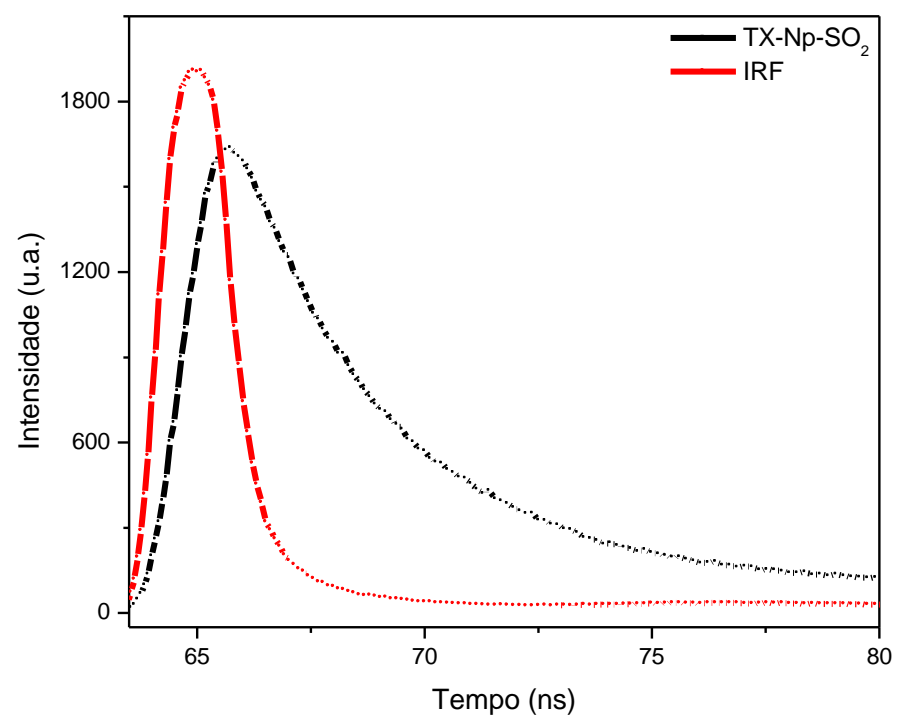

Figura 30 - Curva de decaimento de fluorescência da TX-Np-SO $\mathrm{SO}_{2}$ em metilciclohexano (-) e $\operatorname{IRF}(-), \lambda_{\text {exc }}=280 \mathrm{~nm}$, e temperatura $\mathrm{T}=295 \mathrm{~K}$.

No experimento de fluorescência resolvida no tempo são medidas as curvas da amostra e o decaimento $\mathrm{IRF}^{38}$. O decaimento da TX-Np-SO (Figura 30) mostra uma dinâmica mono exponencial com tempo de vida de 3,62 ns. A Tabela 6 exibe o tempo de fluorescência e os respectivos parâmetros dos ajustes estatísticos. Estes parâmetros avaliam o ajuste da curva de decaimento, sendo que $\chi^{2}$ deve estar entre 0,8 a 1,2; o parâmetro de Durbin Watson (D W) deve apresentar valores entre 1,6 a 2,0 e o parâmetro Z deve ser igual a zero.

Tabela 6 - Tempo de fluorescência da TX-Np-SO 2 e parâmetros estatísticos

\begin{tabular}{ccccc}
\hline & $\boldsymbol{\tau}_{\mathbf{F}}(\mathbf{n s})$ & $\chi^{2}$ & D W & $\mathbf{Z}$ \\
\hline $\mathrm{TX}-\mathrm{Np}-\mathrm{SO}_{2}$ & $3,616 \pm 0,021$ & 1,273 & 1,795 & 0 \\
\hline
\end{tabular}


Os tempos de vida de fluorescência são altamente dependentes da temperatura e do solvente utilizado. A TX-Np- $\mathrm{SO}_{2}$ apresenta em sua estrutura características da tioxantona (TX) e do naftaleno (Np). De acordo com a literatura, em solventes apolares a TX apresenta tempos de vida de fluorescência de $2,55 \mathrm{~ns}^{44}$ e o $\mathrm{Np}$ de $96 \mathrm{~ns}^{45}$. O tempo de vida de fluorescência para a TX-Np-SO é mais semelhante ao da TX de tempo significativamente menor. Estudos anteriores mostram que TX e derivados apresentam tempos de vida de fluorescência curtos e altos rendimentos de tripletes. Este mesmo comportamento foi observado para a TX-Np-SO ${ }_{2}^{29,46,47}$.

\section{- Rendimento Quântico de Fluorescência}

O rendimento quântico de fluorescência $\left(\Phi_{\mathrm{F}}\right)$ da TX-Np-SO 2 a $295 \mathrm{~K}$ foi determinado utilizando naftaleno como padrão de fluorescência $\left(\Phi_{\mathrm{F}}^{\mathrm{o}}=0,21\right)^{42}$. A escolha do naftaleno se deve ao fato de apresentar os máximos de absorção e emissão na mesma região espectral que a TX-Np- $\mathrm{SO}_{2}$. O solvente utilizado neste experimento foi o metilciclohexano. O rendimento quântico foi calculado a partir da Equação $20^{(42)}$.

$$
\Phi_{F}=\frac{\int I(\lambda) \partial \lambda}{\int I^{o}(\lambda) \partial \lambda} \times \frac{A b s^{o}}{A b s} \times \frac{n^{2}}{n^{o^{2}}} \times \Phi_{F}^{o}
$$

onde $A b s^{o}$ e $A b s$ são as absorbâncias do padrão e da TX-Np-SO ${ }_{2}$, respectivamente. $I^{\mathrm{o}}$ e I são as integrais de emissão de fluorescência no intervalo de emissão do padrão e do composto. $n^{\circ}$ é o índice de refração do padrão e $n$ é o índice de refração da amostra de interesse, e $\Phi_{\mathrm{F}}^{\mathrm{o}}$ é o rendimento quântico de fluorescência da amostra padrão e $\Phi_{\mathrm{F}}$ é o rendimento quântico da amostra.

$\mathrm{O}$ rendimento quântico de fluorescência para a TX-Np- $\mathrm{SO}_{2}$ em solvente aprótico foi de 0,06 . O valor do rendimento quântico de fluorescência típico de cetonas é entorno de $\Phi_{\mathrm{F}}=$ 0,02. Esse baixo rendimento quântico está de acordo com a alta eficiência de cruzamento entressistemas (ISC) que leva ao estado triplete e à possível formação de radicais ${ }^{48}$. 


\subsection{Estudos das Reações Elementares}

A técnica de fotólise por pulso de laser é uma excelente ferramenta para determinar velocidades de reação de estados excitados e medir o tempo de vida de transientes formados na ordem de $\mu \mathrm{s}^{49}$.

$\mathrm{O}$ comportamento espectral da TX-Np-SO 2 em três diferentes solventes, metanol, acetonitrila e metilciclohexano, assim como os tempos de vida do estado excitado triplete, foram investigados pela técnica de fotólise por pulso de laser.

Os espectros de absorção triplete-triplete (T-T) da TX-Np-SO foram determinados nesses solventes e os transientes formados foram caracterizados. Também foram determinadas as constantes de velocidade de supressão $\left(k_{q}\right)$ do triplete da TX-Np-SO $\mathrm{SO}_{2}$ por supressores que agem por transferência de energia, transferência de elétrons e por abstração de hidrogênio.

\subsubsection{Estudo dos Transientes da TX-Np-SO}

A Figura 31 mostra o espectro de absorção do transiente de TX-Np- $\mathrm{SO}_{2}$ em metanol, desoxigenado com $\mathrm{N}_{2}$, na região de $700-310 \mathrm{~nm}$ e o decaimento do triplete em $590 \mathrm{~nm}$ na ausência de supressor.

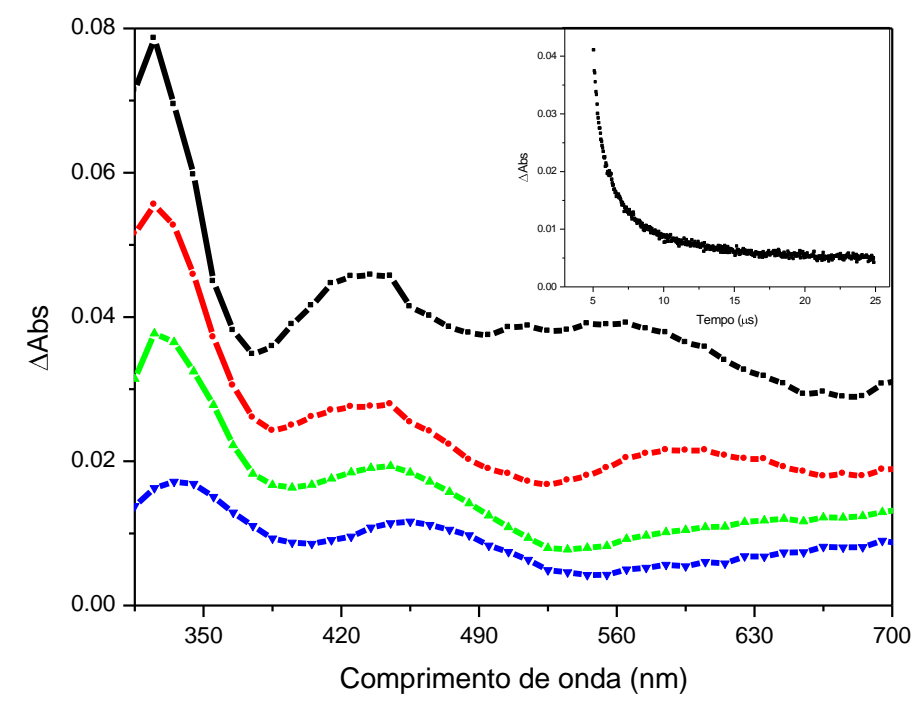

Figura 31 - Espectro de absorção triplete-triplete de TX-Np-SO $\mathrm{SO}_{2}$ metanol $\left(\lambda_{\text {exc }}=355 \mathrm{~nm}\right)$, registrado (-) 2,0 $\mu \mathrm{s}$; (-) 9,2 $\mu \mathrm{s}$; (-) 26,0 $\mu \mathrm{s}$ e (-) 102,0 $\mu \mathrm{s}$ depois do pulso de laser.

Inserção: Decaimento do transiente monitorado a $590 \mathrm{~nm}$. 
A Figura 32 mostra o espectro de absorção do transiente de TX-Np- $\mathrm{SO}_{2}$ em acetonitrila, desoxigenado com $\mathrm{N}_{2}$, na região de 700 - $310 \mathrm{~nm}$ e o decaimento do triplete em $590 \mathrm{~nm}$ na ausência de supressor.

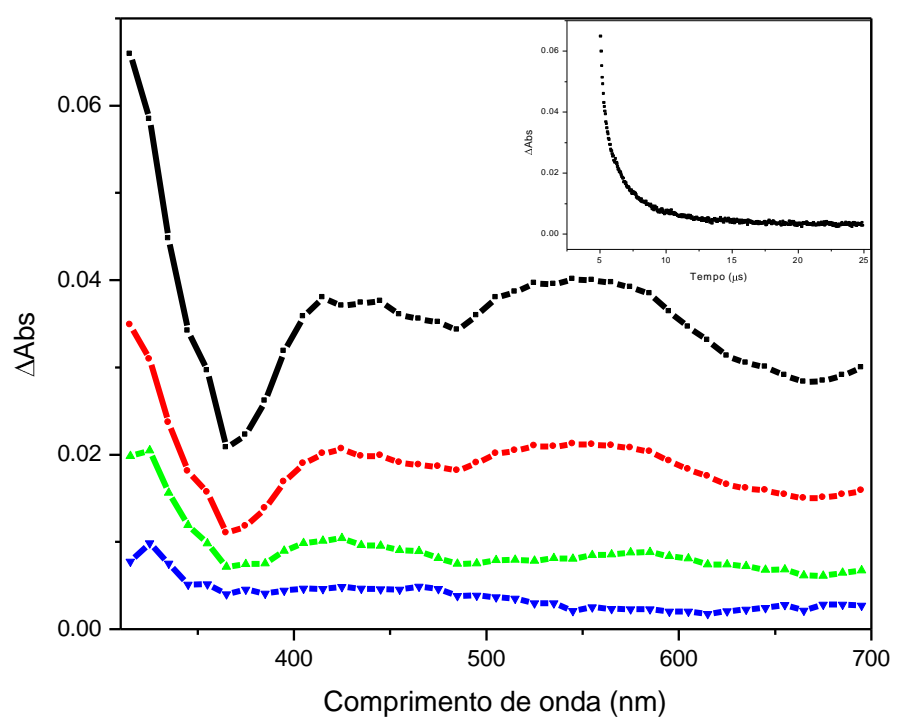

Figura 32 - Espectro de absorção triplete-triplete de TX-Np- $\mathrm{SO}_{2}$, em acetonitrila $\left(\lambda_{\text {exc }}=355 \mathrm{~nm}\right)$, registrado (-) 1,6 $\mu \mathrm{s}$; (-) $8,4 \mu \mathrm{s}$; (-) 25,8 $\mu \mathrm{s}$ e (-) 102,4 $\mu \mathrm{s}$ depois do pulso de laser. Inserção: Decaimento do transiente monitorado a $590 \mathrm{~nm}$.

A Figura 33 mostra o espectro de absorção do transiente de $\mathrm{TX}-\mathrm{Np}-\mathrm{SO}_{2}$ em metilciclohexano, desoxigenado com $\mathrm{N}_{2}$, na região de $700-310 \mathrm{~nm}$ e o decaimento do triplete em $590 \mathrm{~nm}$ na ausência de supressor. 


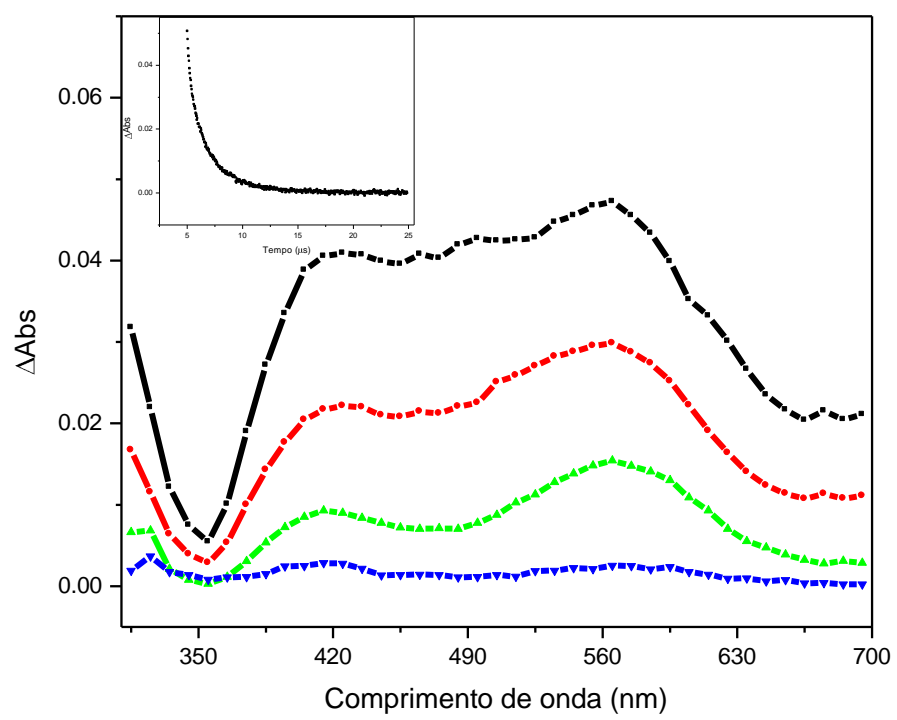

Figura 33 - Espectro de absorção triplete-triplete de TX-Np-SO $\mathrm{SO}_{2}$, em metilciclohexano $\left(\lambda_{\text {exc }}=355 \mathrm{~nm}\right.$ ), registrado (-) 2,0 $\mu \mathrm{s}$; (-) 9,2 $\mu \mathrm{s}$; (-) 26,0 $\mu \mathrm{s}$ e (-) 102,0 $\mu \mathrm{s}$ depois do pulso de laser. Inserção: Decaimento do transiente monitorado a $590 \mathrm{~nm}$.

Analisando os espectros de absorção dos transientes gerados após o pulso de laser nas soluções da TX-Np-SO $\mathrm{SO}_{2}$ observou-se um comportamento similar ao da $\mathrm{TX}_{-} \mathrm{SO}_{2}{ }^{31}$ em relação aos solventes utilizados. Os espectros apresentaram uma banda em torno de $570-590 \mathrm{~nm}$ referente à absorção triplete-triplete, uma outra banda na região de $430 \mathrm{~nm}$ relativa à formação do radical cetila, e uma terceira banda na região de $310 \mathrm{~nm}$ que é referente a uma sobreposição da absorção do estado excitado triplete e os radicais formados.

As bandas de absorção que aparecem na região de 570 - $590 \mathrm{~nm}$ correspondem à absorção triplete-triplete. Em relação à TX-SO $\mathrm{SO}_{2}$, que apresenta o máximo de absorção tripletetriplete em torno de $520 \mathrm{~nm}$, observa-se um deslocamento para comprimentos de onda maiores quando se muda a polaridade do solvente utilizado no experimento. $\mathrm{O}$ efeito de deslocamento do máximo de absorção observado para a TX-Np- $\mathrm{SO}_{2}$ nos três diferentes solventes parece estar associado à polaridade do solvente: quanto maior a polaridade maior é o deslocamento observado no máximo de absorção. Entretanto, no solvente prótico (metanol) o deslocamento foi mais acentuado, sugerindo a possível formação de ponte de hidrogênio. Para exemplificar, em metanol o máximo da banda de absorção triplete-triplete está em $590 \mathrm{~nm}$ e em acetonitrila foi observado em $570 \mathrm{~nm}$.

As bandas na região de 420 - $430 \mathrm{~nm}$ foram atribuídas ao radical cetila. O radical cetila é formado pela abstração de hidrogênio do solvente pelo triplete do TX-Np-SO , Figura 
34. No solvente prótico utilizado o espectro apresentou nessa região uma banda mais definida que a observada para os solventes apróticos, acetonitrila e metilciclohexano.<smiles>[R4]O[SH]1(=O)c2ccccc2C(O)c2c1ccc1ccccc21</smiles>

Figura 34 - Formação do radical cetila da TX-Np- $\mathrm{SO}_{2}$ a partir do estado excitado triplete na presença de solvente prótico.

A absorção do transiente da $\mathrm{TX}-\mathrm{Np}-\mathrm{SO}_{2}$ na região menor de $340 \mathrm{~nm}$ é atribuída à sobreposição da absorção do estado excitado triplete e do radical cetila formados após o pulso de laser.

Em solventes apróticos, como mostrado para a TX-Np-SO $\mathrm{SO}_{2}$ nas Figura 32 e Figura 33 e em estudos anteriores ${ }^{21}$ não há a formação do radical cetila e a absorção na região em torno de $310 \mathrm{~nm}$ corresponde somente ao transiente triplete-triplete. Os transientes da TX-Np-SO em $590 \mathrm{~nm}$, após a excitação, decaem com uma cinética de $1^{\underline{a}}$ ordem (processo unimolecular).

A Tabela 7 mostra os tempos de vida do triplete de TX-Np-SO $\mathrm{SO}_{2}$ nos solventes metanol, acetonitrila e metilciclohexano, sob atmosfera de $\mathrm{N}_{2}$ na ausência de supressor.

Tabela 7 - Tempos de vida do triplete de TX-Np-SO $\mathrm{SO}_{2}$ na ausência de supressor $\left(\tau_{0}\right)$

\section{TX-Np-SO}

Metanol

Acetonitrila

Metilciclohexano

\section{$\tau_{0}(\mu s)$}

16,16

15,96

16,64

Observa-se a partir da Tabela 7 que os tempos de vida da $\mathrm{TX}-\mathrm{Np}-\mathrm{SO}_{2}$ não apresentaram alterações significativas com relação ao solvente utilizado.

Comparando o espectro de absorção do transiente, de TX-Np-SO $\mathrm{SO}_{2}$ com os de TX-SO e o Np (Figura 35), foi observado que o máximo de absorção de TX-Np-SO $\mathrm{S}_{2}$ está em 590 nm 
em quanto que o do composto TX-SO $\mathrm{SO}_{2} 520 \mathrm{~nm}^{31}$ e o do naftaleno em $410 \mathrm{~nm}^{43}$. Para este último composto a excitação foi realizada no comprimento de onda de $266 \mathrm{~nm}$.

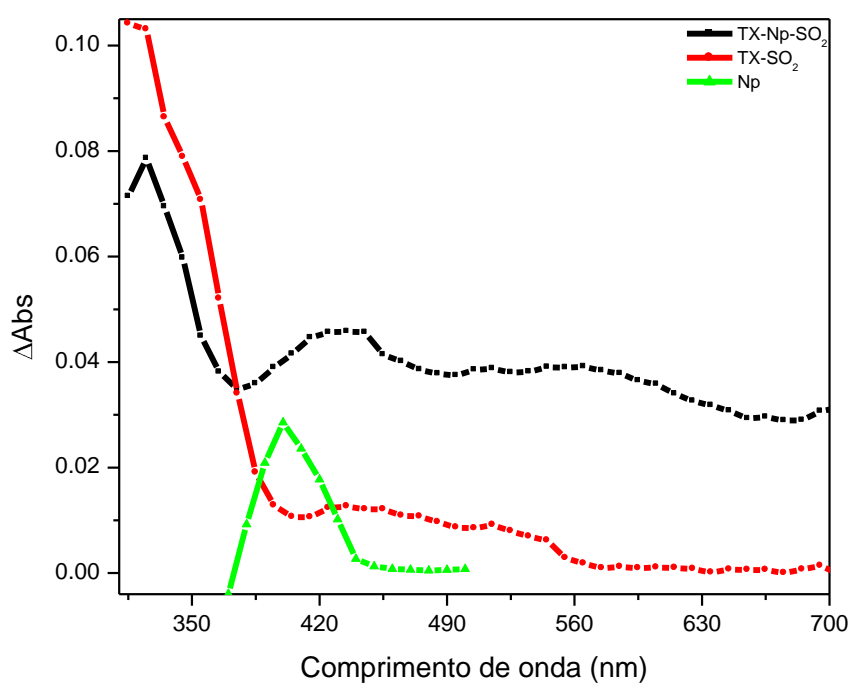

Figura 35 - Espectros de absorção triplete-triplete para a 7,8-benzotioxanton-9-ona-10,10dióxido (TX-Np-SO ${ }_{2}$, tioxanton-9-one-10,10-dióxido $\left(\mathrm{TX}_{-} \mathrm{SO}_{2}\right),\left(\lambda_{\mathrm{exc}}=355 \mathrm{~nm}\right)$; e naftaleno $(\mathrm{Np}),\left(\lambda_{\text {exc }}=266 \mathrm{~nm}\right)$, em metanol.

\subsubsection{Estudo da Supressão do Estado Triplete da TX-Np-SO}

\section{- Determinação das Constantes de Supressão da TX-Np-SO,$\left(k_{q}\right)$}

Os supressores utilizados nesse estudo são compostos nos quais o processo de supressão ocorre por transferência de energia (trans-estilbeno), por transferência de elétrons (EDB e TEA) e abstração de hidrogênio (2-propanol).

\section{Transferência de Energia}

\section{trans-estilbeno}

Para as reações de supressão por transferência de energia deve ser utilizado um supressor para o qual a energia de triplete seja menor que a da amostra a ser suprimida, já que o processo de transferência de energia tem que ser exotérmico.

Em estudos anteriores foi calculada a energia de triplete para a $\mathrm{TX}-\mathrm{SO}_{2}$ e o valor foi de 66,3 $\mathrm{kcal} \mathrm{mol}^{-1(31)}$ e para o supressor trans-estilbeno o valor da energia de triplete é de 49,3 $\mathrm{kcal} \mathrm{mol}^{-1(50)}$, indicando que a supressão por transferência de energia é possível. 
A Figura 36 mostra os decaimentos de absorção do transiente de TX-Np-SO em $590 \mathrm{~nm}$ em metanol para diferentes concentrações de trans-estilbeno e o gráfico de SternVolmer da TX-Np-SO 2 correspondente.

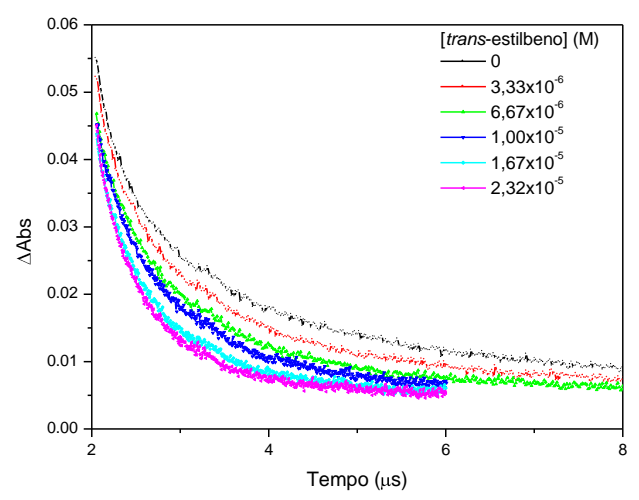

(a)

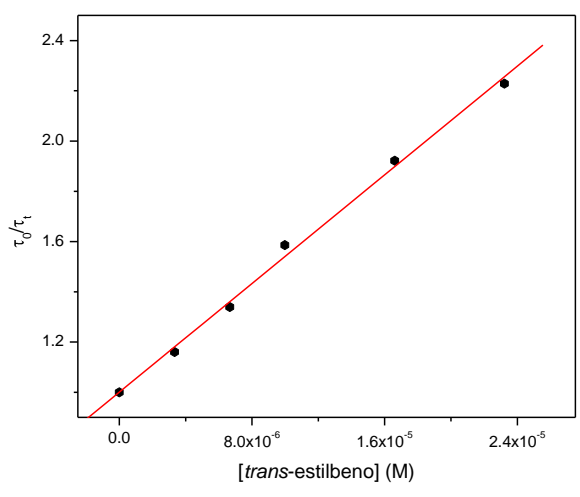

(b)

Figura 36 - Decaimentos de absorção triplete-triplete de TX-Np-SO em 590 nm, para diferentes concentrações de trans-estilbeno (a). Gráfico de Stern-Volmer para a supressão da TX-Np-SO $\mathrm{SO}_{2}$ porans-estilbeno, em metanol (b).

A Figura 37 mostra os decaimentos de absorção do transiente de TX-Np- $\mathrm{SO}_{2}$ em $590 \mathrm{~nm}$, em acetonitrila, para diferentes concentrações de trans-estilbeno e o gráfico de SternVolmer correspondente.

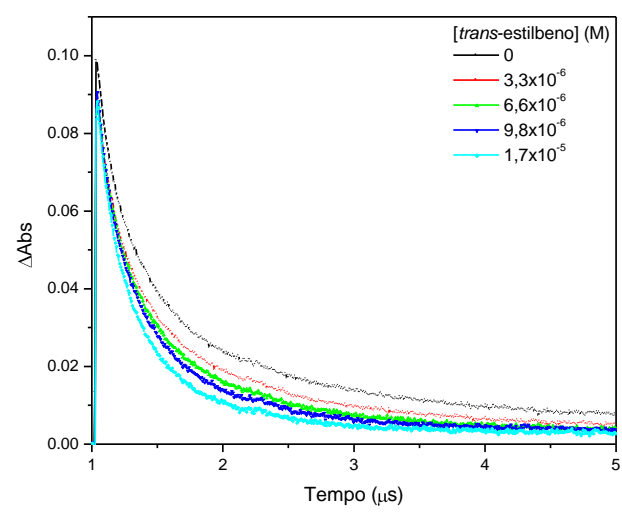

(a)

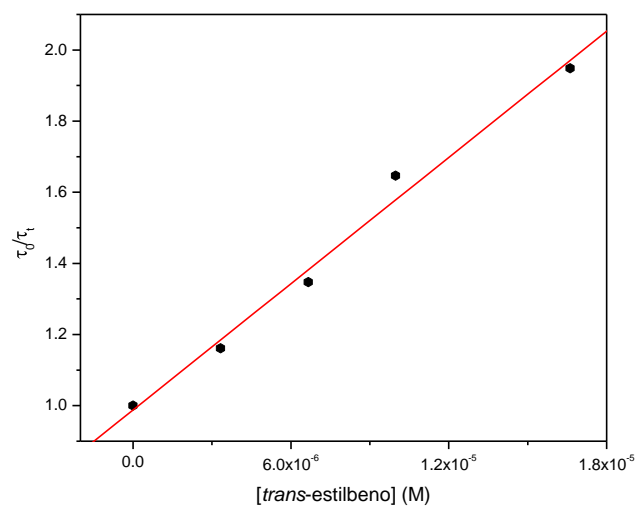

(b)

Figura 37 - Decaimentos de absorção triplete-triplete de TX-Np-SO $\mathrm{S}_{2}$ em 590 nm, para diferentes concentrações de trans-estilbeno (a). Gráfico de Stern-Volmer para a supressão da TX-Np-SO 2 por trans-estilbeno, em acetonitrila (b). 
A Figura 38 mostra os decaimentos de absorção do transiente de TX-Np-SO em $590 \mathrm{~nm}$ em metilciclohexano para diferentes concentrações de trans-estilbeno e o gráfico de Stern-Volmer correspondente.

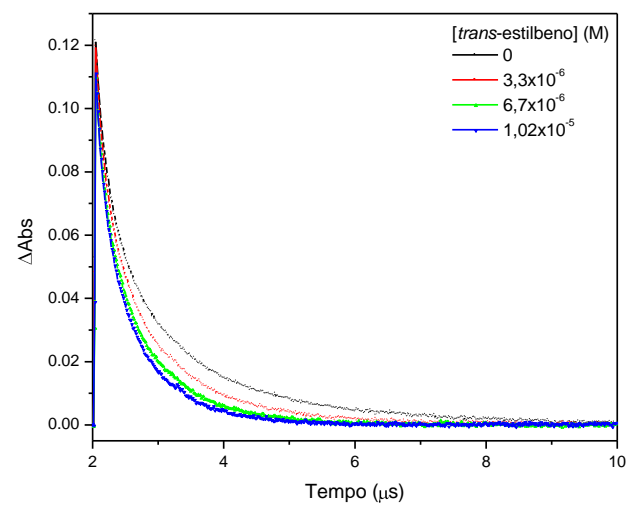

(a)

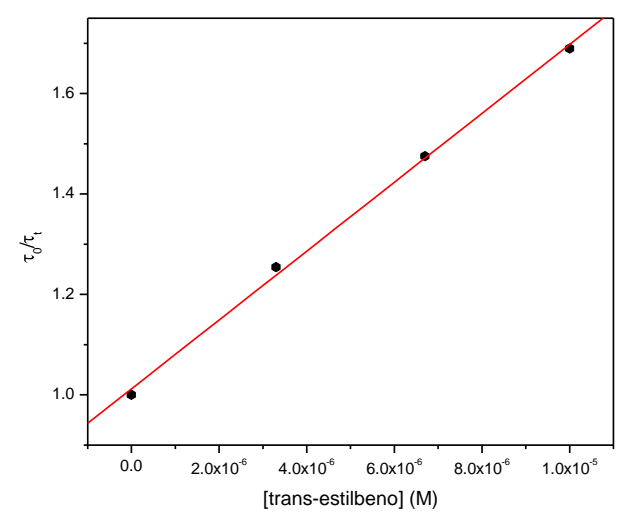

(b)

Figura 38 - Decaimentos de absorção triplete-triplete de TX-Np-SO $\mathrm{S}_{2}$ em 590 nm, para diferentes concentrações de trans-estilbeno (a). Gráfico de Stern-Volmer para a supressão da TX-Np-SO 2 por trans-estilbeno, em metilciclohexano (b).

Os valores das constantes de supressão pelo aceptor de energia foram de $4,1 \times 10^{9}$, $6,7 \times 10^{9}$ e $5,7 \times 10^{9} \mathrm{M}^{-1} \mathrm{~s}^{-1}$ em metanol, acetonitrila e metilciclohexano, respectivamente, e estão na ordem do controle difusional.

Os valores das constantes difusionais $\left(k_{\text {difusão }}\right)$ para os solventes utilizados no estudo, a temperatura ambiente, são $1,2 \times 10^{10} \mathrm{M}^{-1} \mathrm{~s}^{-1}$ para o metanol, $1,9 \times 10^{10} \mathrm{M}^{-1} \mathrm{~s}^{-1}$ para acetonitrila e $9,6 \times 10^{9} \mathrm{M}^{-1} \mathrm{~s}^{-1}$ para metilciclohexano ${ }^{42}$.

A transferência de energia ocorrida na presença do supressor trans-estilbeno ocorre através da colisão entre as moléculas de TX-Np- $\mathrm{SO}_{2}$ no estado excitado triplete com as moléculas de trans-estilbeno em seu estado fundamental ${ }^{24}$. A Figura 39 mostra o mecanismo proposto para a supressão pelo aceptor de energia trans-estilbeno ${ }^{2}$. 
<smiles>O=C1c2ccccc2S(=O)(=O)c2c1ccc1ccccc21</smiles><smiles>CC(C)C(C)C(C)C</smiles><smiles>C(=C/c1ccccc1)\c1ccccc1</smiles><smiles>O=C1c2ccccc2S(=O)(=O)c2c1ccc1ccccc21</smiles>

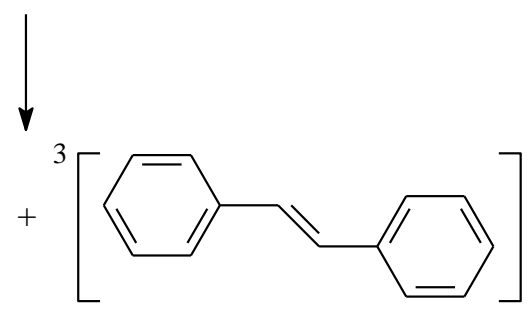

Figura 39 - Supressão do estado excitado triplete de TX-Np-SO $\mathrm{S}_{2}$ por trans-estilbeno.

\section{$>\quad$ Transferência de Elétrons}

Para as reações de supressão por transferência de elétron utilizaram-se duas aminas terciárias, a $p$-dimetilamina benzoato de etila (EDB) e a trietilamina (TEA).

\section{$p$-Dimetilamina Benzoato de Etila (EDB)}

Por não apresentarem hidrogênios ligados ao nitrogênio, para estes supressores a reação ocorre por transferência de elétrons. Isto é confirmado pelos altos valores das constantes de supressão calculadas para as aminas, $3,7 \times 10^{9} \mathrm{M}^{-1} \mathrm{~s}^{-1}$ em metanol, $4,8 \times 10^{9} \mathrm{M}^{-1} \mathrm{~s}^{-}$ ${ }^{1} \mathrm{em}$ acetonitrila e $4,2 \times 10^{9} \mathrm{M}^{-1} \mathrm{~s}^{-1}$ em metilciclohexano, visto que as reações que envolvem transferência de elétrons são mais rápidas que as reações envolvendo transferência de hidrogênio ${ }^{2}$.

O decaimento de absorção do transiente da TX-Np- $\mathrm{SO}_{2}$ em metanol, na ausência e presença de diferentes concentrações de EDB é mostrado na Figura 40, assim como o gráfico de Stern-Volmer correspondente. 


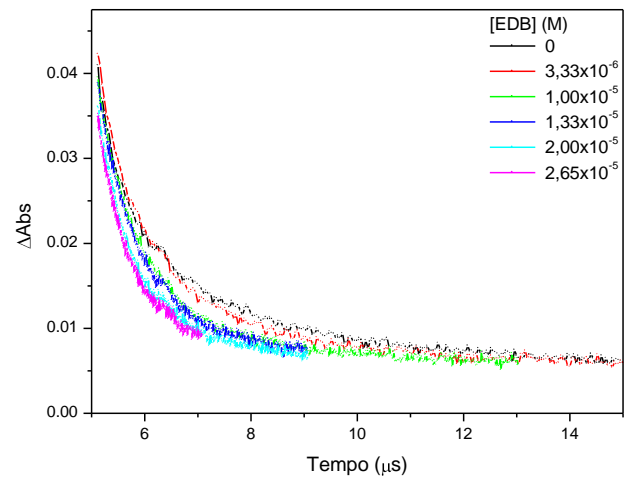

(a)

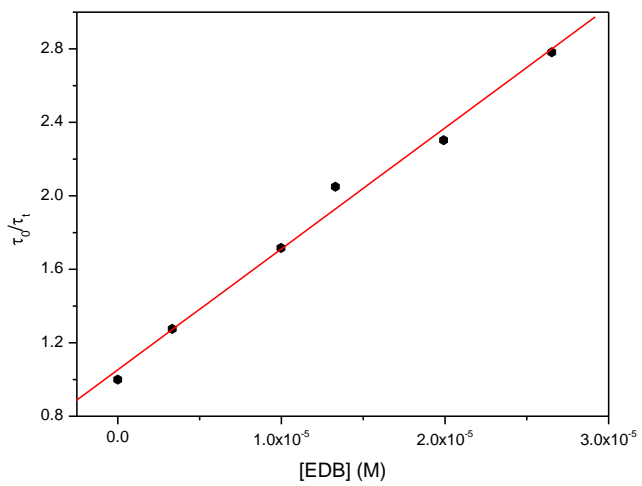

(b)

Figura 40 - Decaimento da absorção triplete-triplete de TX-Np-SO em 590 nm, com diferentes concentrações de EDB (a). Gráfico de Stern-Volmer para a supressão da TX-Np-SO 2 por EDB, em metanol (b).

A Figura 41 mostra os decaimentos de absorção do transiente da TX-Np-SO em acetonitrila em $590 \mathrm{~nm}$ para diferentes concentrações de EDB, assim como o gráfico de SternVolmer correspondente.

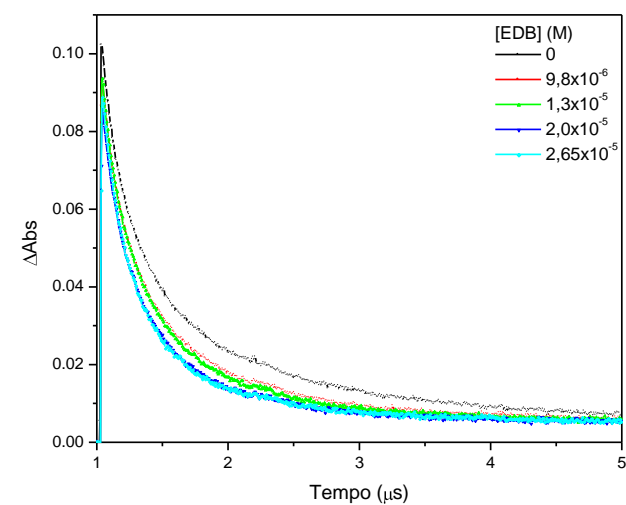

(a)

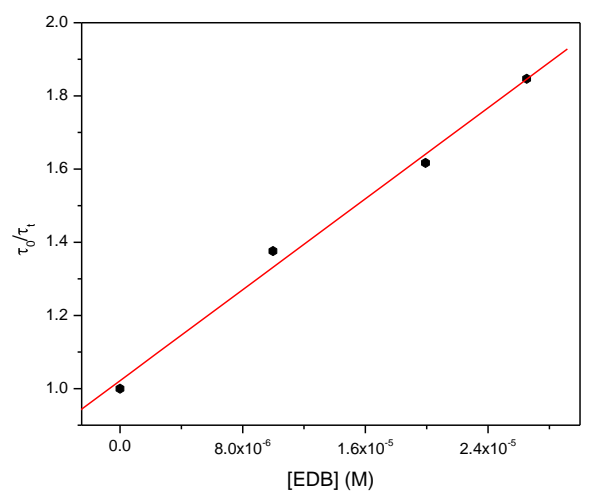

(b)

Figura 41 - Decaimento da absorção triplete-triplete de TX-Np-SO $\mathrm{S}_{2}$ em 590 nm, com diferentes concentrações de EDB (a). Gráfico de Stern-Volmer para a supressão da $\mathrm{TX}-\mathrm{Np}-\mathrm{SO}_{2}$ por EDB, em acetonitrila (b).

A Figura 42 mostra os decaimentos de absorção do transiente da TX-Np-SO em $590 \mathrm{~nm}$ em metilciclohexano para diferentes concentrações de EDB, assim como o gráfico de Stern-Volmer correspondente. 


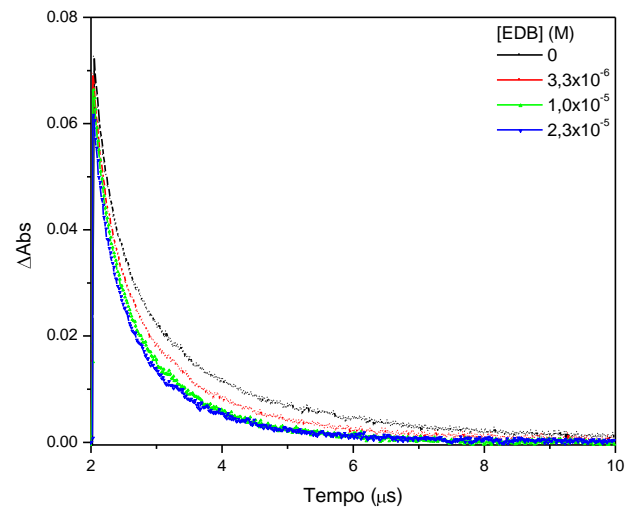

(a)

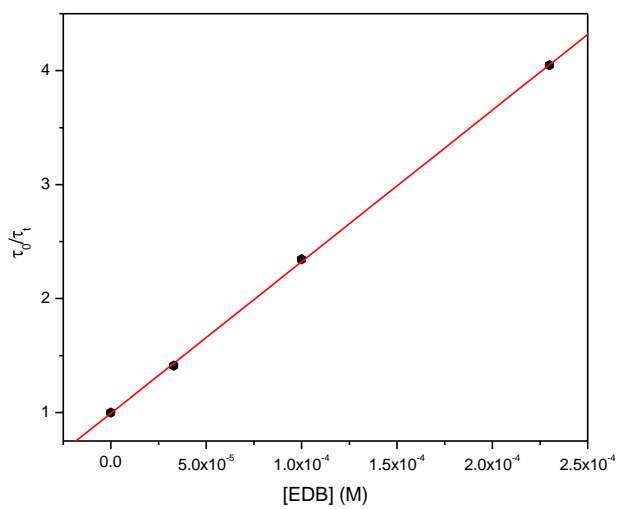

(b)

Figura 42 - Decaimento da absorção triplete-triplete de TX-Np-SO $\mathrm{Sm}_{2} 590$ nm, com diferentes concentrações de EDB (a). Gráfico de Stern-Volmer para a supressão da $\mathrm{TX}-\mathrm{Np}-\mathrm{SO}_{2}$ por EDB, em metilciclohexano (b).

A reação de transferência de elétrons que acontece no processo de desativação do estado excitado triplete da TX-Np-SO 2 por EDB está mostrada na Figura $43^{51}$.<smiles>CC[C@H](C)OC(=O)c1ccc(N(C)C)cc1</smiles>

Figura 43 - Supressão do estado excitado triplete da TX-Np-SO 2 por EDB.

\section{Tretilamina (TEA)}

$\mathrm{O}$ estudo da constante de supressão da TX-Np-SO $\mathrm{Sela}_{2}$ amina alifática TEA também foi realizado nos solventes metanol, acetonitrila e metilciclohexano. Os valores das constantes de supressão calculadas para a TEA foram $1,9 \times 10^{9} \mathrm{M}^{-1} \mathrm{~s}^{-1} \mathrm{em}$ metanol, $1,7 \times 10^{9} \mathrm{M}^{-1} \mathrm{~s}^{-1} \mathrm{em}$ acetonitrila e 2,6×109 $\mathrm{M}^{-1} \mathrm{~s}^{-1}$ em metilciclohexano. A seguir são mostrados os gráficos de decaimento de absorção do transiente de TX-Np- $\mathrm{SO}_{2}$ em metanol na ausência e presença de diferentes concentrações de TEA, Figura 44, e o gráfico de Stern-Volmer correspondente. 


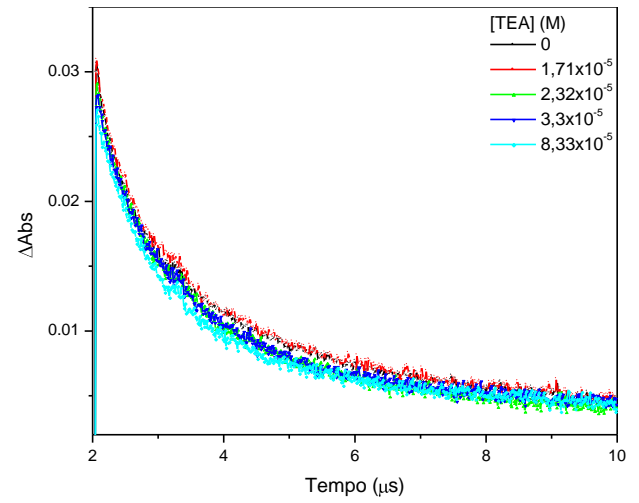

(a)

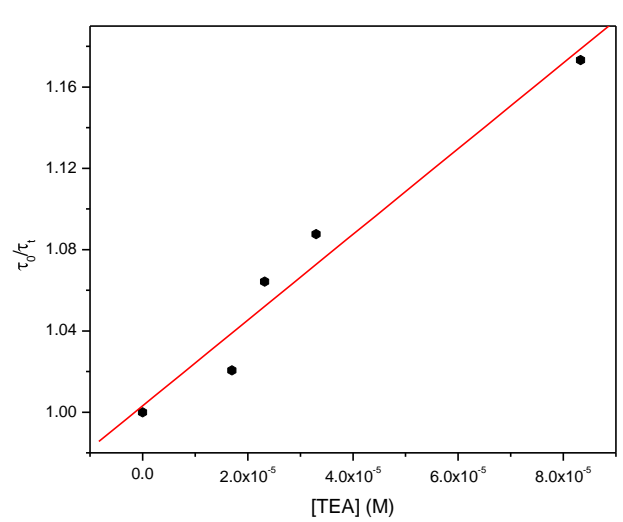

(b)

Figura 44 - Decaimento da absorção triplete-triplete de TX-Np-SO $\mathrm{SO}_{2} \mathrm{em} 50 \mathrm{~nm}$, com diferentes concentrações de TEA (a). Gráfico de Stern-Volmer para a supressão da TX-Np-SO 2 por TEA, em metanol (b).

A Figura 45 mostra os decaimentos de absorção do transiente de TX-Np-SO em $590 \mathrm{~nm}$ em acetonitrila para diferentes concentrações de TEA e o gráfico de Stern-Volmer correspondente.

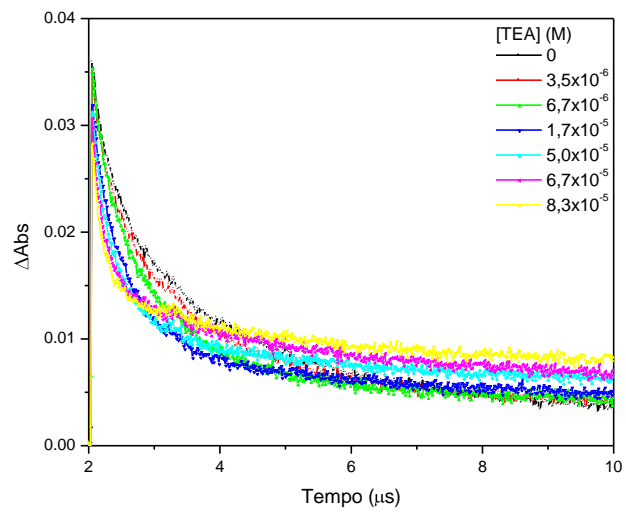

(a)

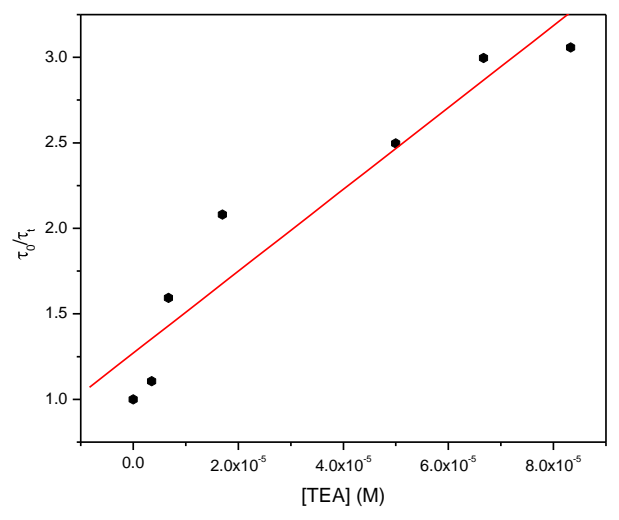

(b)

Figura 45 - Decaimento da absorção triplete-triplete de TX-Np-SO $\mathrm{SO}_{2} 590$ nm, com diferentes concentrações de TEA (a). Gráfico de Stern-Volmer para a supressão da TX-Np-SO 2 por TEA, em acetonitrila (b).

A Figura 46 mostra os decaimentos de absorção do transiente da TX-Np- $\mathrm{SO}_{2}$ em $590 \mathrm{~nm}$ em metilciclohexano para diferentes concentrações de TEA e o gráfico de SternVolmer correspondente. 


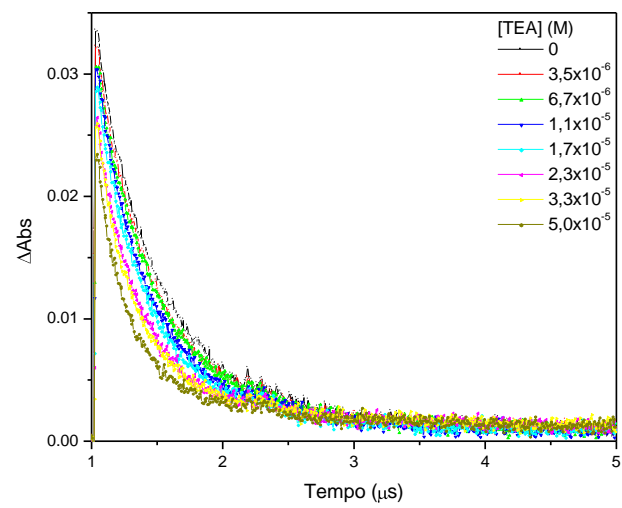

(a)

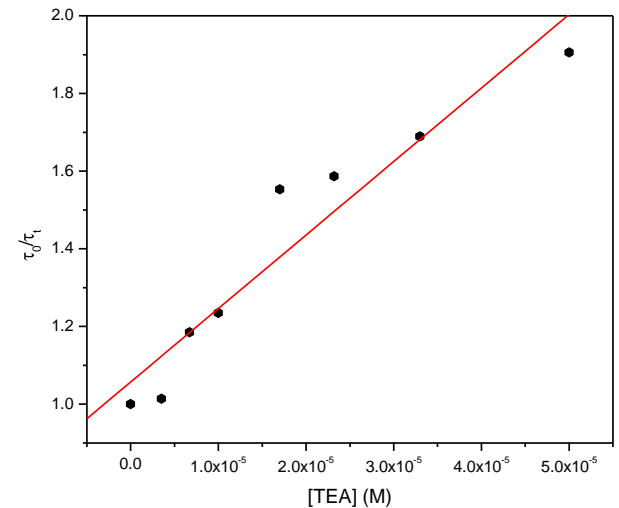

(b)

Figura 46 - Decaimento da absorção triplete-triplete de TX-Np-SO $\mathrm{SO}_{2} \mathrm{em} 90 \mathrm{~nm}$, com diferentes concentrações de TEA (a). Gráfico de Stern-Volmer para a supressão da TX-Np-SO ${ }_{2}$ por TEA, em metilciclohexano (b).

A Figura 47 mostra a reação de supressão do estado excitado triplete da TX-Np- $\mathrm{SO}_{2}$ pela amina TEA $^{51}$.<smiles>CC[C@@H](C)CC=[N+](CC)CC</smiles>

Figura 47 - Supressão do estado excitado triplete da TX-Np-SO $\mathrm{S}_{2}$ pela TEA.

\section{Reação de Abstração de Hidrogênio}

\section{2-propanol}

Nas reações de supressão por abstração de hidrogênio foi usado o 2-propanol como supressor. As constantes de velocidade de abstração de hidrogênio para as reações com o álcool foram $7,8 \times 10^{8} ; 5,4 \times 10^{8}$ e $6,2 \times 10^{8} \mathrm{M}^{-1} \mathrm{~s}^{-1}$ para metanol, acetonitrila e metilclohexano, respectivamente.

As Figura 48 a Figura 50 mostram os decaimentos em 590 nm para a supressão da TX$\mathrm{Np}-\mathrm{SO}_{2}$ por 2-propanol, medidos nos diferentes solventes. 


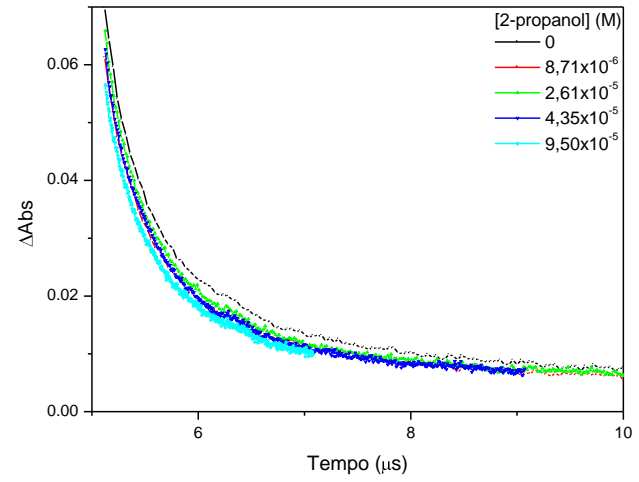

(a)

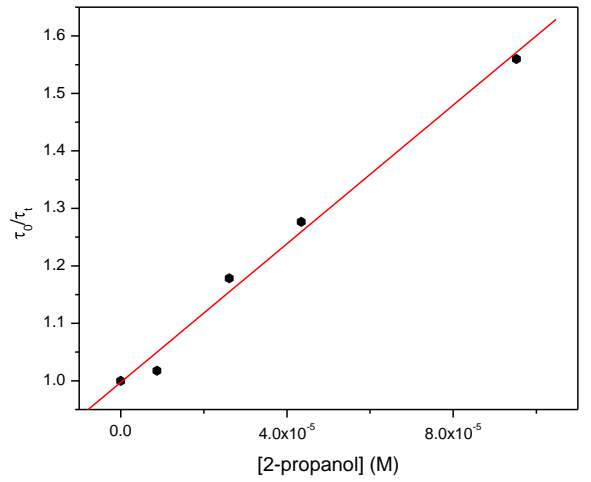

(b)

Figura 48 - Decaimento da absorção triplete-triplete de TX-Np-SO em 590 nm, com diferentes concentrações de 2-propanol (a). Gráfico de Stern-Volmer para a supressão da TX-Np-SO 2 por 2-propanol, em metanol (b).

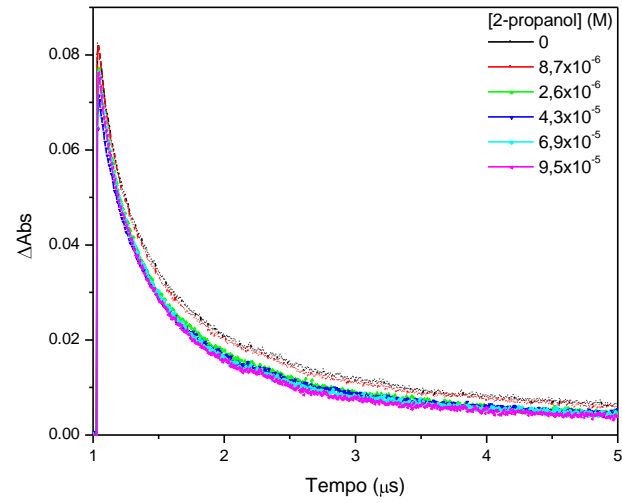

(a)

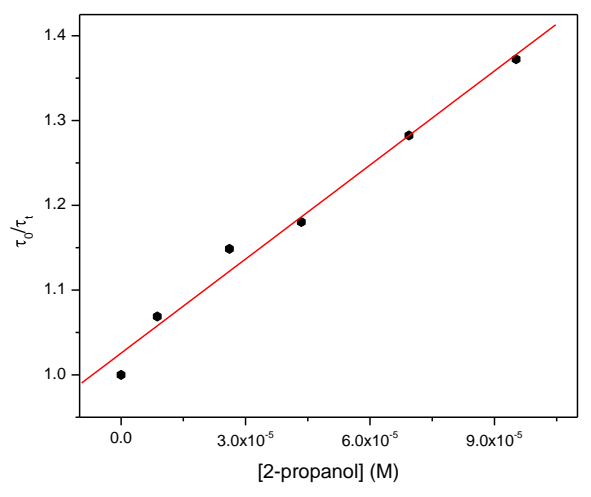

(b)

Figura 49 - Decaimento da absorção triplete-triplete de TX-Np-SO $\mathrm{SO}_{2} 590$ nm, com diferentes concentrações de 2-propanol (a). Gráfico de Stern-Volmer para a supressão da TX-Np-SO 2 por 2-propanol, em acetonitrila (b). 


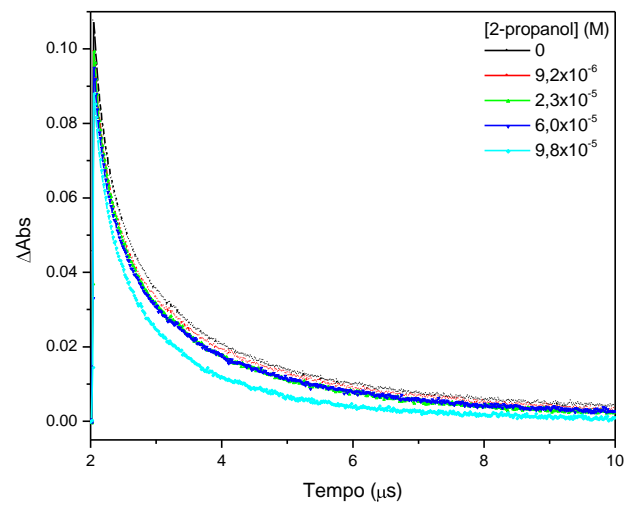

(a)

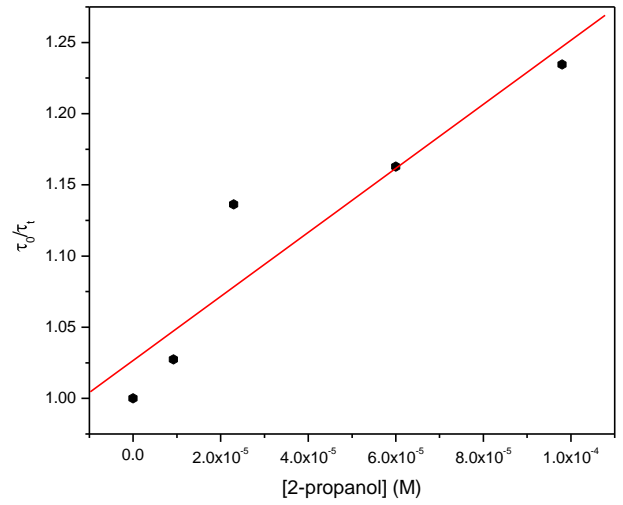

(b)

Figura 50 - Decaimento da absorção triplete-triplete de TX-Np-SO em 590 nm, com diferentes concentrações de 2-propanol (a). Gráfico de Stern-Volmer para a supressão da TX-Np-SO 2 por 2-propanol, em metilciclohexano (b).

A reação de transferência de hidrogênio que ocorre no processo de desativação do estado excitado triplete da TX-Np-SO $\mathrm{SO}_{2}$ por 2-propanol é mostrada na Figura $51^{50}$.<smiles>C[C@H](Cc1ccc2c(c1)C(O)c1c(ccc3ccccc13)S2(=O)=O)C(C)(C)O</smiles>

Figura 51 - Supressão do estado excitado triplete de TX-Np-SO $\mathrm{S}_{2}$ por 2-propanol.

A Tabela 8 resume os valores da constante de supressão $\left(k_{q}\right)$ para os quatro supressores (2-propanol, EDB, TEA e trans-estilbeno) nos solventes metanol, acetonitrila e metilciclohexano. Os valores obtidos foram de mesma ordem de grandeza em todos os solventes, sugerindo pouca dependência com o solvente. 
Tabela 8 - Valores para as constantes de supressão da $\mathrm{TX}-\mathrm{Np}-\mathrm{SO}_{2}$ por 2-propanol, EDB, TEA e trans-estilbeno

\begin{tabular}{ccc}
\hline Solvente & Supressor & $\mathbf{k}_{\mathbf{q}}\left(\mathbf{M}^{-1} \mathbf{s}^{-1}\right)$ \\
\hline \multirow{2}{*}{ Metanol } & 2-Propanol & $7,8 \times 10^{8}$ \\
& EDB & $3,7 \times 10^{9}$ \\
& TEA & $1,9 \times 10^{9}$ \\
& trans-estilbeno & $4,1 \times 10^{9}$ \\
Acetonitrila & 2-Propanol & $5,4 \times 10^{8}$ \\
& EDB & $4,8 \times 10^{9}$ \\
& TEA & $1,7 \times 10^{9}$ \\
& trans-estilbeno & $6,7 \times 10^{9}$ \\
Metilciclohexano & 2-Propanol & $6,2 \times 10^{8}$ \\
& EDB & $4,2 \times 10^{9}$ \\
& TEA & $2,6 \times 10^{9}$ \\
& trans-estilbeno & $5,7 \times 10^{9}$ \\
\hline
\end{tabular}




\subsection{Aplicação da TX-Np-SO $\mathrm{S}_{2}$ como Fotoiniciador de Polimerização}

4.3.1 Polimerização do monômero metacrilato de metila (MMA) fotoiniciada por TX$\mathrm{Np}^{-\mathrm{SO}_{2}}$ na presença dos co-iniciadores trietilamina (TEA) e $p$-dimetilamina benzoato de etila (EDB)

Nesta etapa do trabalho foi realizado estudo da cinética de polimerização empregando a TX-Np-SO $\mathrm{SO}_{2}$ como fotoiniciador. O monômero utilizado para o estudo foi o metacrilato de metila (MMA). Este monômero vem sendo empregado em diversos estudos de fotopolimerização iniciada por fotoiniciadores bimoleculares (Tipo II $)^{52,53}$. Avaliou-se também o uso de dois co-iniciadores, as aminas trietilamina (TEA) e a p-dimetilamina benzoato de etila (EDB). As irradiações do sistema de polimerização foram realizadas utilizando uma lâmpada de mercúrio/xenônio com um monocromador de corte fixado em 360 nm, o que permitiu a excitação do meio reacional numa região espectroscópica específica.

O espectro de emissão da lâmpada usando o monocromador e o espectro de absorção da TX-Np-SO $\mathrm{S}_{2}$ no meio reacional, MMA/TEA/MeOH, é mostrado na Figura 52.

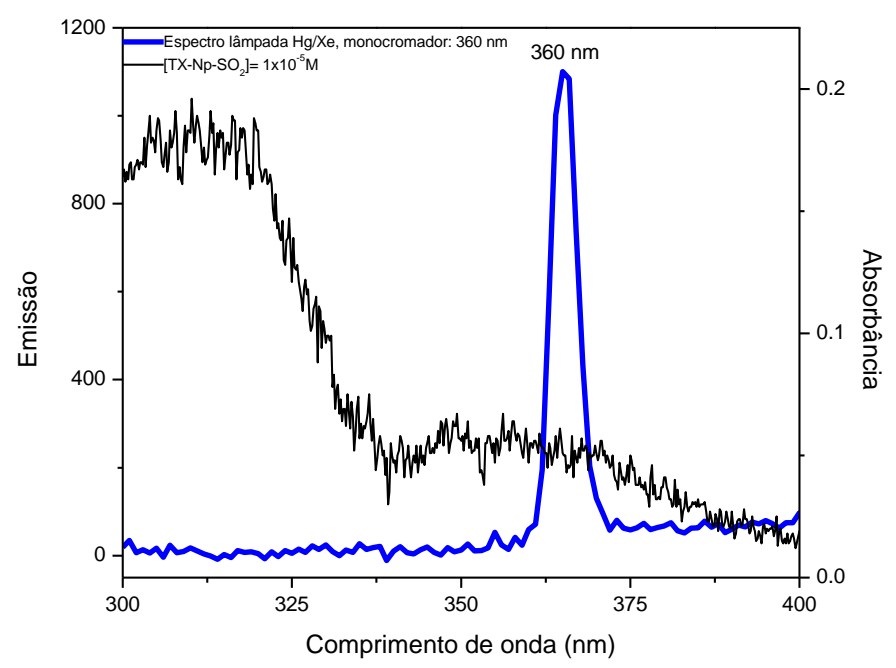

Figura 52 - Espectro de emissão da lâmpada de mercúrio/xenônio utilizada nos experimentos de dilatometria, $\lambda_{\text {mon }}=360 \mathrm{~nm}$ e o espectro de absorção de TX-Np-SO $\mathrm{SO}_{2}$ no meio reacional usado nas fotopolimerizações. 


\subsubsection{Sistema de polimerização MMA/TX-Np-SO $/$ TEA}

\section{Avaliação da polimerização de MMA fotoiniciada pelo sistema TX-Np-SO$/$ TEA}

O primeiro estudo do sistema de polimerização fotoiniciada do MMA por TX-Np-SO foi realizado na presença do co-iniciador TEA. Nos experimentos de polimerização foram utilizados o MMA e o solvente metanol na proporção 1:1. As concentrações do iniciador (TX$\mathrm{Np}-\mathrm{SO}_{2}$ ) e do monômero MMA foram mantidas constantes em $1 \times 10^{-5}$ e 4,67 M, respectivamente. A concentração da TEA foi variada entre 0,02 e 0,24 M e as soluções foram desoxigenadas com nitrogênio por 40 minutos antes de cada irradiação.

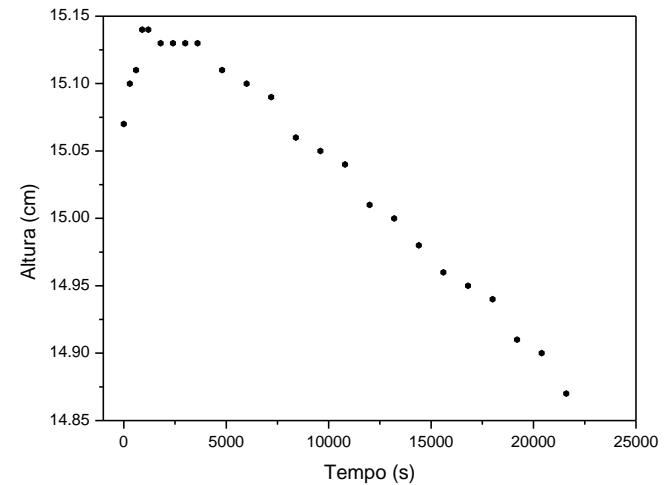

(a)

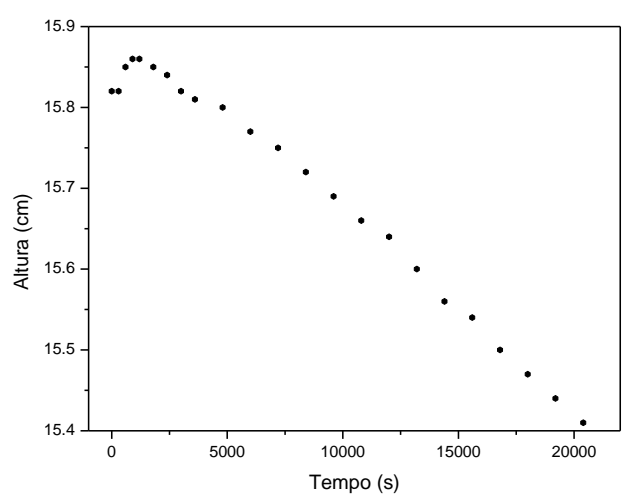

(c)

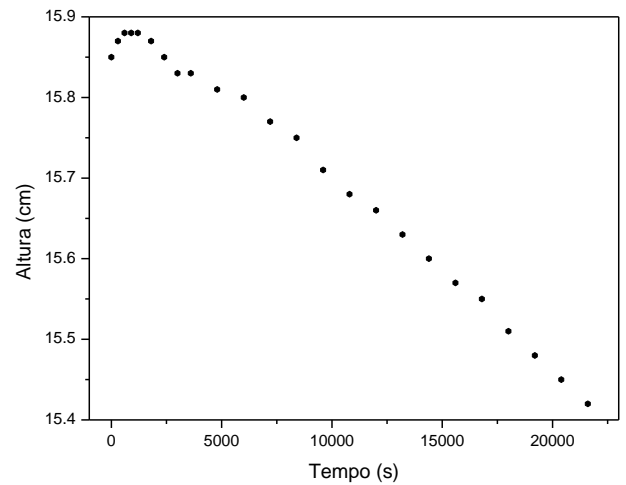

(b)

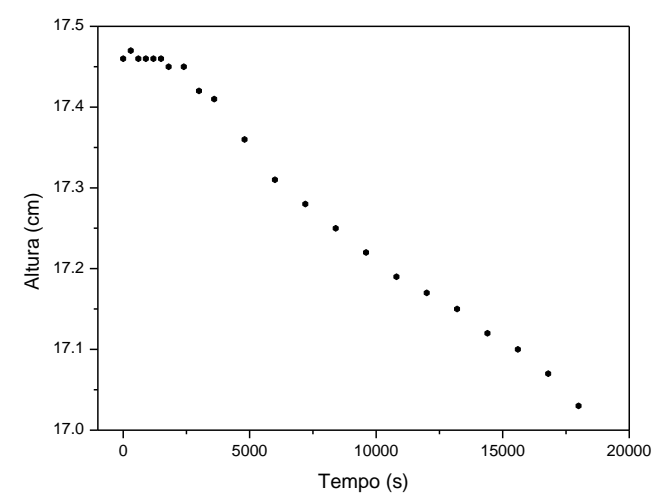

(d) 


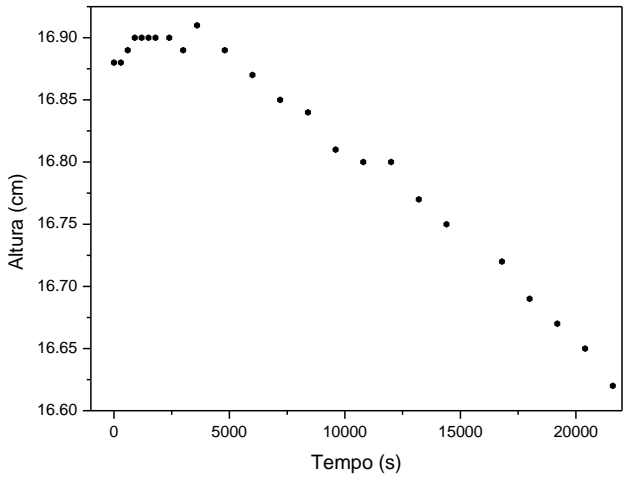

(e)

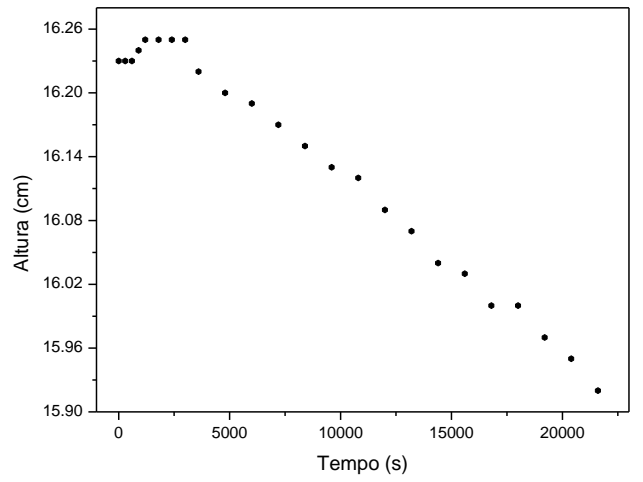

(f)

Figura 53 - Variação da altura da solução no capilar do dilatômetro em função do tempo de irradiação para a polimerização do MMA pelo sistema TX-Np-SO ${ }_{2} / \mathrm{TEA}$. [TEA] = 0,02 M (a); 0,04 M (b); 0,08 M (c); 0,12 M (d); 0,18 M (e) e 0,24 M (f).

Foi avaliado o comportamento da mistura de MMA e metanol sem a adição do iniciador e do co-iniciador, quando submetido à irradiação devido a que durante as polimerizações observou-se um aumento inicial no volume das soluções, e só após um determinado período a contração do mesmo. Observou-se um aumento no volume da solução no início da irradiação até atingir equilíbrio. Isto mostra que o aumento do volume no início da irradiação nas polimerizações não está associado a possíveis interações do iniciador e/ou co-iniciador, Figura 54.

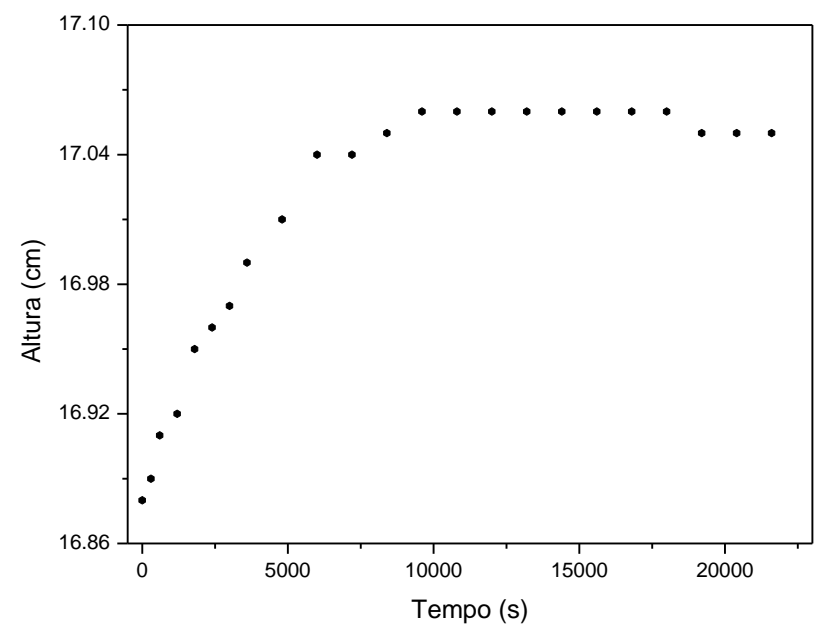

Figura 54 - Variação da altura da solução no capilar do dilatômetro em função do tempo de irradiação para solução contendo MMA e $\mathrm{MeOH}(1: 1)$. 
Para as polimerizações contendo o sistema iniciador, os valores da altura e do tempo de irradiação aplicaram-se as equações descritas anteriormente (Equação 14 a Equação 17). Os gráficos de concentração de MMA convertido em função do tempo de irradiação são mostrados na Figura 55.

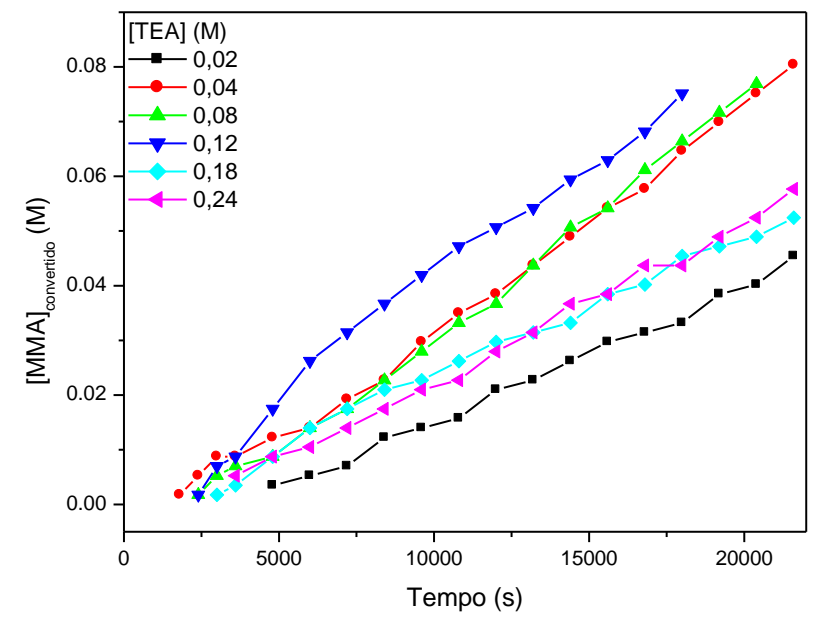

Figura 55 - Conversão de monômero na fotopolimerização de MMA na presença de TX-Np$\mathrm{SO}_{2}$ (iniciador em diferentes concentrações de TEA).

As velocidades de polimerização $(R p)$ do metacrilato de metila foram obtidas a partir das inclinações das curvas de concentração do MMA convertido em função do tempo de irradiação para as diferentes concentrações de TEA utilizadas. Assim, foi possível obter o gráfico da velocidade de polimerização em função da concentração da amina, Figura 56.

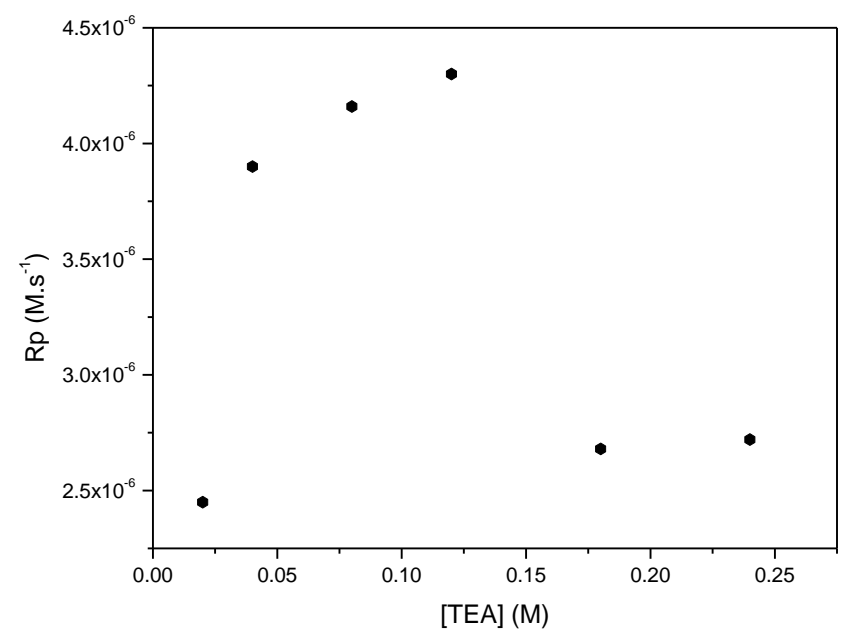

Figura 56 - Dependência da velocidade de polimerização do MMA com a concentração de TEA. 
A Tabela 9 apresenta as velocidades de polimerização para cada concentração de amina usada no sistema de fotopolimerização.

Tabela 9 - Velocidades de polimerização para diferentes concentrações de TEA utilizada no sistema

\begin{tabular}{cc}
\hline [TEA $](\mathbf{M})$ & $\mathbf{R p}\left(\mathbf{M ~ s}^{-1}\right)$ \\
\hline 0,02 & $2,45 \times 10^{-6}$ \\
0,04 & $3,9 \times 10^{-6}$ \\
0,08 & $4,16 \times 10^{-6}$ \\
0,12 & $4,53 \times 10^{-6}$ \\
0,18 & $2,67 \times 10^{-6}$ \\
0,24 & $2,72 \times 10^{-6}$ \\
\hline
\end{tabular}

Observando os dados da Tabela 9, a velocidade de polimerização $(R p)$ aumenta com a concentração de TEA até um valor de $0,12 \mathrm{M}$, a partir da qual ocorre a diminuição da $R p$.

Esse comportamento pode ser explicado levando em consideração que o aumento da concentração de TEA irá aumentar a interação entre o estado singlete de TX-Np-SO e da amina, resultando na formação de um exciplexo, o qual é desativado para os respectivos estados fundamentais.

$$
\mathrm{TX}-\mathrm{Np}-\mathrm{SO}_{2} \stackrel{\mathrm{h} v}{\longrightarrow}{ }^{1} \mathrm{TX}-\mathrm{Np}-\mathrm{SO}_{2} \stackrel{\mathrm{A}}{\longrightarrow}{ }^{1}\left[\mathrm{TX}-\mathrm{Np}-\mathrm{SO}_{2} \cdots \mathrm{A}\right] \longrightarrow \mathrm{TX}-\mathrm{Np}-\mathrm{SO}_{2}+\mathrm{A}
$$

Figura 57 - Mecanismo proposto de desativação do estado singlete da TX-Np-SO 2 por uma amina, (A).

Uma elevada concentração do radical amino também pode contribuir para a desativação dos exciplexos tripletes $\left({ }^{3}\left[\mathrm{TX}-\mathrm{Np}-\mathrm{SO}_{2}{ }^{\cdots \cdots} \mathrm{TEA}\right]\right)$ e, dessa forma, ocorrerá uma diminuição de concentração dos radicais iniciadores resultando na diminuição da velocidade de polimerização. 


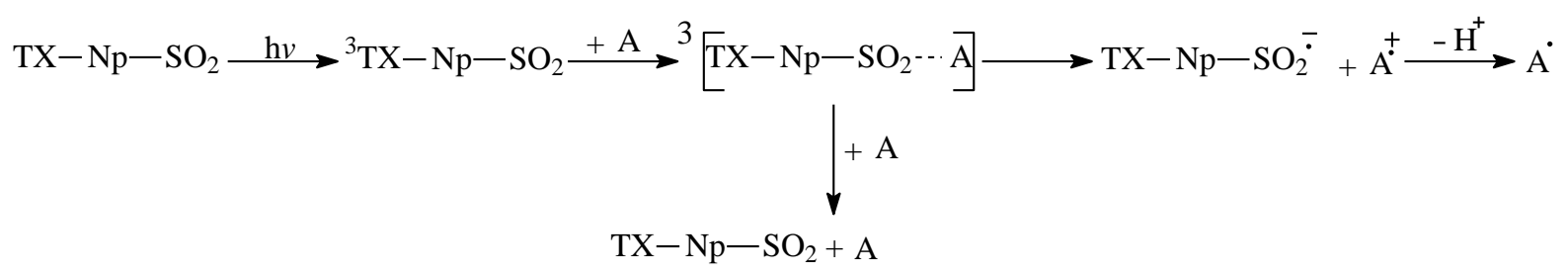

Figura 58 - Mecanismo proposto de desativação de exciplexos tripletes por uma amina, (A).

Estes mecanismos anteriores descrevem a eficiência das aminas em diminuir o processo de polimerização ${ }^{54}$.

\section{Determinação do Rendimento Quântico de Polimerização $\left(\Phi_{\mathbf{m}}\right)$}

O rendimento quântico de polimerização $\left(\Phi_{\mathrm{m}}\right)$, definido como o número de unidades de monômeros polimerizados por fóton absorvido, foi determinado utilizando a Equação 21:

$$
\Phi_{m}=\frac{R p}{I_{a}^{\prime}}
$$

Equação 21

A intensidade de luz absorvida pelo fotoiniciador $\left(I_{a}\right)$ foi calculada a partir da Equação 22:

$$
I_{a}=I_{I} \times\left(-10^{-A b s}-\right.
$$

onde $\mathrm{I}_{\mathrm{I}}$ é a intensidade de luz incidente na amostra determinada experimentalmente. O termo $\mathrm{I}_{\mathrm{a}}$ ' é obtido dividindo o valor de $\mathrm{I}_{\mathrm{a}}$ pelo volume de solução irradiada no dilatômetro.

Para as fotopolimerizações o valor da intensidade de luz absorvida $\left(\mathrm{I}_{\mathrm{a}}{ }^{\prime}\right)$ pela amostra foi de $2,04 \times 10^{-8}$ Einstein $\mathrm{L}^{-1} \mathrm{~s}^{-1}$.

A Tabela 10 resume a velocidade de polimerização $(R p)$, o rendimento quântico de polimerização $\left(\Phi_{\mathrm{m}}\right)$ e a massa molar numérica média $\left(\overline{M_{n}}\right)$ da polimerização do MMA pelo sistema TX-Np-SO $\mathrm{SO}_{2}$ TEA, para cada concentração de TEA. 
Tabela 10 - Velocidade de polimerização, rendimento quântico de polimerização e massa molar numérica média para a polimerização do MMA fotoiniciada pelo sistema TX-Np$\mathrm{SO}_{2} / \mathrm{TEA}$

\begin{tabular}{cccc}
\hline [TEA] $(\mathbf{M})$ & $\boldsymbol{R} \boldsymbol{p}\left(\mathbf{M} \times \mathbf{s}^{\mathbf{- 1}}\right)$ & $\boldsymbol{\Phi}_{\mathbf{m}}\left(\mathbf{m o l} \times\right.$ Einstein $\left.^{\mathbf{- 1}}\right)$ & $\overline{M_{n}}\left({\left.\mathbf{g} \times \mathbf{m o l}^{\mathbf{1}}\right)}^{-1}\right.$ \\
\hline 0,02 & $2,45 \times 10^{-6}$ & 120 & 270.000 \\
0,04 & $3,9 \times 10^{-6}$ & 190 & 480.000 \\
0,08 & $4,16 \times 10^{-6}$ & 205 & 355.000 \\
0,12 & $4,53 \times 10^{-6}$ & 225 & 875.000 \\
0,18 & $2,67 \times 10^{-6}$ & 130 & 440.000 \\
0,24 & $2,72 \times 10^{-6}$ & 135 & 625.000 \\
\hline
\end{tabular}

Dos dados da Tabela 10 observa-se que a massa molar numérica média, $\overline{M_{n}}$, aumenta com a concentração de TEA até $0,12 \mathrm{M}$, a partir desse valor há uma diminuição da massa molar numérica média. Esse resultado está de acordo com o fato de que até a concentração de 0,12 M tem-se um aumento na concentração de radicais formados, isto leva a formação de cadeias poliméricas maiores. A partir de $0,12 \mathrm{M}$ a desativação do exciplexo triplete $\left({ }^{3}\right.$ [TX-Np$\left.\mathrm{SO}_{2}{ }^{\cdots \cdots} \mathrm{TEA}\right]$ ) torna-se predominante e o rendimento de radicais iniciadores da cadeia polimérica diminui ${ }^{54}$.

A Figura 59 a seguir mostra o mecanismo proposto para a formação de radicais que irá dar início a polimerização.

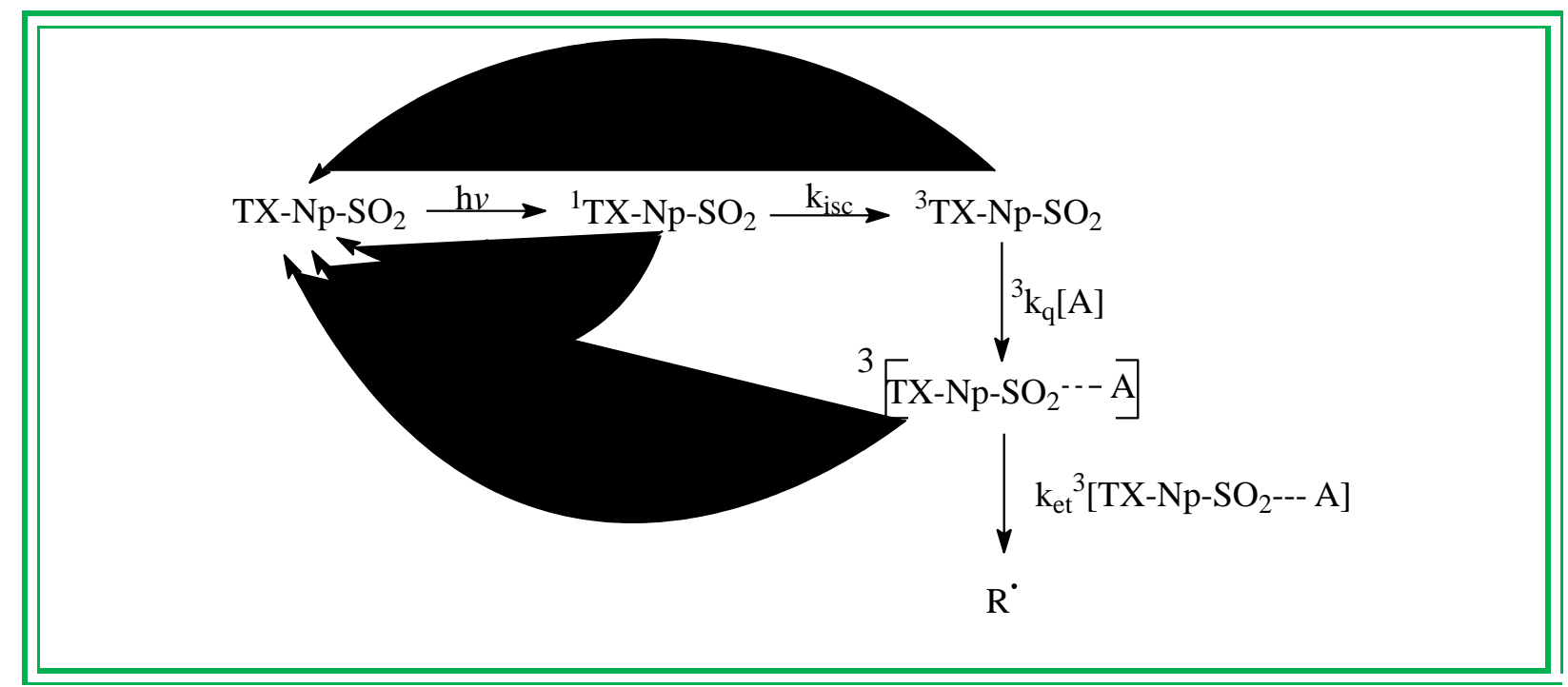

Figura 59 - Mecanismo proposto para a produção dos radicais livres fotoiniciadores no sistema TX-Np-SO 2 TEA. 


\subsubsection{Sistema de polimerização MMA/TX-Np-SO 2 /EDB}

\section{Avaliação da polimerização de MMA fotoiniciada pelo sistema TX-Np-SO $/$ EDB}

A Figura 60 abaixo ilustra a cinética de polimerização utilizando o método de dilatometria para diferentes concentrações da amina EDB. Os gráficos apresentam a variação da altura da solução no dilatômetro em função do tempo de irradiação. Neste experimento as concentrações da TX-Np-SO $\mathrm{SO}_{2}$ o MMA foram mantidas constantes em $1 \times 10^{-5}$ e 4,67 M, respectivamente. A concentração da $\mathrm{EDB}$ foi variada entre 0,02 a $0,36 \mathrm{M}$ e as soluções foram desoxigenadas com nitrogênio por 40 minutos antes de cada irradiação.

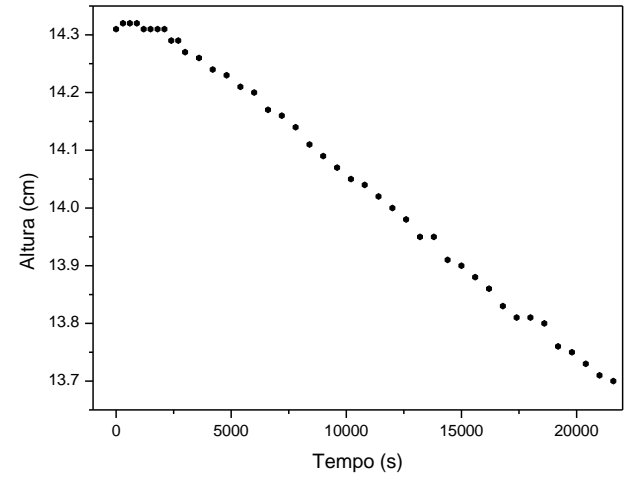

(a)

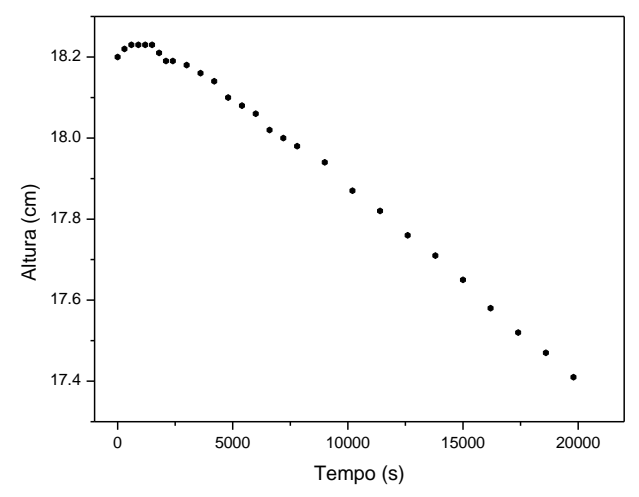

(c)

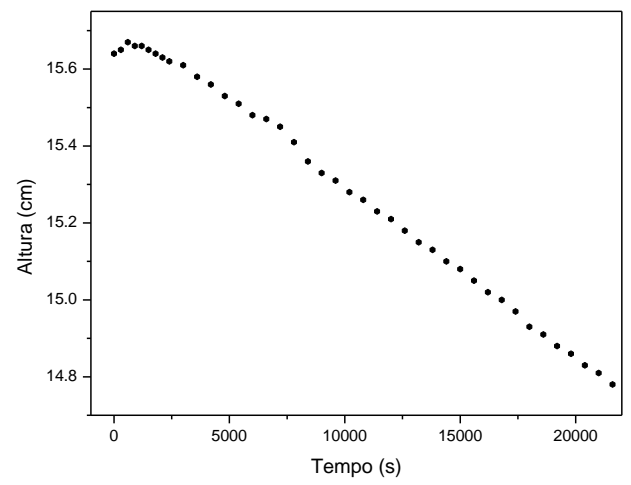

(b)

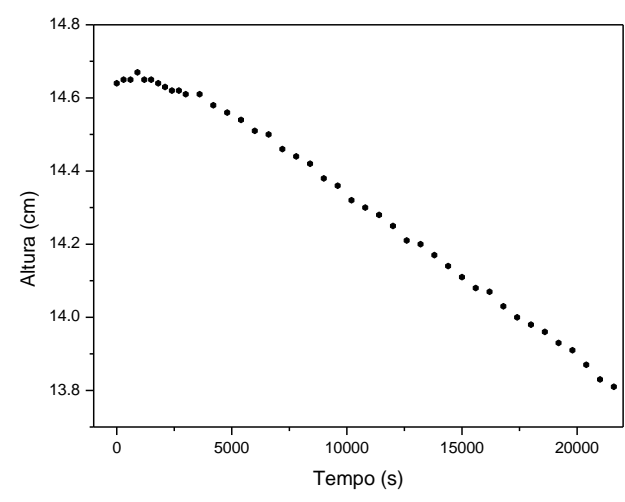

(d) 


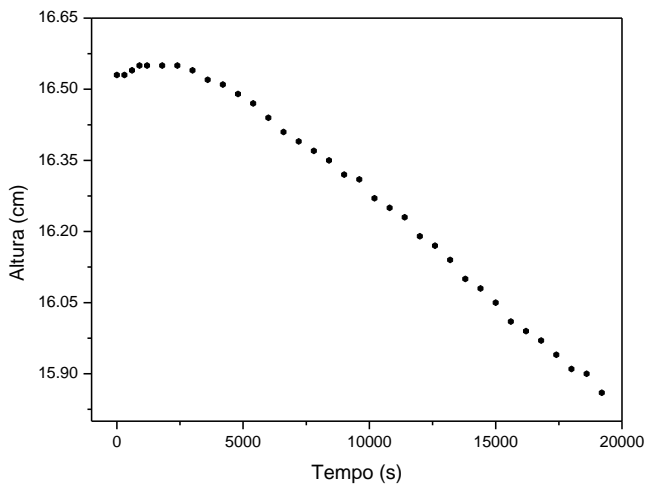

(e)

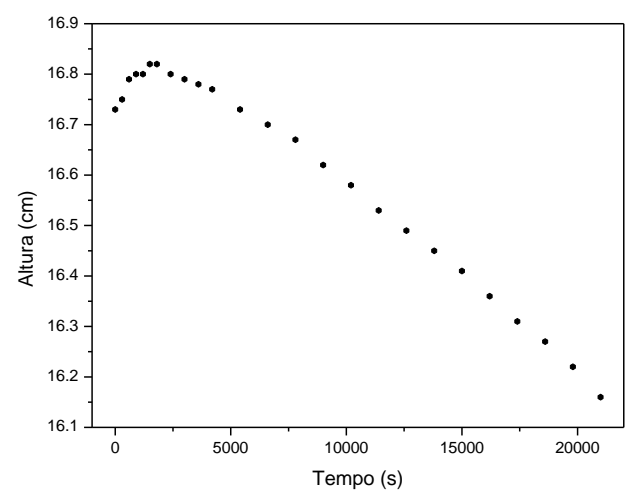

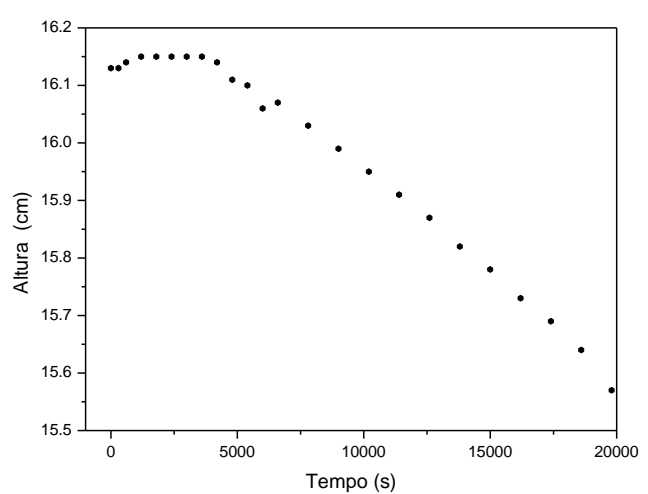

(f)

$(\mathrm{g})$

Figura 60 - Variação da altura da solução no capilar do dilatômetro em função do tempo de irradiação para a polimerização de MMA pelo sistema TX-Np-SO $2 / E D B$. [EDB]=0,02 M (a); 0,04 M (b); 0,08 M (c); 0,12 M (d); 0,18 M (e); 0,24 M (f) e 0,36 M (g).

O gráfico de concentração de monômero transformado em função do tempo de irradiação, Figura 61, foi construído utilizando as (Equação 14 a Equação 17). A Figura 62 mostra as velocidades de polimerização para as diferentes concentrações do co-iniciador. 


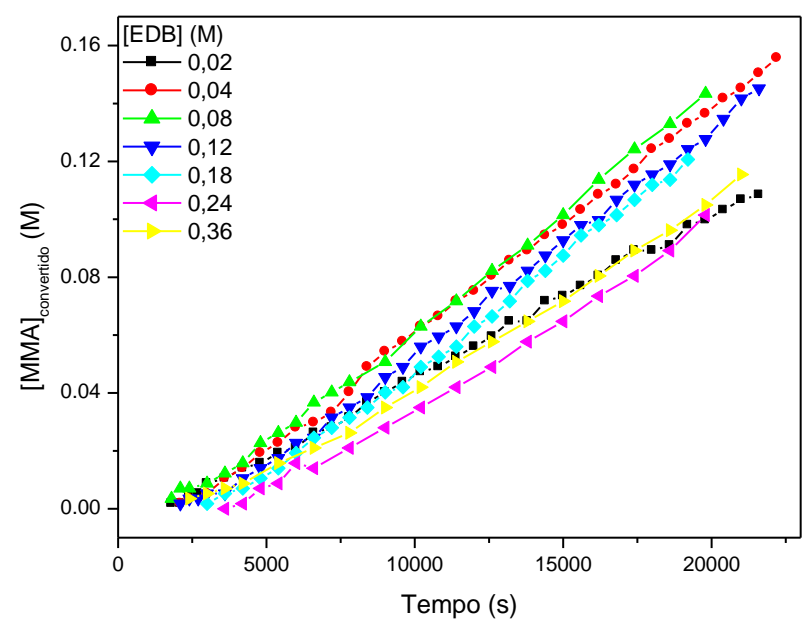

Figura 61 - Conversão de monômero na fotopolimerização de MMA na presença de TX-Np$\mathrm{SO}_{2}$ (iniciador com diferentes concentrações de EDB).

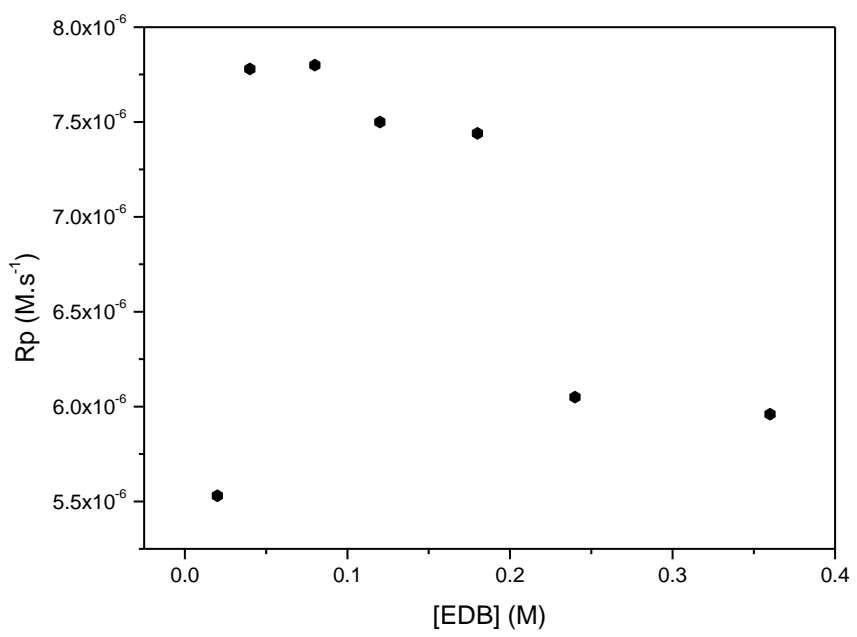

Figura 62 - Dependência da velocidade de polimerização de MMA com a concentração de EDB.

As velocidades de polimerização para cada concentração de amina (EDB) são mostradas na Tabela 11 a seguir.

\section{Determinação do Rendimento Quântico de Polimerização $\left(\Phi_{m}\right)$}

Os rendimentos quânticos de polimerização $\left(\Phi_{\mathrm{m}}\right)$ para o sistema com a EDB são mostrados na Tabela 11, assim como as velocidades de polimerização $(R p)$, e a massa molar numérica média $\left(\overline{M_{n}}\right)$ para cada concentração da amina. 
Tabela 11 - Velocidade de polimerização, rendimento quântico de polimerização e massa molar numérica média para a polimerização do MMA fotoiniciada pelo sistema TX-Np$\mathrm{SO}_{2} / \mathrm{EDB}$

\begin{tabular}{cccc}
\hline $\mathbf{E D B}](\mathbf{M})$ & $\mathbf{R} \boldsymbol{p}\left(\mathbf{M} \times \mathbf{s}^{-\mathbf{1}}\right)$ & $\boldsymbol{\Phi}_{\mathbf{m}}\left(\mathbf{m o l} \times\right.$ Einstein $\left.^{-\mathbf{1}}\right)$ & $\overline{M_{n}}\left({\left.\mathbf{g} \times \mathbf{m o l}^{\mathbf{1}}\right)}\right.$ \\
\hline 0,02 & $5,53 \times 10^{-6}$ & 270 & 730.000 \\
0,04 & $7,78 \times 10^{-6}$ & 380 & 1.210 .000 \\
0,08 & $7,8 \times 10^{-6}$ & 382 & 1.260 .000 \\
0,12 & $7,5 \times 10^{-6}$ & 370 & 1.110 .000 \\
0,18 & $7,44 \times 10^{-6}$ & 365 & 900.000 \\
0,24 & $6,05 \times 10^{-6}$ & 296 & 1.120 .000 \\
0,36 & $5,95 \times 10^{-6}$ & 292 & 1.240 .000 \\
\hline
\end{tabular}

Nas fotopolimerizações com a amina EDB foi observado um aumento da velocidade de polimerização até a concentração de $0,08 \mathrm{M}$, e acima dessa concentração a velocidade apresentou decréscimo. Este comportamento revela a eficiência das aminas na diminuição do processo de polimerização, observado para a amina $\mathrm{TEA}^{54}$.

Os dados para a amina EDB, Tabela 11, mostram a variação da massa molar numérica média $\overline{M_{n}}$ em relação à concentração de EDB: aumento do valor de $\overline{M_{n}}$ até a concentração de $0,08 \mathrm{M}$ e acima dessa concentração o valor de $\overline{M_{n}}$ permanece constante ${ }^{3}$. 


\section{CONCLUSÕES}




\section{CONCLUSÕES}

O derivado da S,S-dioxidotioxantona, 7,8-benzotioxanton-9-ona-10,10-dióxido, foi sintetizado e caracterizado. Através da caracterização pôde-se confirmar a presença de grupos funcionais específicos assim como a presença de elementos determinantes para a caracterização da TX-Np-SO .

Estudos por fotólise por pulso de laser permitiram identificar a região de absorção triplete-triplete da 7,8-benzotioxanton-9-ona-10,10-dióxido $\left(\lambda_{\text {máx }}=310\right.$ e $\left.590 \mathrm{~nm} ; \tau=16 \mu \mathrm{s}\right)$. As constantes de supressão do estado triplete de TX-Np-SO mostraram que as reações são mais rápidas para os supressores por transferência de energia e de elétrons, apresentando valores da ordem de $10^{9} \mathrm{M}^{-1} \mathrm{~s}^{-1}$, indicando que as reações são controladas por difusão. Também foi possível verificar que para o supressor associado à transferência de hidrogênio a constante era $10^{8} \mathrm{M}^{-1} \mathrm{~s}^{-1}$.

Foram determinadas as propriedades fotofísicas, espectro de emissão de fluorescência e fosforescência, e o rendimento quântico de fluorescência $(\Phi=0,06)$. O tempo de vida de fosforescência determinado foi de $\tau=800 \mathrm{~ms}$ a $77 \mathrm{~K}$, sugerindo uma transição $\left(\pi, \pi^{*}\right)$ para o estado excitado triplete de energia mais baixa. O tempo de vida de fluorescência foi de $\tau=3,62 \mathrm{~ns}$, seguindo as características da tioxantonas e derivados, estando de acordo com o rendimento quântico de fluorescência.

A TX-Np-SO $\mathrm{S}_{2}$ mostrou-se eficiente na fotoiniciação da polimerização do metacrilato de metila utilizando como co-iniciadores TEA e EDB. Os resultados de fotopolimerização mostraram que para concentrações maiores que 0,12 M para TEA e 0,08 M para a EDB há uma diminuição da velocidade de polimerização. Observou-se também que as massas molares para os polímeros obtidos a partir da EDB foram maiores em relação as usando o co-iniciador TEA. A massa molar aumenta até a concentração de 0,08 M de EDB e acima desta concentração o valor da massa molar permaneceu constante. 
APÊNDICE 


\section{APÊNDICE}

A seguir são apresentados os espectros de $\mathrm{RMN}$ de ${ }^{1} \mathrm{H},{ }^{13} \mathrm{C}$, Cosy e os mapas de correlação HSQC e HMBC.

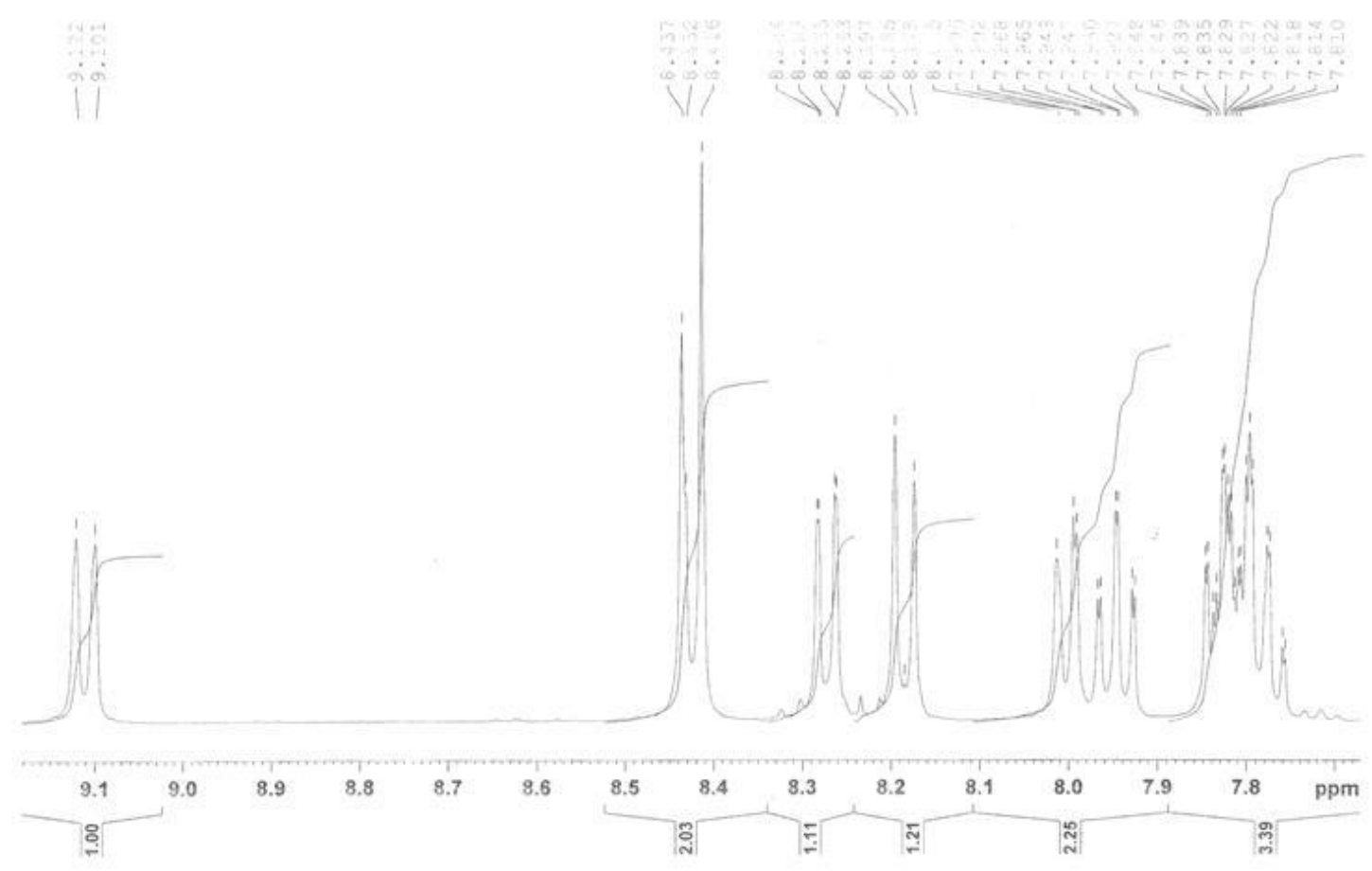

Espectro de RMN de ${ }^{1} \mathrm{H}$ da TX-Np-SO,$\left(\mathrm{CDCl}_{3}, 400 \mathrm{MHz}\right)$. 


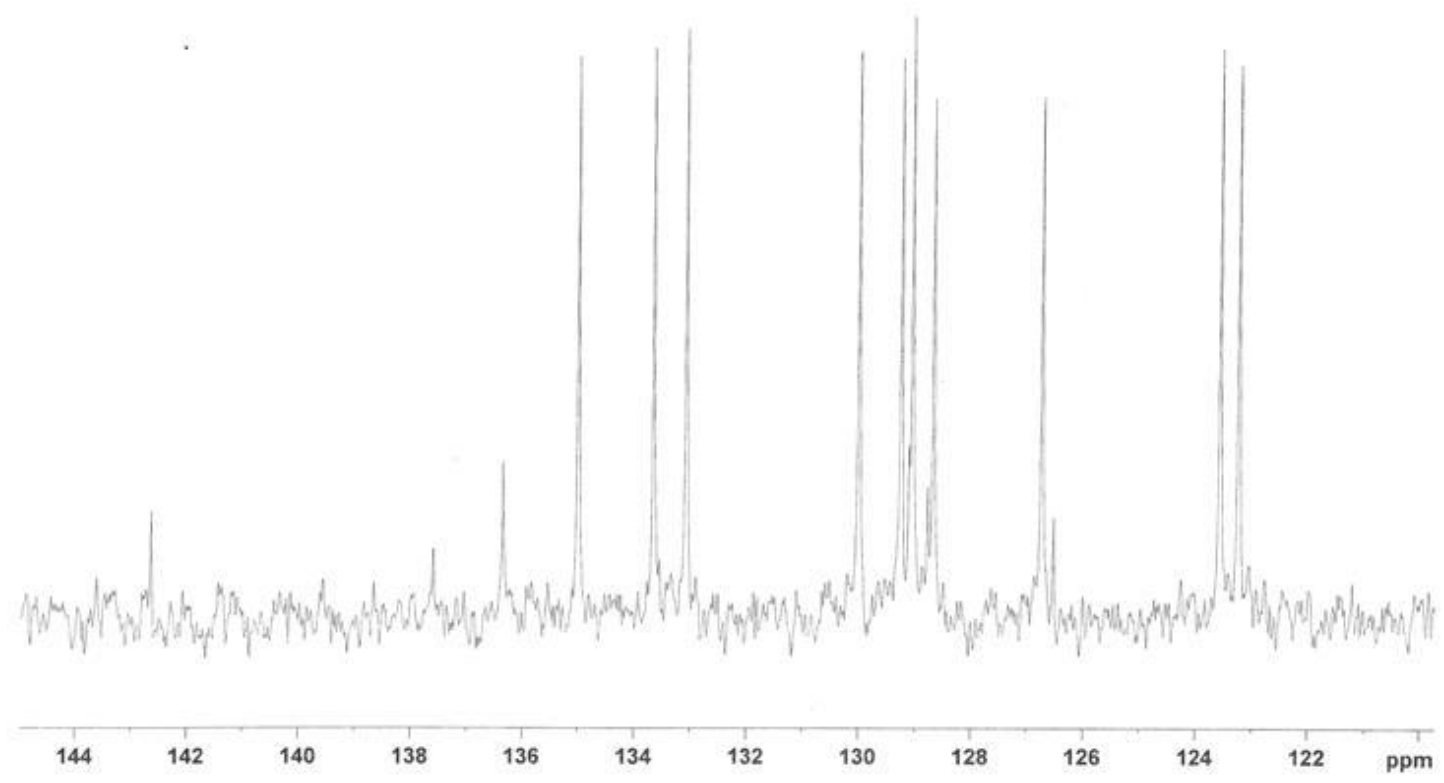

Espectro de RMN de ${ }^{13} \mathrm{C}$ da TX-Np-SO,$\left(\mathrm{CDCl}_{3}, 100 \mathrm{MHz}\right)$. 


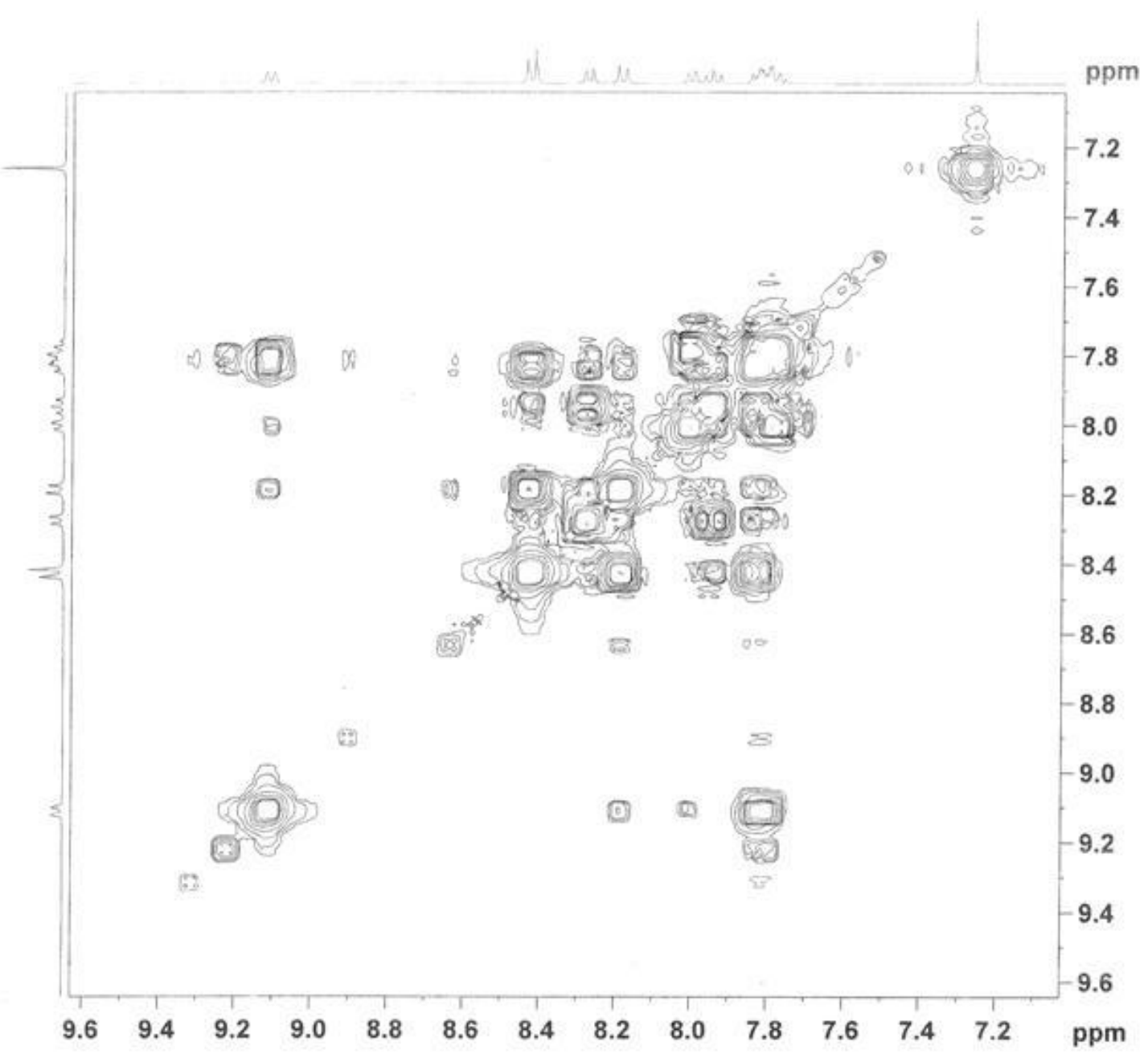

Espectro de Cosy ${ }^{1} \mathrm{H}^{-1} \mathrm{H}$ de TX-Np- $\mathrm{SO}_{2},\left(\mathrm{CDCl}_{3}, 400 \mathrm{MHz}\right)$. 


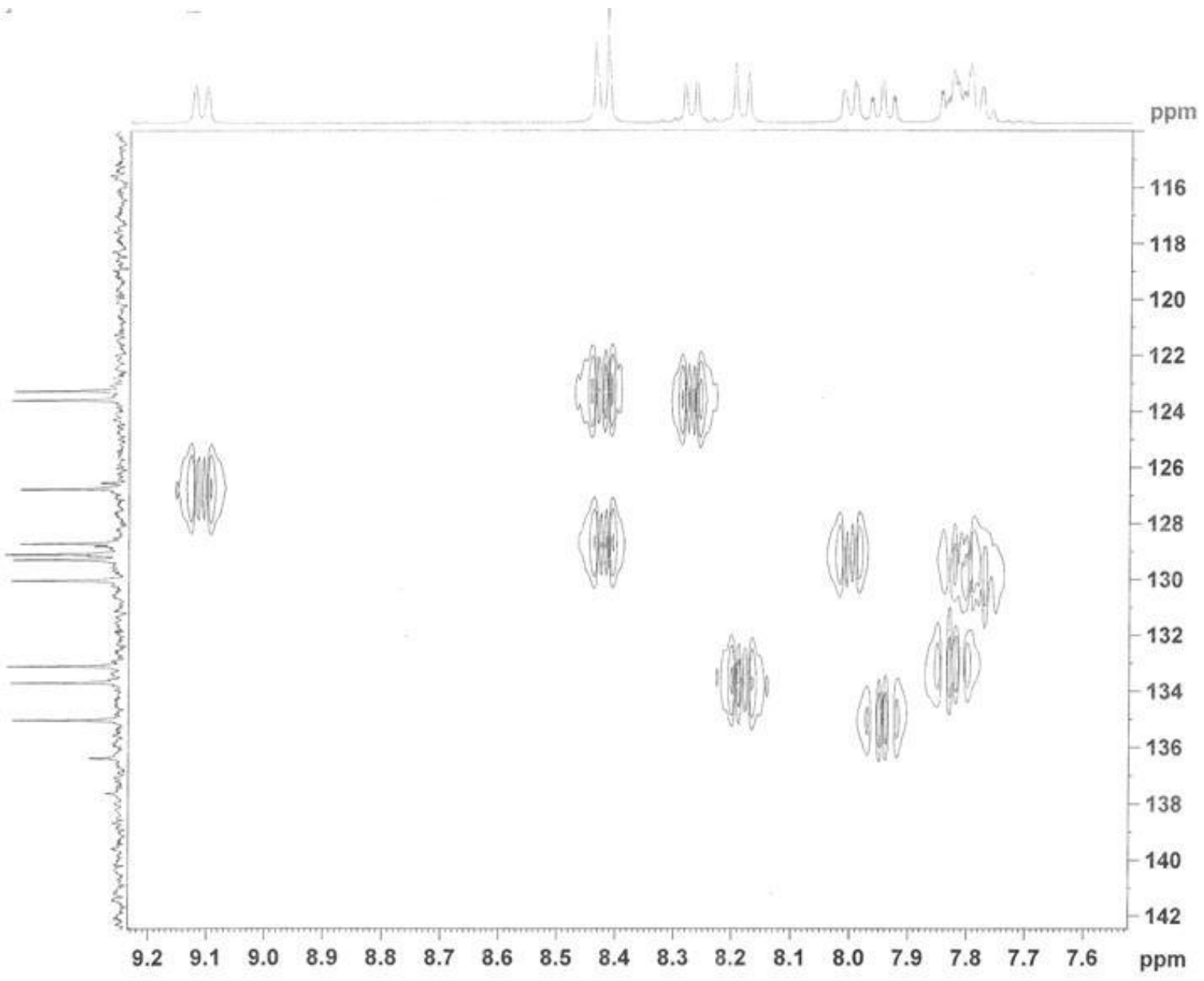

Mapa de correlação HSQC da TX-Np-SO $\left(\mathrm{CDCl}_{3}, 400 \mathrm{MHz}\right)$. 


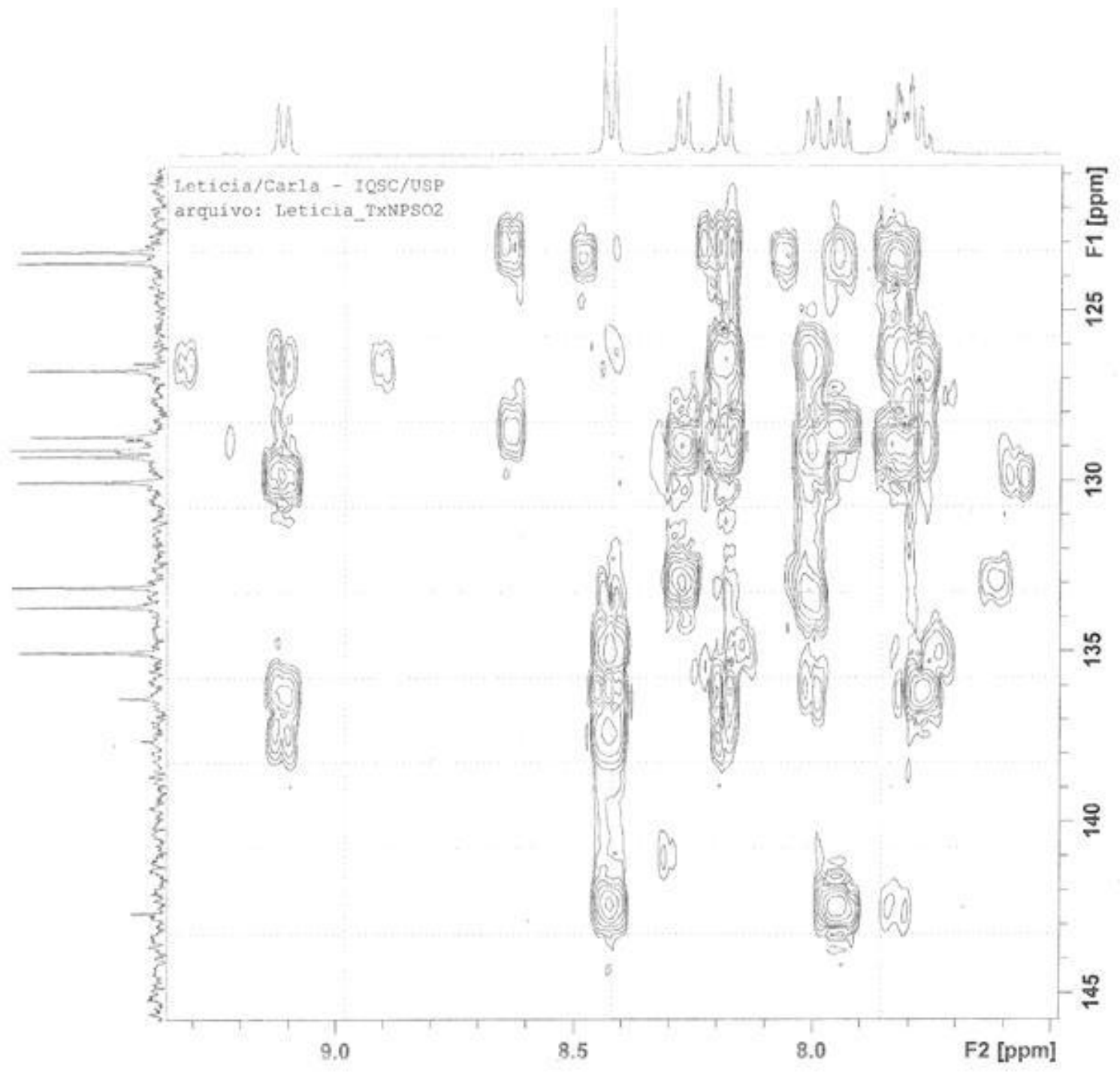

Mapa de correlação HMBC da TX-Np-SO $\left(\mathrm{CDCl}_{3}, 400 \mathrm{MHz}\right)$. 
REFERÊNCIAS 


\section{REFERÊNCIAS}

${ }^{1}$ ROHATGE-MURKHERJEE, K. K. Fundamentals of photochemistry. New Delhi: New Age International, 1978. 347 p.

${ }^{2}$ TURRO, N. J. Modern molecular photochemistry. Sausalito: University Science Books, 1991. $628 \mathrm{p}$.

${ }^{3}$ RODRIGUES, M. R.; NEUMANN, M. G. Fotopolimerização: princípios e métodos. Polímeros: Ciência e Tecnologia, v. 13, p. 276-286, 2003.

${ }^{4}$ ALLEN, N. S. Photoinitiators for UV and visible curing of coatings and properties. Journal of Photochemistry and Photobiology A: Chemistry, v. 100, p. 101-107, 1996.

${ }^{5}$ NEUMANN, M. G.; SCHMITT, C. C.; MACIEL, H. The photopolymerization of styrenesulfonate initiated by dyes - The effect of monomer aggregation. Journal of Photochemistry and Photobiology A: Chemistry, v. 175, p. 15-21, 2005.

${ }^{6}$ DAVIDSON, R. S. Polymeric and polymerisable free radical photoinitiators. Journal of Photochemistry and Photobiology A: Chemistry, v. 69, p. 263-275, 1993.

${ }^{7}$ DAVIDSON, R. S. The chemistry of photoinitiators - some recent developments. Journal of Photochemistry and Photobiology A: Chemistry, v. 73, p. 81-96, 1993.

${ }^{8}$ KORKUT, S. E.;TEMEL, G.; BALTA,D.K.; ARSU, N.; SENER, M. K. Type II photoinitiator substituted zinc phthalocyanine: synthesis, photophysical and photopolymerization studies. Journal of Luminescence, v.136, p. 389-394, 2013.

${ }^{9}$ LAKOWICS, J.R. Principles of fluorescence spectroscopy. New York: Plenum Press, 1999. p. 698.

${ }^{10}$ SMOLUCHOWSKI, R. Theory of grain boundary diffusion. Physical Review, v. 87, p. 482-487, 1952.

${ }^{11}$ SKOOG, D.; HOLLER, F.; NIEMAN, T. Princípios de análise instrumental. Porto Alegre: Bookman, 2002. 836 p. 
${ }^{12}$ COSTA, P.; PILLI, R.; PINHEIRO, S.; VASCONCELLOS, M. Substâncias carboniladas e derivados. Rio de Janeiro: LTC, 2007. 490 p.

${ }^{13}$ SILVERSTEIN, R. M.; WEBSTER, F. X.; KIEMLE, D. J. Identificação espectroscópica de compostos orgânicos. Porto Alegre: Bookman, 2003. 412 p.

${ }^{14}$ GILBERT, A.; BAGGOT, J.; WAGNER, P. J. Essencials of molecular photochemistry. New York: CRC, 1991. 552 p.

${ }^{15}$ MANO, E. B. Introdução a Polímeros. 3 ed. São Paulo: Edgard Blucher, 1985. 191 p.

${ }^{16}$ ODIAN, G. Principles of polymerization. 3 ed. New York: Wiley-Interscience, 1991. $789 \mathrm{p}$.

${ }^{17}$ WALTSON, D. J.; LORIMER, J. P. Polymers. Oxford: Oxford University, 2000. 111 p.

${ }^{18}$ GUIMARÃES, P. I. C. Estudo da influencia dos iniciadores na polimerização da 2-fenil-2oxalina. Polímeros, v. 10, p. 224-229, 2000.

${ }^{19}$ VOLL, D.; HUFENDIEK, A.; JUNKERS, T.; BARNER-KOWOLLIK, C. Quantifying photoinitiation efficiencies in a multiphotoinitiated free-radical polymerization.

Macromolecular Rapid Communications, v. 33, p. 47 -53, 2012.

${ }^{20}$ GEHLEN, M. H.; BUCHVISER, S. F.; RORIGUES, M. R.; NEUMANN, M. G.

Fotoiniciação de polimerização vinílica. Química Nova, v. 21, p. 794-801, 1998.

${ }^{21}$ SAVARY, F. M.; JACQUES, C. L.; WIEDER, F.; FOUASSIER, J. P. Time dependent solvent effects on the $T_{1}-T_{n}$ absorption spectra of thioxanthone: a picoseconds investigation. Journal of Photochemistry and Photobiology A: Chemistry, v. 126, p. 7-14, 2000.

${ }^{22}$ FERREIRA, G. C.; SCHMITT, C. C.; NEUMANN, M. G. Dependence of the thioxanthone triplet-triplet absorption spectrum with solvent polarity and aromatic ring substitution.

Journal Brazilian Chemical Society, v. 17, p. 905-909, 2006.

${ }^{23}$ DOGRUYOL, S. K.; DOGRUYOL, Z.; ARSU, N. A thioxanthone-based visible photoinitiator. Journal of Polymer Science Part A: Polymer Chemistry, v. 49, p. 4037 4043, 2011. 
${ }^{24}$ RODRIGUES,J. F.; SILVA, F. A.; NETTO-FERREIRA, J. C. Laser flash photolysis study of the photochemistry of thioxanthone in organic solvents. Journal of the Brazilian Chemical Society, v. 21, p. 960-965, 2010.

${ }^{25}$ RABEK, J. F. Mechanisms of photochemical reactions in polymers: theory and aplications. Bristol: John Wiley, 1987. 756 p.

${ }^{26}$ TEMEL, G.; ARSU, N. An annelated thioxanthone as a new type II initiator. Journal of Photochemistry and Photobiology A: Chemistry, v. 202, p. 63-66, 2009.

${ }^{27}$ BALTA, D. K.; CETINER, N.; TEMEL, G.; TURGUT, Z.; ARSU, N. An annelated thioxanthone thioxanthone as a new type II initiator. Journal of Photochemistry and Photobiology A: Chemistry, v. 199, p. 316-321, 2008.

${ }^{28}$ COKBAGLAN, L.; ARSU, N.; YAGCI, Y.; JOCKUSCH, S.; TURRO, N. J. 2Mercaptothioxanthone as a novel photoinitiator for free radical polymerization. Macromolecules, v. 36, p. 2649-2653, 2003.

${ }^{29}$ CORRALES, T.; CATALINA, F.; ALLEN, N. S.; PEINADO, C. Novel water soluble copolymers based on thioxanthone: photochemistry and photoinitiators activity. Journal of Photochemistry and Photobiology A: Chemistry, v. 169, p. 95-100, 2005.

${ }^{30}$ BALTA,D. K.; CETINER, N.; TEMEL, G.; TURGUT, Z.; ARSU, N.Thioxanthoneantracene: a new photoinitiator for free radical polymerization in the presence of oxygen. Macromolecules, v. 40, p. 4138-4141, 2007.

${ }^{31}$ NETTO-FERREIRA, J. C.; SILVA, E. S. L.; LUCAS, N. C. Photochemistry of thioxanthen-9-one-10,10-dioxide: a remarkably reactive triplet excited state. Journal of Photochemistry and Photobiology A: Chemistry, v. 225, p. 135-141, 2011.

${ }^{32}$ STILL, I.W.J. Photochemical reduction of $\beta$ - and $\gamma$ keto sulfones. The Journal of Organic Chemistry, v. 33, p. 2730-2734, 1968.

${ }^{33}$ TURRO, N. J.; RAMAMURTHY, V.; SCAIANO, J. C. Principles of molecular photochemistry. Sausalito: University Science Books, 2009. 495 p.

${ }^{34}$ ARNAUT, L.; FORMOSINHO, S.; BURROWS, H. Chemical Kinectics: from molecular structure to chemical reactivity. Amsterdam: Elsevier, 2007. 549 p. 
${ }^{35}$ PORTER, G. Flash photolysis and spectroscopy: a new method for the study of free radical reactions. Proceedings of the Royal Society A, v. 200, p.284-300, 1950.

${ }^{36}$ GOI, B. E. Estudo de polimerização fotoiniciada por corantes em diferentes meios. 2006. 191 f. Tese (Doutorado em Físico-Química) - Instituto de Química de São Carlos, Universidade de São Paulo, São Carlos, 2006.

${ }^{37}$ LUZCHEM RESEARCH. Laser flash photolysis LFP: Operating Manual. Ottawa: Luzchem Research, 2006. 158 p.

${ }^{38}$ EASYLIFE V ${ }^{\mathrm{TM}}$ Complementes Your Fluorescence Intensity Measurements. Birmingham. Produced by Optical Building Blocks Corporation. 2007. Disponível em:

<http://www.obbcorp.com/technotes.html\#Systems>. Acesso em: 30 jun. 2013.

${ }^{39}$ CANEVAROLO, S. V. Cromatografia de exclusão por tamanho. In: TÉCNICAS de caracterização de polímeros. São Paulo: Artliber, 2003, p. 117-146.

${ }^{40}$ FERNANDEZ, L. E.; VARETTI, E. L. An experimental and theoretical study of the vibrational properties of $\mathrm{CF}_{3} \mathrm{SO}_{2} \mathrm{Cl}$. The Journal of the Argentine Chemical Society, v. 97, p. 199-209, 2009.

${ }^{41}$ MARTIN, R. H.; DEFAY, N.; GEERTS-EVRARD, F.; GIVEN, P. H.; JONES, J.R.; WEDEL, R.W. Aplications of NMR spectroscopy in the field of polycondensed aromatic systems. IX-Tri and tetracyclic derivayives of chromone, 1-thiochromone, xanthen-9-one, thioxanthen-9-one and related structures. Tetrahedron, v. 21, p. 1833-1845, 1965.

${ }^{42}$ MONTALTI, M.; CREDI, A.; PRODI, L.; GANDOLFI, M. T. Handbook of Photochemistry. New York: CRC, 2006. 650 p.

${ }^{43}$ DEMPTER, D. N.; MORROW, T.; QUINN, M. F. Extinction coefficients for triplet-triplet absorption in ethanol solutions of antracene, naphtalene, 2,5-diphenyloxazole, 7-dithylamino4-methyl coumarin and 4-methyl-7-amino-carbostyril. Journal of Photochemistry, v. 2, p. 329-341, 1973.

${ }^{44}$ BURGET, D.; JACQUES, P. Unusual solvente effects on the fluorescence quenching rate constants of a thioxanthone derivative by n-butylamine and isoprene. Chemical Physics Letters, v. 291, p.207-214, 1998. 
${ }^{45}$ MONTALTI, M.; CREDI, A.; PRODI, L.; GANDOLFI, M. T. Handbook of Photochemistry. New York: CRC, 2006. 650 p.

${ }^{46}$ FOUASSIER, J. P.; JACQUES, P.; ENCINAS, M. V.; Solvent effects on the thioxanthone triplet quenching by vinyl monomers. Chemical Physics Letters, v. 148, p. 309-312, 1988.

${ }^{47}$ KARASU, F.; ARSU, N.; JOCKUSCH, S.; TURRO, N. J. Mechanistic studies of photoinitiated free radical polymerization using a bifunctional thioxanthone acetic acid derivative as photoinitiator. Macromolecules, v. 42, p. 7318-7323, 2009.

${ }^{48}$ BALTA, D. K.; ARSU, N.; YAGCI, Y.; SUNDARESAN, A. K.; JOCKUSCH, S.; TURRO, N. J. Mechanism of photoinitiated free radical polymerization by thioxanthone anthracene in the presence of air. Macromolecules, v. 44, p. 2531-2535, 2011.

${ }^{49}$ DAS, D.; NATH, D.N. Photoreaction of thioxanthone with indolic and phenolic derivatives of biological relevance: magnetic field effect study. Journal of Physical Chemistry A, v. 112, p. 11619-11626, 2008.

${ }^{50}$ RODRIGUES, J. F. Estudo do efeito de substituintes na fotoquímica de tioxantona por fotólise de pulso de laser em nanossegundo. 2010. 170 f. Tese (Doutorado em Ciências) Instituto de Ciências Exatas, Universidade Federal Rural do Rio de Janeiro, Seropédica, 2010.

${ }^{51}$ TAKAIZUMI, A. A. C.; DOS SANTOS, F.R.; da SILVA, M. T.; NETTO-FERREIRA, J. C. Estudo da reativiade do estado excitado triplete de 1,4-diaza-9-fluorenonas frente a doadores de hidrogênio e de elétron. Química Nova, v. 32, p. 1799-1804, 2009.

${ }^{52}$ CORRALES, T.; PEINADO, C.; CATALINA, F.; NEUMANN, M. G.; ALLEN, N. S.; RUFS, A. M.; ENCINAS, M. V. Photopolymerization of methyl methacrylate initiated by thioxanthone derivatives: photoinitiation mechanism. Polymer, v. 41, p. 9103-9109, 2000.

${ }^{53}$ RODRIGUES, M. R.; CATALINA, F.; NEUMANN, M. G. MMA photopolymerization initiated by thionine/triethylamine. Journal of Photochemistry and Photobiology A: Chemistry, v. 127, p. 147-152, 1999.

${ }^{54}$ NEUMANN, M. G.; SCHMITT, C. C.; GOI, B. E. The mechanism of the photoinitiation of the methylmethacrylate polymerization by the neutral red/triethylamine system. Journal of Photochemistry and Photobiology A: Chemistry, v. 174, p. 239-245, 2005. 